Supplement of Biogeosciences Discuss., 11, 17339-17360, 2014

http://www.biogeosciences-discuss.net/11/17339/2014/

doi:10.5194/bgd-11-17339-2014-supplement

(C) Author(s) 2014. CC Attribution 3.0 License.

(c) (1)

Supplement of

Radiative forcing bias of surface albedo modifications linked to simulated forest cover changes at northern latitudes

R. M. Bright et al.

Correspondence to: R. M. Bright (ryan.m.bright@ntnu.no) 


\section{S1. Contents}

This supporting material file is structured as follows:

- S2. Additional Material and Methods

- S3. Description of Albedo Parameterizations in Land Surface Models (Schemes)

- S4. Regression Model and Theoretical Basis

- S5. Daily Albedo Time Series: Observations vs. Predictions

- S6. Contribution Analysis: Snow Metamorphosis and Vegetation Structure

\section{S2. Materials and Methods}

\section{S.2.1. Regional geography and climate}

The forests in our study region may be considered part of the boreal forest that extends as an almost continuous belt around the upper northern hemisphere. Managed forests of the region (Fig. 1) are dominated by Norway spruce (Picea abies H. Karst.), Scots pine (Pinus sylvestris L.) and Birch (Betula pendula Roth and B. pubescens Ehrh.), with understory vegetation often dominated by bilberries (Vaccinium myrtillus L.), other Vaccinium species, and various herb communities [Granhus et al., 2012]. The region experiences a continental climate ('Subarctic/Boreal') characterized by long cold winters with short mild summers and moderate, seasonally distributed precipitation [Peel et al., 2007]. Where logging activities are concentrated, snow covers the ground from December through early April in the lower elevations of the central, southern, and eastern parts of the region (ca. $200 \mathrm{~m}$ ) - and from late October through early May in the northern and western parts of the region (ca. $800 \mathrm{~m}$ ) [Norwegian Meteorological Institute, 2013a]

\section{S.2.2. Albedo, LIDAR, and meteorological data}

We employ Version 006 (v006) MCD43A 1-day daily Albedo/BRDF product [Zhuosen Wang and Schaaf, 2013; Zhuosen W ang et al., 2012]. The v006 product uses multiple clear sky views available 
over a 16-day period to provide daily albedo values that represent the best BRDF possible with the day of interest emphasized. This includes as many overpasses that are available per day (while earlier versions of the algorithm, including the Direct Broadcast version, were limited to only 4 observations per day [Shuai, 2010]), enabling it to better capture the daily albedo with an algorithm that more strongly emphasizes all contributions from the single day of interest [Wright et al., 2014]. We take the direct beam ("black-sky") albedo at local solar noon for the winterspring seasons spanning Jan. 1, 2007 through May 9, 2009, re-projected to UTM32 WGS84.

Observations of forest structural attributes like leaf area index (LAI), canopy height, and canopy cover fraction are based on aerial LIght Detection and Ranging (LIDAR) campaigns undertaken in June, 2009 [Solberg et al., 2006; Solberg et al., 2009]. The data, gridded at $10 \times 10 \mathrm{~m}$ resolution in UTM32 WGS84, are resampled to the MODIS pixel resolution (463 m x $463 \mathrm{~m}$ ). Daily meteorological observations of mean and maximum wind speed $\left(\mathrm{ms}^{-1}\right)$, mean and maximum nearsurface temperature $\left({ }^{\circ} \mathrm{C}\right)$, snow depth $(\mathrm{cm})$, and precipitation $(\mathrm{mm})$ are taken from measuring stations in the municipalities of Drevsjø (675 m), Flisa (200 m), and Rena (250 m) [Norwegian Meteorological Institute, 2013b] located in eastern Norway in the county of Hedmark, shown in Figure S1.

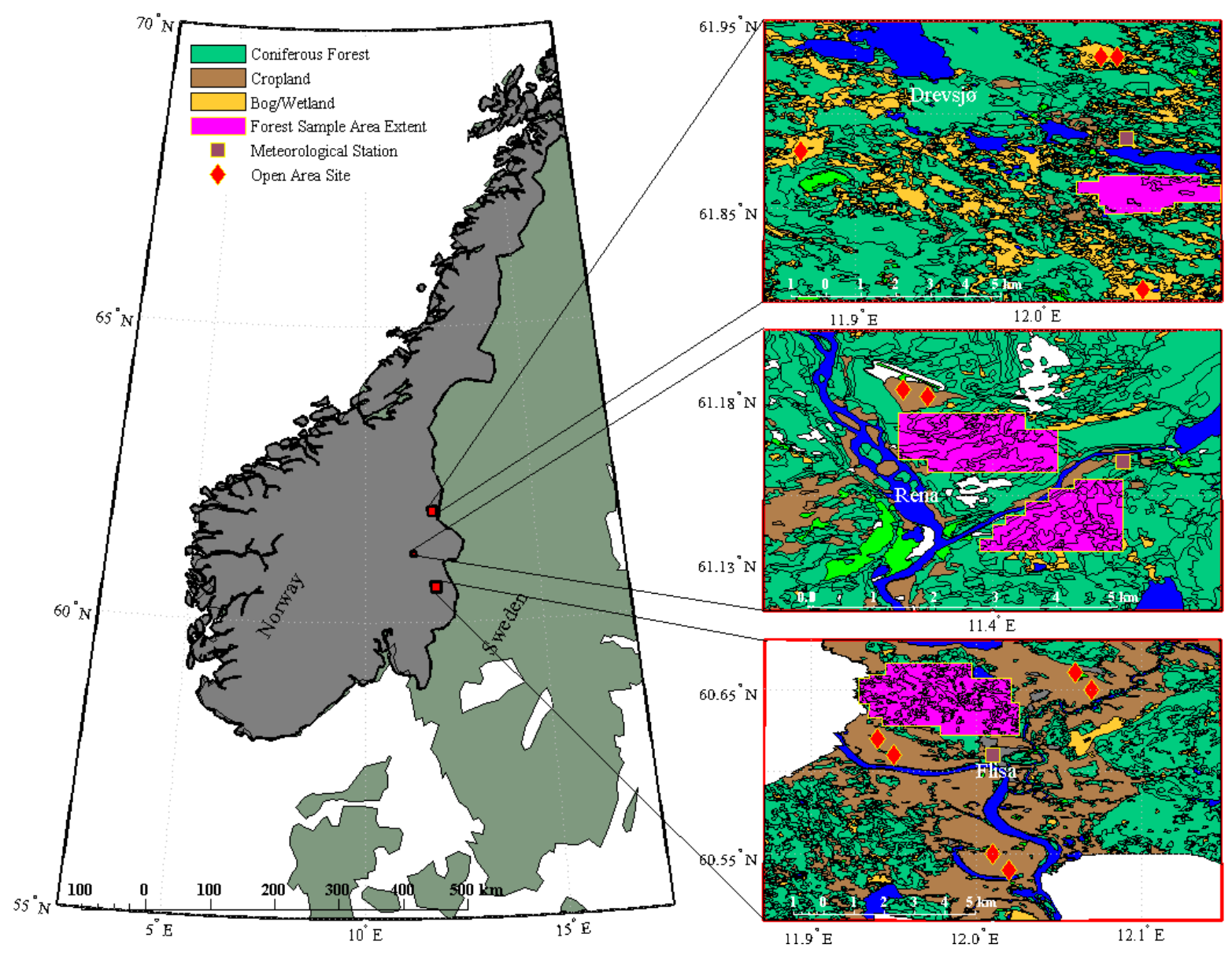

Figure S1. Study regions shown with open area ("Cropland" or "Bog/wetland") and coniferous forested sites included in the analysis. Meteorological station locations are also indicated and have the following geographic coordinates: RENA (61.16 N, 11.44 W); DREVSJØ (61.89 N, 12.05 W); FLISA (60.61 N, 12.01 W). 
Local forest management plans are used to identify forest stands of pure ( $>95 \%$ volume, $\mathrm{m}^{3} / \mathrm{ha}$ ) evergreen needleleaf forest cover within a $5 \mathrm{~km}$ radius and $50 \mathrm{~m}$ altitude range of a weather monitoring station. The management plan data are checked to ensure that all stands are older than 3 years of age in 2009 .

In addition, 12 open area sites within the same $5 \mathrm{~km}$ proximity to a weather station -8 cropland and $4 \mathrm{bog} /$ wetland - comprise an un-masked sample (Fig. S1). Sites were selected using Google Earth $^{\mathrm{TM}}$ to visually confirm land use cover type. In total, 250 forested MODIS pixels (approximately 5,300 hectares) and 12 open area pixels are included in the sample.

\section{S.2.3. 2007-2009 Nov. - May daily historical meteorology}

Daily historical meteorological time series for our three case regions are presented in Figure S2. Note that Nov. and Dec. 2006 are excluded. 


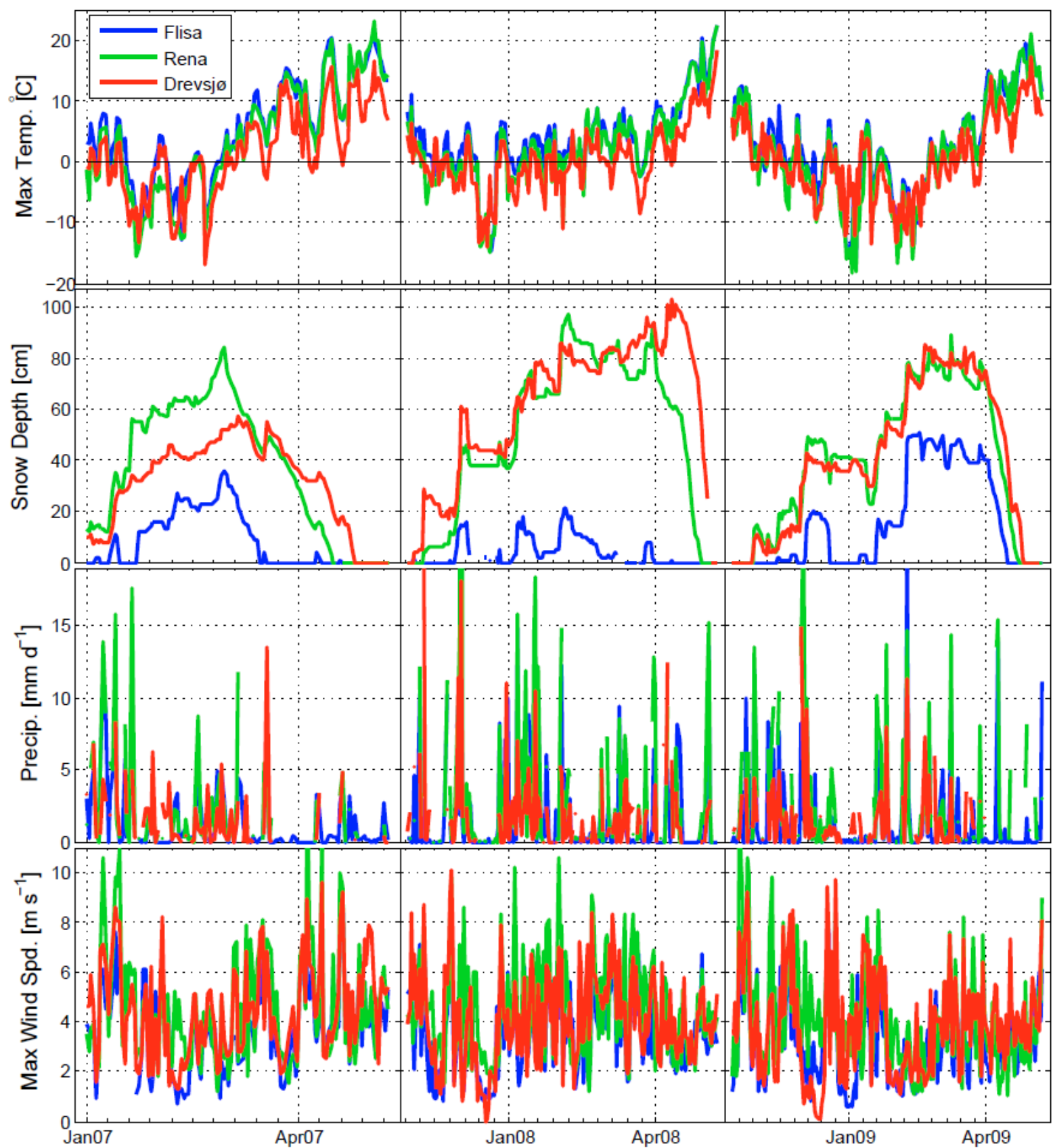

Figure S2. 2007 - 2009 observed daily meteorology [10 m], Nov. - May (excludes Nov. \& Dec. 2006).

\section{S.2.4. Forest structure}

Table S1 presents forest structure characteristics of our forest sample after resampling LIDAR observations to the MODIS product (MCD43A) spatial resolution.

Table S1. Min., Max., and Median tree height, canopy cover fraction (CC), and LAI in the sampled evergreen needleleaf forests of each study region (sampled June, 2009). H80 is used as a proxy for tree height.

\begin{tabular}{lcccc}
\hline $\begin{array}{l}\text { Study } \\
\text { Region }\end{array}$ & $\begin{array}{c}\text { Sample } \\
\text { Area }\end{array}$ & Tree height, h $(\mathrm{m})$ & $\mathrm{CC}(\%)$ & LAI $\left(\mathrm{m}^{-2} \mathrm{~m}^{-2}\right)$ \\
\hline
\end{tabular}




\begin{tabular}{lllllllllll}
\hline & $\left(\mathrm{km}^{2}\right)$ & & & & & & & \\
\hline $\begin{array}{l}\text { Number of } \\
\text { MCD43A } \\
\text { pixels) }\end{array}$ & & Min & Max & Median & Min & Max & Median & Min & Max & Median \\
\hline Flisa $(n=65)$ & 14.0 & 3.1 & 15.8 & 11.8 & $25 \%$ & $77 \%$ & $63 \%$ & 0.55 & 2.35 & 1.73 \\
Rena $(n=34)$ & 7.3 & 5.7 & 13.0 & 9.8 & $50 \%$ & $80 \%$ & $63 \%$ & 1.31 & 1.82 & 1.52 \\
$\begin{array}{l}\text { Drevsjø } \\
(n=36)\end{array}$ & 7.7 & 3.2 & 10.2 & 7.5 & $27 \%$ & $52 \%$ & $40 \%$ & 0.43 & 1.21 & 0.81 \\
$\begin{array}{l}\text { Regional } \\
\text { Mean }\end{array}$ & $29.0^{\mathrm{a}}$ & 4.0 & 13.0 & 9.7 & $34 \%$ & $69.7 \%$ & $55.3 \%$ & 0.76 & 1.79 & 1.35 \\
\hline
\end{tabular}

${ }^{\mathrm{a}}$ Value is column sum.

\section{S.2.5. 2007-2009 daily albedo over forests, Nov. - May}

Daily MODIS "black-sky" albedo (MCD43A) in evergreen needleleaf forests in each of our study regions. Note that Nov. and Dec. 2006 are excluded.

Flisa

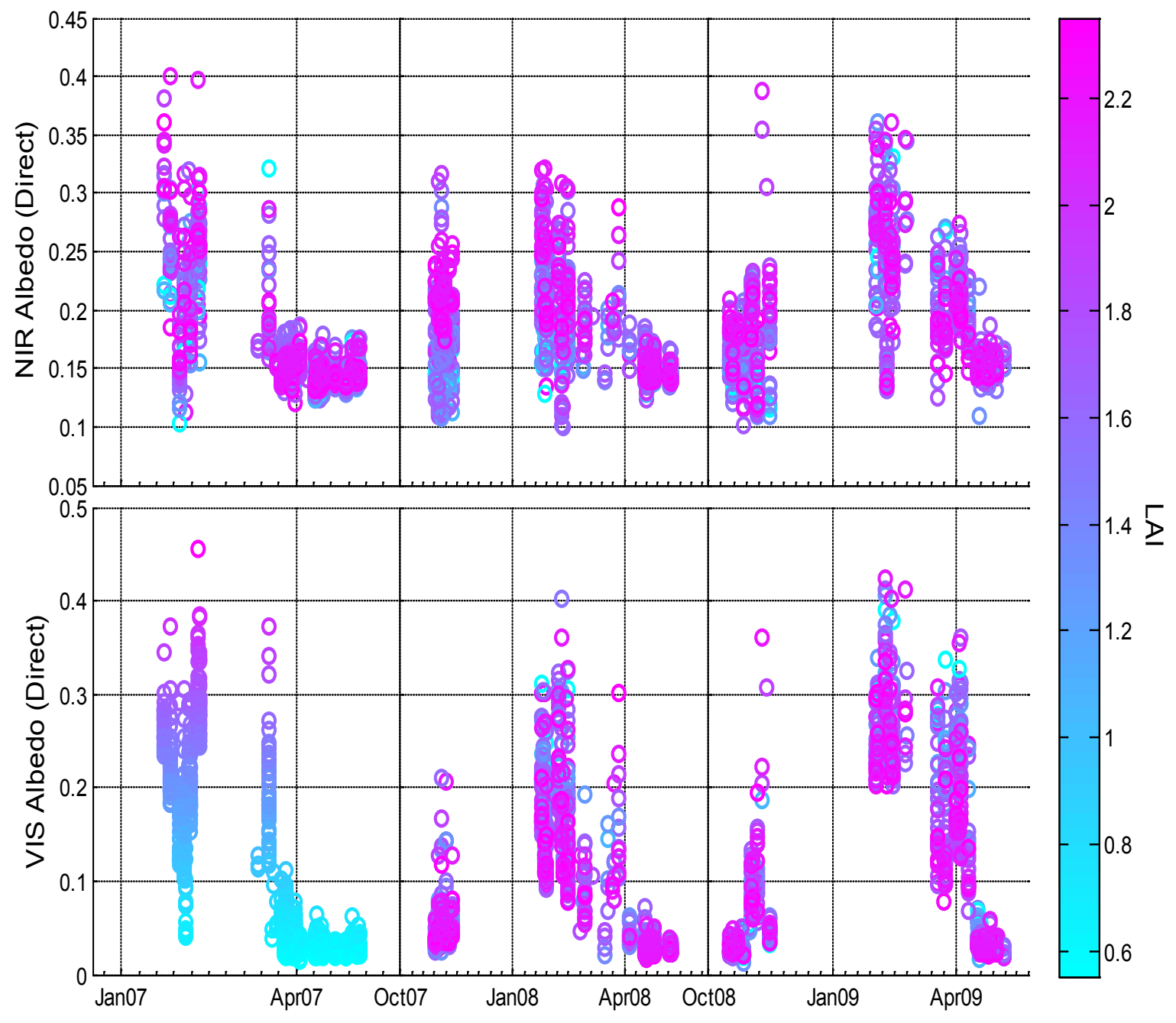

Figure S3. MODIS direct beam ("black sky") daily albedo time series for the study region in Flisa municipality, Hedmark, Norway. 
Large snow events in the coldest months of Jan. and Feb. in Flisa combined with high snow interception rates by forested canopies enhanced canopy albedo, resulting in higher albedos in forests with high LAIs (Figure S3).

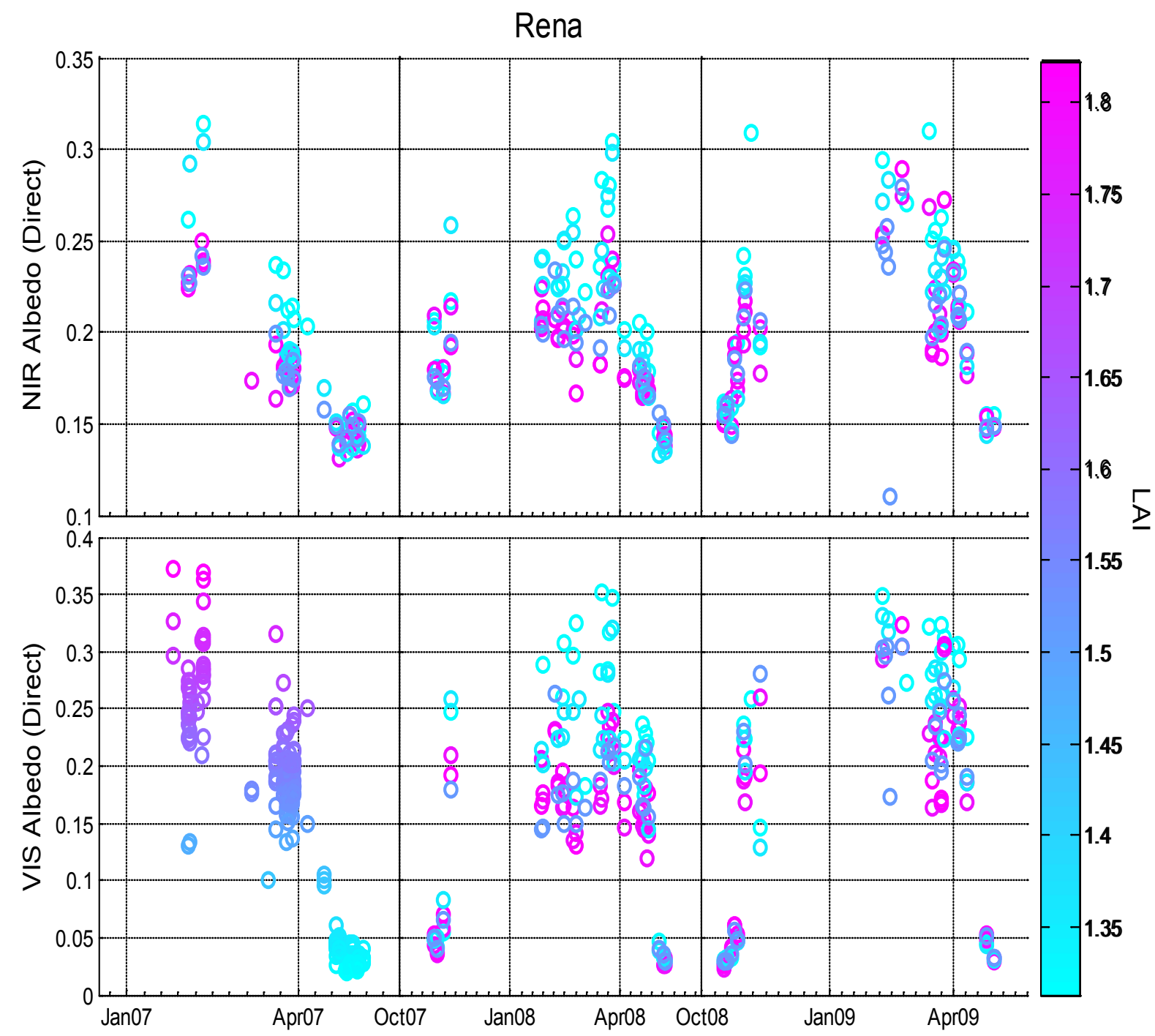

Figure S4. MODIS direct beam ("black sky") daily albedo time series for the study region in Rena municipality, Hedmark, Norway. 


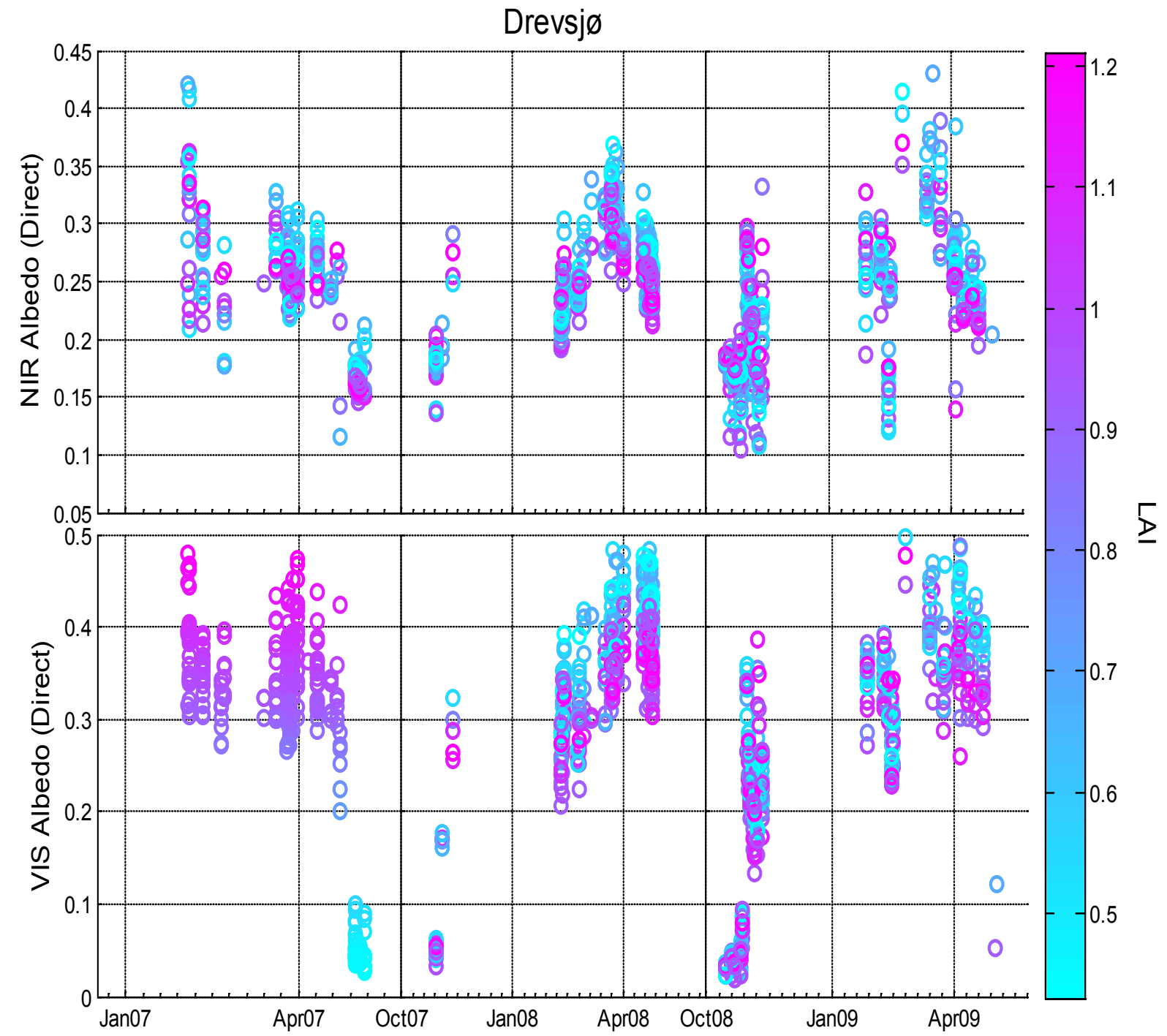

Figure S5. MODIS direct beam ("black sky") daily albedo time series for the study region in Drevsjø municipality, Hedmark, Norway.

\section{S.3. Albedo parameterizations in Land Surface Models (or schemes)}

The following sub-sections contain descriptions of the albedo schemes in the land models included in our study. We do not comprehensively review and describe albedo parameterizations in land models or snow physical models, as this has been done extensively in recent years. See refs. [Essery et al., 2013; Mölders et al., 2008; Pedersen and Winther, 2005; Pirazinin, 2009; Rutter et al., 2009; Z. W ang and Zeng, 2009].

\section{S.3.1. JULES (2-stream)}

The Joint UK Land-Environment Simulator (JULES) employs a two-stream approximation of radiation interception adopted from Sellers [Sellers, 1985] to calculate surface spectral albedos [MJ Best et al., 2011; Essery et al., 2001]. Optical parameter values and all parameterizations used in this study stem from the JULES technical documentation [M Best, 2009]. 
Snow albedos are calculated using a simplified parameterization of a spectral snow albedo model [Wiscombe and Warren, 1980] in which snow aging is based on prognostic grain size, with minimum and maximum values set to $50 \mu \mathrm{m}$ and $2000 \mu \mathrm{m}$, respectively. Fresh snowfall rates of $2.5 \mathrm{~mm} \mathrm{~d}^{-1}$ $\left(\mathrm{kg} \mathrm{m}^{2}\right)$ reset grain size to its minimum, and grain area growth rate is determined by surface temperature, distinguishing between fresh and aged cold snow at grain size thresholds of $150 \mu \mathrm{m}$.

Canopy-intercepted snow is not parameterized in the JULES 2-stream model version applied in this study [M Best, 2009]; thus, surface albedo is parameterized as the weighted fraction of the zenith angle dependent direct beam snow albedo $\alpha_{s}$ and snow-free albedo $\alpha_{0}$ as determined by snow cover fraction:

$\alpha=f_{s} \alpha_{s}+\left(1-f_{s}\right) \alpha_{0}$

where snow cover fraction $f_{s}$ is parameterized following Oleson [2004] and is based on snow depth $d$ and momentum roughness length $z_{0}$ :

$f_{s}=\frac{d}{d+10 z_{0}}$

Momentum roughness length $z_{0}$ is based on vegetation height $h$, where for "trees", $z_{0}$ is set to $\mathrm{h} / 20$. In our simulations, $h$ is based on airborne LIDAR measurements (H80). Height statistics per region are shown in Table $\mathrm{S} 1$.

\section{S.3.2. JULES (All-band)}

The snow albedo scheme in the "All-band" version of JULES is diagnostic, where snow albedo $\alpha_{s}$ takes the albedo of cold deep snow $\alpha_{c d s}$ for temperatures below $-2 \mathrm{C}$ and a value between the snow-free albedo $\alpha_{0}$ and $\alpha_{c d s}$ when temperatures are between $-2 \mathrm{C}$ and the melting point of snow. Snow-free and cold deep snow albedos are estimated using a parameterization for radiative fraction $f_{r}$ that is based on the 1 -sided leaf area index (LAI):

$\alpha_{0}=\left(1-f_{r}\right) \alpha_{\text {soil }}+f_{r} \alpha_{0}^{\infty}$

$\alpha_{c d s}=\left(1-f_{r}\right) \alpha_{s}^{0}+f_{r} \alpha_{s}^{\infty}$

where $\alpha_{\text {soil }}$ is the albedo of snow-free soil underlying vegetation and $\alpha_{s}^{0}, \alpha_{0}^{\infty}$, and $\alpha_{s}^{\infty}$ are the vegetation-dependent albedos. Albedo parameters of the "All-band" version are presented in Best et al. [2009]. However, since our radiative transfer model differentiates between NIR and VIS bands, we instead take observed latitude- and vegetation-dependent NIR and VIS albedos for "Grassland" and "Needleleaf Forests reported in Gao et al [2005] and observed soil albedos from Lawrence \& Chase [2007], shown in Table S2. Maximum values for vegetation-dependent cold deep snow albedos are used $\left(\alpha_{s}^{0}\right)$ and Eq. S4 is ignored since band-dependent $\alpha_{s}^{\infty}$ values are unavailable. 
Table S2. Vegetation-dependent snow-free albedos are means for IGBP Class "Evergreen Needleleaf" $\left(60-70^{\circ} \mathrm{N}\right)$ and "Grasslands" $\left(50-70^{\circ} \mathrm{N}\right)$, while vegetation-dependent snow albedos are maximums $\left(\alpha_{s}^{0}\right)$ [Gao et al., 2005]. Soil albedos values are means of dry and saturated values reported in Table 4 of Lawrence \& Chase [2007].

\begin{tabular}{lll}
\hline & NIR & VIS \\
\hline$\alpha_{\text {soil }}$ & 0.170 & 0.090 \\
$\alpha_{0}^{\infty}$, "Evergreen Needleleaf" & 0.160 & 0.024 \\
$\alpha_{0}^{\infty}$, "Grassland" & 0.241 & 0.063 \\
$\alpha_{s}^{0}$, "Evergreen Needleleaf" & 0.222 & 0.279 \\
$\alpha_{s}^{0}$, "Grassland" & 0.569 & 0.831 \\
\hline
\end{tabular}

Total surface albedo $\alpha$ is parameterized as a combination of the snow-free albedo $\alpha_{0}$ and a weighted value based on snow mass:

$\alpha=\alpha_{0}+\left(\alpha_{s}-\alpha_{0}\right)\left(1-\mathrm{e}^{-0.2 S}\right)$

Where $S$ is snow mass $\left(\mathrm{kg} \mathrm{m}^{-2}\right)$ and $\alpha_{s}$ and $\alpha_{0}$ are the snow and snow-free albedo, respectively. We estimate $S$ using observed snow depth [Norwegian Meteorological Institute, 2013b] and an empirical model of snow density based on meteorological predictors [Meloysund et al., 2007].

\section{S.3.3. CLM4}

Direct beam albedos in the Community Land Model version 4.0 (CLM4) are calculated from the two-stream approximation of Dickinson [1983] and Sellers [1985] assuming a random distribution of leaf angles and using mean canopy LAI observations (based on airborne LIDAR) and a SAI of 1 from Zeng et al. [2002]. All vegetation and intercepted snow optical parameters are taken from the CLM4.0 technical documentation [2010] which are based on the works of Dorman \& Sellers [1989] and Asner [1998]. Spectral-dependant soil albedos are the mean "Boreal" wet and dry values presented in Lawrence \& Chase [2007] which are based on MODIS observations.

Canopy snow fraction $f_{c s}$ is determined by intercepted snow which is based on accumulated snow loading and unloading and a maximum interception capacity determined by total leaf and stem area index (LSAI $=$ LAI + SAI) and an empirical constant from Dickinson et al. [1993]. The albedo of the canopy is based on the exposed fraction $L S A I_{e x}$ :

$$
L S A I_{e x}=\operatorname{LSAI}\left(1-f_{c s}\right)
$$

In this study we do not employ the snow radiative transfer model SNICAR and thus do not account for snow impurities from aerosol deposition; instead, we rely on the same simplified parameterizations of the snow spectral models [Wiscombe and Warren, 1980] employed in JULES [M Best, 2009]. Snow aging is based on effective grain size evolution in a single snow layer that is prognosed by near-surface temperature as a proxy, since we do not employ the snow physics 
model needed to obtain snow temperature, temperature gradients (multiple layers), or densities. The minimum effective grain radius of fresh snow is $54.5 \mu \mathrm{m}$ and the maximum for refrozen liquid water is set at $1000 \mu \mathrm{m}$.

Ground albedo is a weighted share of soil and the zenith angle dependent snow albedo, where the parameterization for the fraction of ground covered by snow $f_{s}$ is based on the work of Niu and Yang [2007]:

$$
f_{s}=\tanh \left(\frac{d}{2.5 z_{0 m, g}\left[\min \left(\rho_{\text {snow }}, 800\right) / \rho_{\text {new }}\right]^{m}}\right)
$$

Where $d$ is snowdepth (m), $z_{0 m, g}$ is momentum roughness length of soil $(0.01 \mathrm{~m}), \rho_{\text {new }}$ is the density of fresh snow set at $100 \mathrm{~kg} \mathrm{~m}^{-3}, \rho_{\text {snow }}$ is the snow density in the current time step, and $m$ an empirical constant set at 1 for global applications. Since the snow physics model is needed to estimate $\rho_{\text {snow }}$, we rely instead on an empirical parameterization described in Meløysund et al. [2007] based on common meteorological predictors.

\section{S.3.4. JSBACH}

The albedo scheme in the Jena Scheme for Biosphere-Atmosphere Coupling in Hamburg (JSBACH) distinguishes between the albedo of snow on the ground and snow intercepted in forest canopies [Reick et al., 2012]:

$\alpha=f_{g}\left[\left(1-f_{s}\right) \alpha_{g 0}+f_{s} \alpha_{g s}\right]+\left(1-f_{g}\right)\left[\left(1-f_{c}\right) \alpha_{c 0}+f_{c} \alpha_{c s}\right]$

where $f_{g}$ is the exposed ground ("canopy gap") fraction, $f_{c}$ fraction of canopy covered with snow, and $f_{s}$ is the snow-covered ground fraction. Values for broadband NIR and VIS albedos for snow-covered canopies $\alpha_{s c}$, snow-covered ground $\alpha_{s g}$, exposed ground $\alpha_{g 0}$, and canopy $\alpha_{c 0}$ are from Otto et al. [2011] .

Table S3. Albedo values applied in our analysis, from Otto et al. [2011] .

\begin{tabular}{lll}
\hline & NIR & VIS \\
\hline$\alpha_{g 0}{ }^{a}$ & 0.28 & 0.05 \\
$\alpha_{c 0}$ & 0.26 & 0.05 \\
$\alpha_{s g}, \max$ & 0.7 & 0.9 \\
$\alpha_{s g}, \min$ & 0.3 & 0.5 \\
$\alpha_{s c}$ & 0.25 & 0.25 \\
\hline
\end{tabular}

a "Shrubs cold" PFT

The fraction of exposed ground $f_{g}$ is a function of leaf and stem ("plant") area indices (LSAI):

$f_{g}=\mathrm{e}^{-L S A I}$ 
where a value of 1 for SAI is used for all forest PFTs. The albedo of snow covered ground $\alpha_{s g}$ decreases linearly with surface temperature that ranges from a minimum value at melting point to a maximum value for temperatures of less than $-5 \mathrm{C}$; the albedo of snow-covered canopies $\alpha_{s c}$ is fixed. Solar-zenith angle dependency of snow albedo is not taken into account in the scheme.

Canopy intercepted snow in JSBACH is estimated with the simple prognostic snow interception modeling scheme outlined in Roesch et al. [2001], where the intercepted snow is based on snowfall rate, unloading rate due to temperature (melt/drip and slipping), unloading rate due to wind, and sublimation. Parameterizations determining unloading rates from temperature and wind in are adapted from the empirical works of Nakai et al. [1994], Yamazaki et al. [1996], Betts $\&$ Ball [1997], and Miller [1962]. Canopy intercepted snow is limited by a maximum storage capacity that is based on LAI $\left(2 \mathrm{~mm} \mathrm{H}_{2} \mathrm{O}\right.$-eq./ unit LAI), with the snow-covered fraction $f_{c}$ as the ratio of intercepted snow to snow interception capacity.

Here, we exclude sublimation as we do not have the necessary meteorological data required to estimate vapor pressure gradients nor the capacity to model air exchange rates around the snow surface.

\section{S.3.5. CLASS}

Like JSBACH, the Canadian Land Surface Scheme (CLASS) distinguishes between snow intercepted in forest canopies and snow on ground (as in Eq. (S8)), and relies on plant area index (LSAI) to estimate the fraction of exposed ground ("sky-view") in the same way (as Eq. (S9)) [Verseghy, 2009; Verseghy et al., 1993]. However, the direct beam albedo may be calculated separately in CLASS and is zenith angle dependent for snow covered surfaces. Additionally, the albedo of ground underlying the forest canopy is weighted by canopy transmissivity - which is also zenith angle dependent - to account for the decreased shortwave radiation incident at ground surface.

Canopy transmissivity to shortwave radiation is obtained by applying a form of Beer's law of radiation transfer in non-scattering media:

$$
\tau_{c}=\mathrm{e}^{-\kappa L S A I}
$$

where the extinction coefficient $\mathcal{\kappa}$ is estimated following Goudriaan [1988] and is both PFT and spectral dependent

$$
\kappa=k \cos (S Z A)^{-1}
$$

where $k$ is a correction factor accounting for forward scattering and non-random leaf distributions - which for needleleaf trees is 0.3 and 0.4 , respectively, for NIR and VIS bands.

In CLASS, canopy intercepted snow is parameterized following Hedstrom \& Pomeroy [Hedstrom and Pomeroy, 1998] and is described by the balance between loading rate from fresh snowfall and unloading rate that is governed by an exponential empirical coefficient. Canopy interception capacity is parameterized following Bartlett et al. [2006] and Schmidt \& Gluns [1991] using plant 
area index (LSAI). The fraction of canopy covered in snow $f_{c}$ is the ratio of intercepted snow to interception capacity.

CLASS employs a prognostic snow-albedo scheme that accounts for a declining albedo with snow age. In the absence of fresh snow, $\alpha_{s}$ decreases exponentially with time from its fresh value to an old value (Table S4, "old dry" snow) following Aguado [1985], Robinson \& Kukla [1984] , and Dirmhirn \& Eaton [1975]. If temperature is at or above freezing, a lower value for melting snow is applied (Table S4, "old melting" snow).

Table S4. Albedo values applied in our analysis, from Verseghy [2009].

\begin{tabular}{lll}
\hline & NIR & VIS \\
\hline$\alpha_{g 0}{ }^{\mathrm{a}}$ & 0.19 & 0.03 \\
$\alpha_{c 0}$ & 0.19 & 0.03 \\
$\alpha_{s g} \& \alpha_{s c}$, fresh & 0.73 & 0.95 \\
$\alpha_{s g} \& \alpha_{s c}$, old dry & 0.56 & 0.84 \\
$\alpha_{s g} \& \alpha_{s c}$, old melting & 0.38 & 0.62 \\
\hline
\end{tabular}

a "Evergreen broadleaf shrub" PFT, Appendix Table A in Verseghy [2009].

Because it is not mentioned in Verseghy [2009], the albedo value for "fresh snow" is assumed to be reset if snowfall exceeds $2 \mathrm{~mm} \mathrm{~d}^{-1}$ ( $\mathrm{H}_{2} \mathrm{O}$-eq.).

\section{S.3.6. GISS II}

In the Goddard Institute for Space Studies (GISS) model II albedo scheme [Hansen et al., 1983] which is still employed in the more recent "Model E" version [G A Schmidt et al., 2006] - total surface albedo $\alpha$ is parameterized in the same way as the JULES "All-band" scheme and is a combination of the snow-free albedo $\alpha_{0}$ and a weighted value based on snow depth and surface masking depth. Snow albedo $\alpha_{s}$ is age-based and prognostic, where the albedo of fresh snow decays linearly as a function of time to a minimum value unless reset by $2 \mathrm{~mm}$ of fresh snowfall. The snow-free albedo $\alpha_{0}$ and surface masking depth $d_{m}$ terms are vegetation dependent, with those applied in this study shown in Table S5. Surface masking depth is $10 \mathrm{~m}$.

Table S5. Albedo values are mean values for "Winter" and "Spring" in Hansen et al. [1983].

\begin{tabular}{lll}
\hline & NIR & VIS \\
\hline$\alpha_{0}$, "Evergreen" & 0.20 & 0.07 \\
$\alpha_{0}$, "Grass" & 0.31 & 0.10 \\
$\alpha_{s}$, fresh & 0.6 & 0.90 \\
$\alpha_{s}$, old & 0.35 & 0.60 \\
\hline
\end{tabular}

\section{S.4. Regression model}


The best performing non-linear multiple regression model (in terms of Akaike's Information Criterion; ACC) is that which is based on a single predictor of forest structure and two climate predictors:

$\alpha=\overbrace{k_{1}+k_{2}\left(1-\mathrm{e}^{-L A I}\right)}^{\text {Snow-free albedo }}+\overbrace{k_{3} \tanh \left(d / k_{4}\right)\left(\mathrm{e}^{-\mathrm{k}_{5}(L A I)}+\left[1-\frac{1}{1+\mathrm{e}^{-k_{6} T^{M A X}}}\right]\right)}^{\text {w/Snow on ground \& in canopy }}$

Where $d$ is snow depth $(\mathrm{cm}), T^{M A X}$ is the maximum daily temperature $\left({ }^{\circ} \mathrm{C}\right)$, and $L A I$ is leaf area index $\left(\mathrm{m}^{2} \mathrm{~m}^{-2}\right)$. The forest canopy is distinguished from the ground surface with a sky-view factor $\mathrm{e}^{-L A I}$ (or canopy radiative fraction $\left(1-\mathrm{e}^{-L A I}\right)$ ). The snow-free albedo in the absence of the forest canopy (i.e., the ground albedo) is represented by $k_{1}$; in the presence of the forest canopy, the snow-free albedo is the sum of $k_{1}$ and the term $k_{2}$ scaled by the canopy radiative fraction. In winter and spring, in addition to forest structure, meteorology plays a role in determining the total albedo. Those meteorological variables which have been found to significantly and consistently affect the albedo of snow-covered surfaces across a variety of sites and regions include temperature and snow depth [Broch et al., 2000; Mölders et al., 2008; Pedersen and Winther, 2005]. Temperature plays a strong role in the metamorphosis of effective grain surface area [Aoki et al., 2003; Brun, 1989]. Further, canopy unloading of intercepted snow due to slippage and melt, and thus the albedo of the forest canopy, is also greatly influenced by temperature [Kunsinen et al., 2012; Nakai et al., 1994; Yamazaki et al., 1996]. Here, we find that maximum daily temperature $\left(T^{M A X}\right)$ is a robust predictor of both the albedo of the forest canopy and snowcovered surface. The relationship with temperature can be described well with a logistic function, which is supported by analysis of others [Aoki et al., 2003; Bright et al., 2013; Bright et al., 2014].

Snow depth is often used in parameterizations of snow cover fraction [Nin and Yang, 2007; Roesch et al., 2001; Yang et al., 1997], with snow cover being important for the albedo of exposed ground. The relationship with the albedo of snow-covered ground and snow depth is best described with a hyperbolic tangent function which is in line with that originally proposed by Yang et al. [1997], later refined in Niu \& Yang [2007], and currently used in the CLM4 scheme [Oleson et al., 2010]. Here, the parameter $k_{4}$ replaces the snow density and roughness terms in refs. [Niu and Yang, 2007; Oleson et al., 2010] since these variables are not directly available.

Table S6. Regression model parameters and performance metrics. All parameters are statistically significant ( $\mathrm{p}$-values $<0.001)$.

\begin{tabular}{lllllllll}
\hline Model & $k_{1}$ & $k_{2}$ & $k_{3}$ & $k_{4}$ & $k_{5}$ & $k_{6}$ & $\mathbf{r}^{2}$ & RMSE \\
\hline SW $(0.3-5 \mu \mathrm{m})$ & 0.15 & -0.06 & 0.27 & 4.58 & 2.69 & 0.05 & 0.86 & 0.045 \\
NIR $(0.7-5 \mu \mathrm{m})$ & 0.19 & -0.05 & 0.16 & 3.10 & 4.75 & 0.07 & 0.70 & 0.047 \\
VIS $(0.3-0.7 \mu \mathrm{m})$ & 0.09 & -0.07 & 0.37 & 4.55 & 2.01 & 0.04 & 0.89 & 0.058 \\
\hline
\end{tabular}

We did not detect any strong correlation between albedo and solar zenith angle $(r=0.21)$, and further, we did not detect any strong negative correlation between wind speed and albedo $(\mathrm{r}=$ 0.07) from canopy unloading, as reported by others [A K Betts and Ball, 1997; Miller, 1962]. 


\section{S.5. Daily Albedo Time Series: Observations vs. Predictions}

\section{S.5.1. JULES (All-band)}
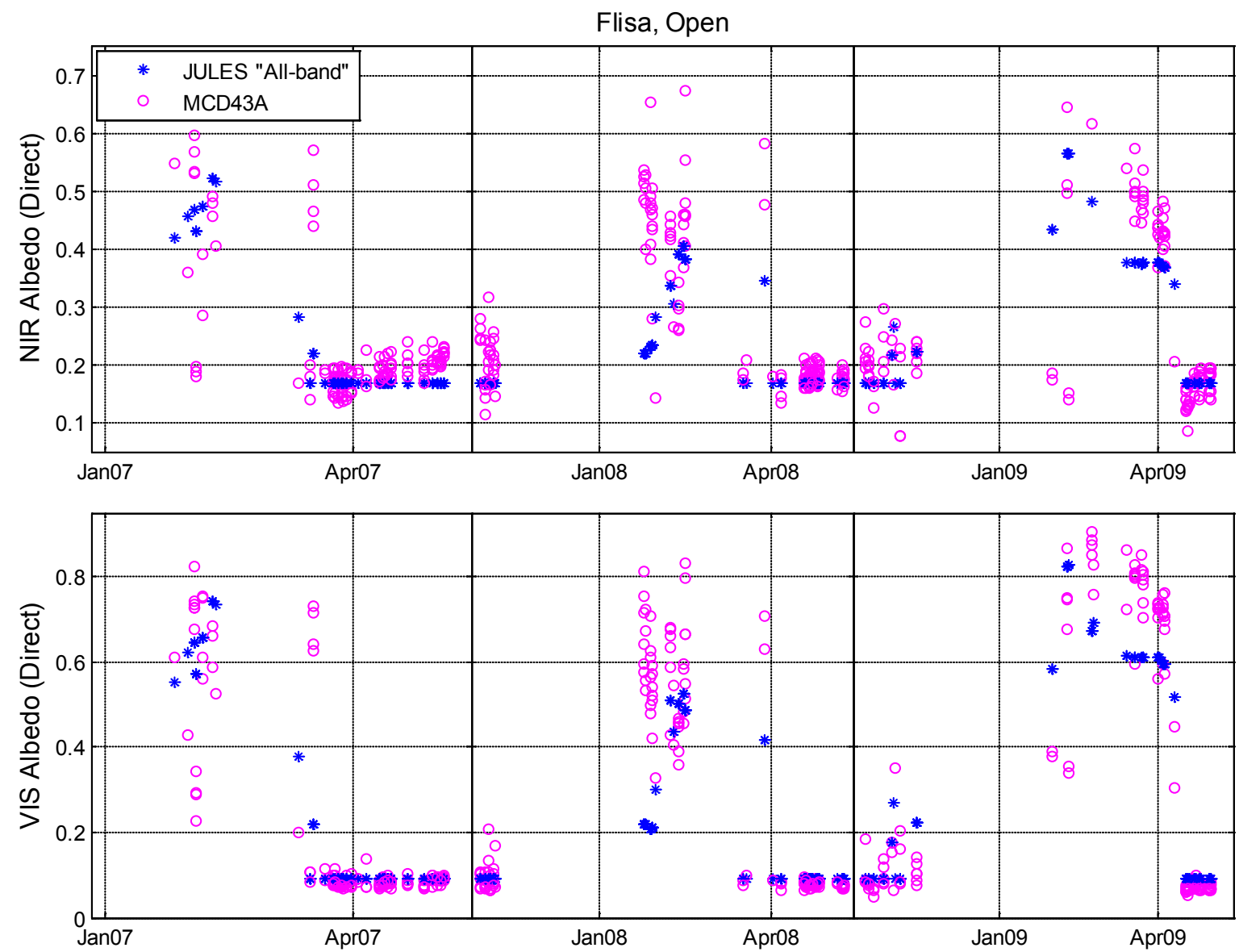

Figure S6. Predicted and observed daily black-sky albedo at the open sites (cropland) in Flisa. 
Rena, Open
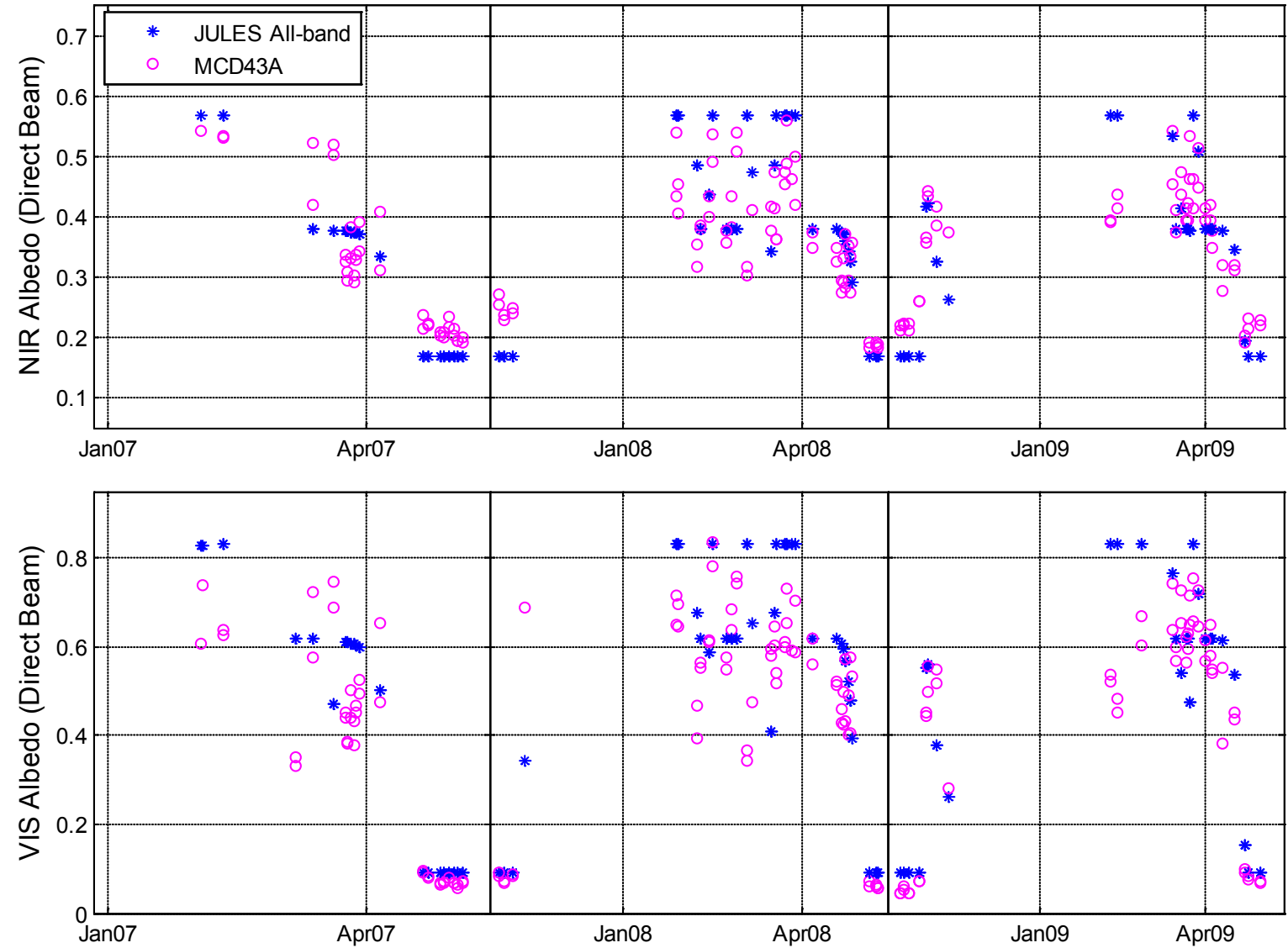

Figure S7. Predicted and observed daily black-sky albedo at the open sites (cropland) in Rena. 

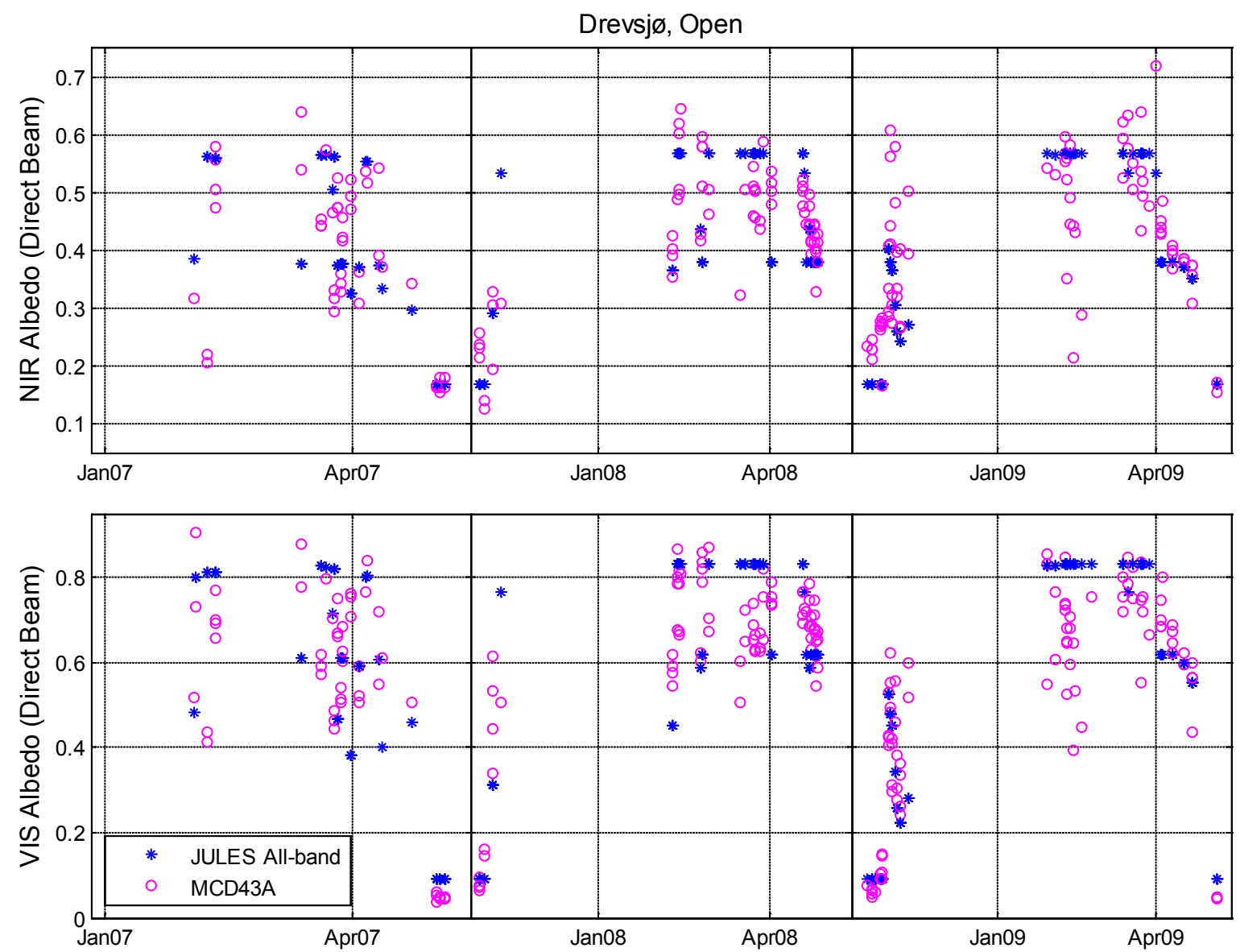

Figure S8. Predicted and observed daily black-sky albedo at the open sites (wetland/peatland) in Drevsjø. 
Flisa, Forest
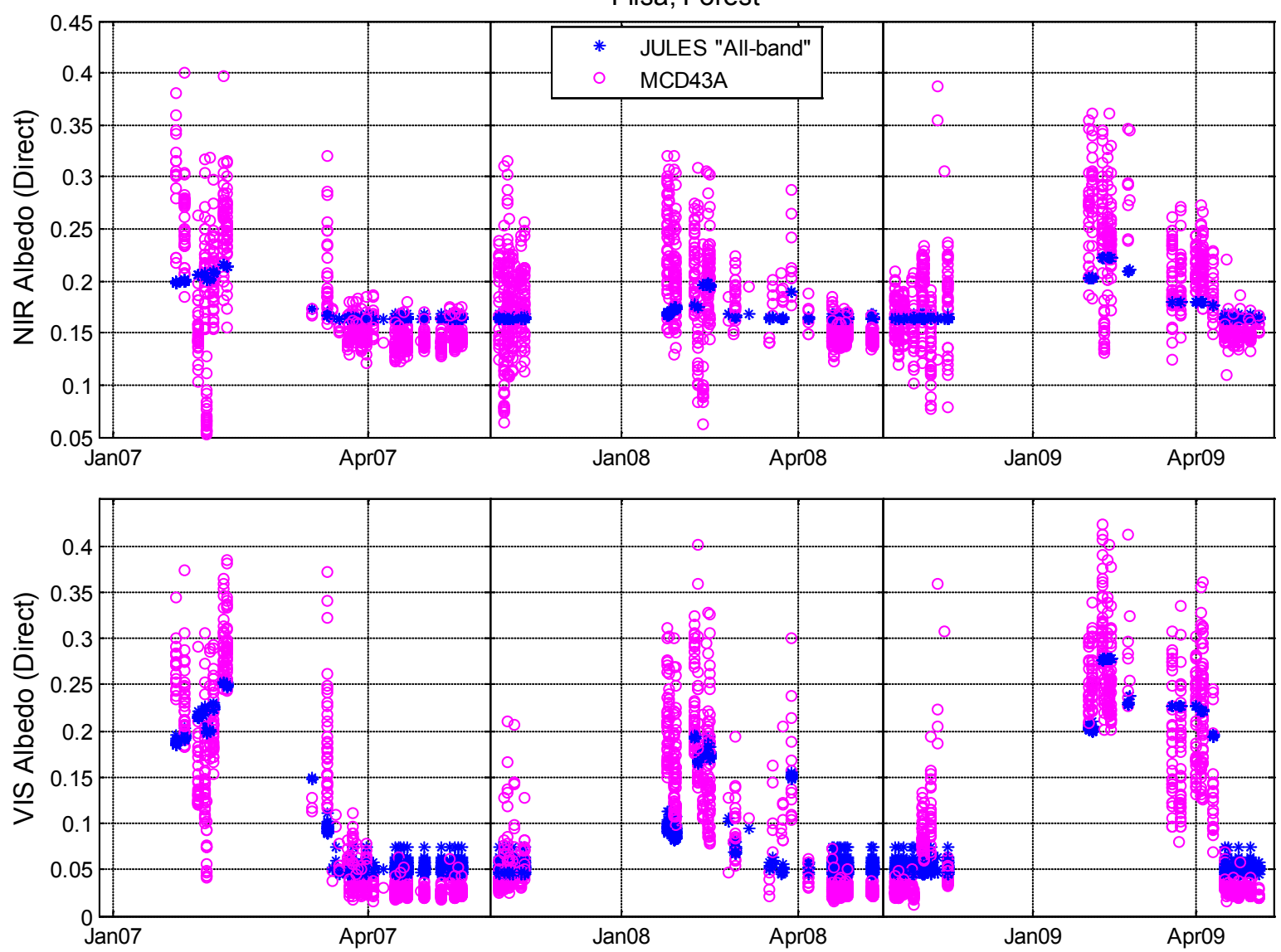

Figure S9. Predicted and observed daily black-sky albedo at the forested sites (evergreen needleleaf) in Flisa. 
Rena, Forests
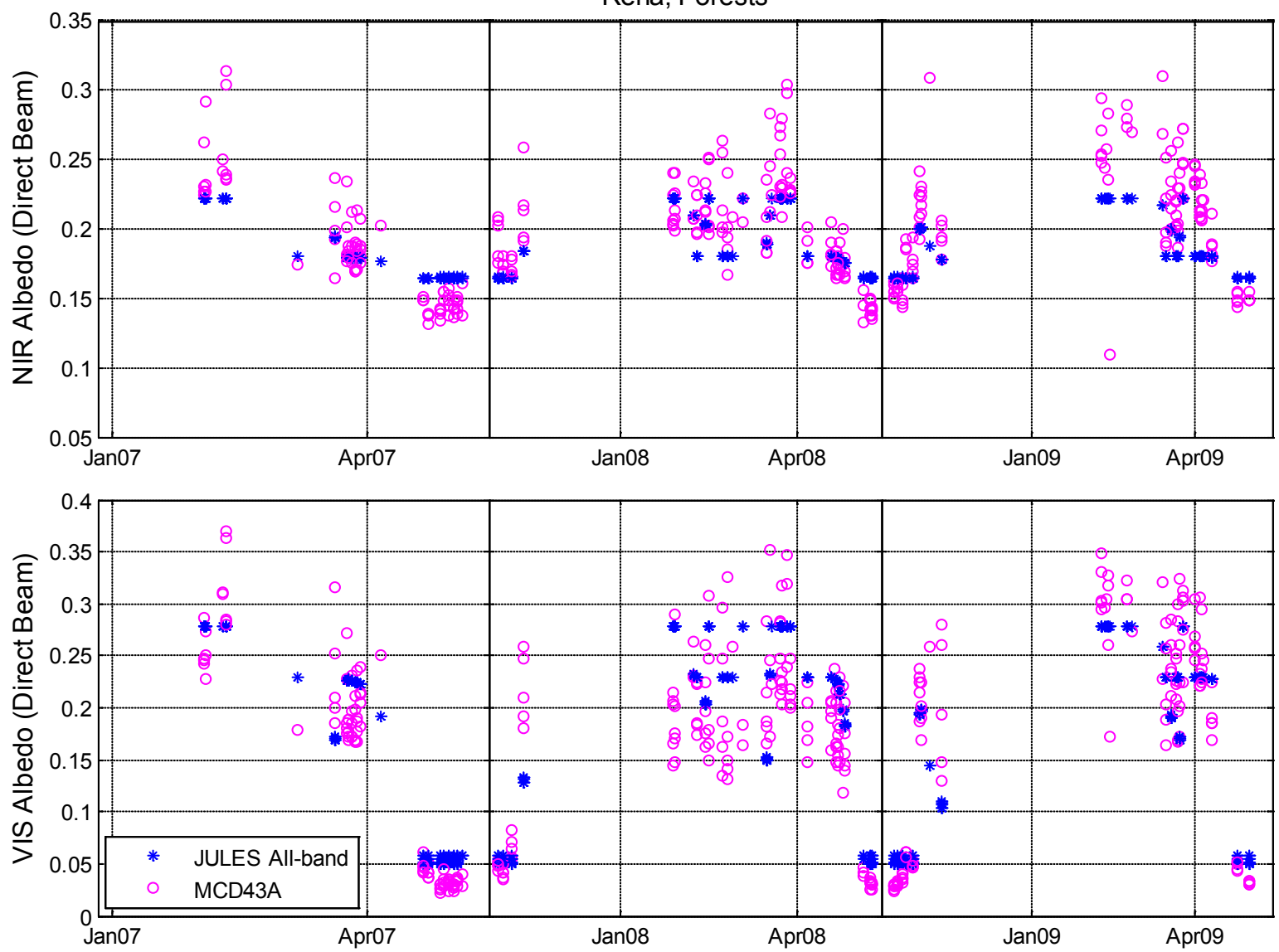

Figure S10. Predicted and observed daily black-sky albedo at the forested sites (evergreen needleleaf) in Rena. 
Drevsjø, Forests
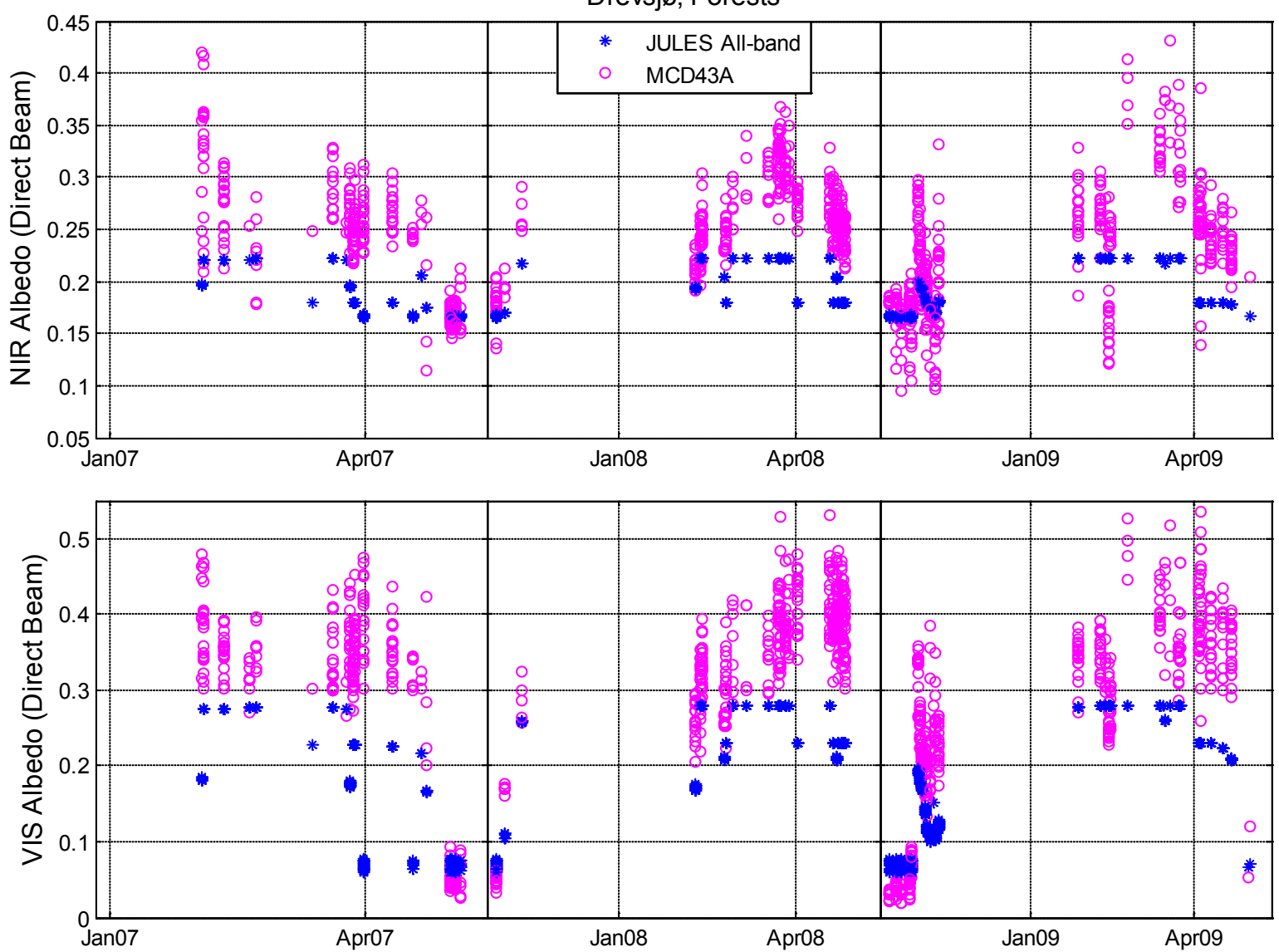

Figure S11. Predicted and observed daily black-sky albedo at the forested sites (evergreen needleleaf) in Drevsjø.

\section{S.5.2. JULES 2-stream}


Flisa, Open
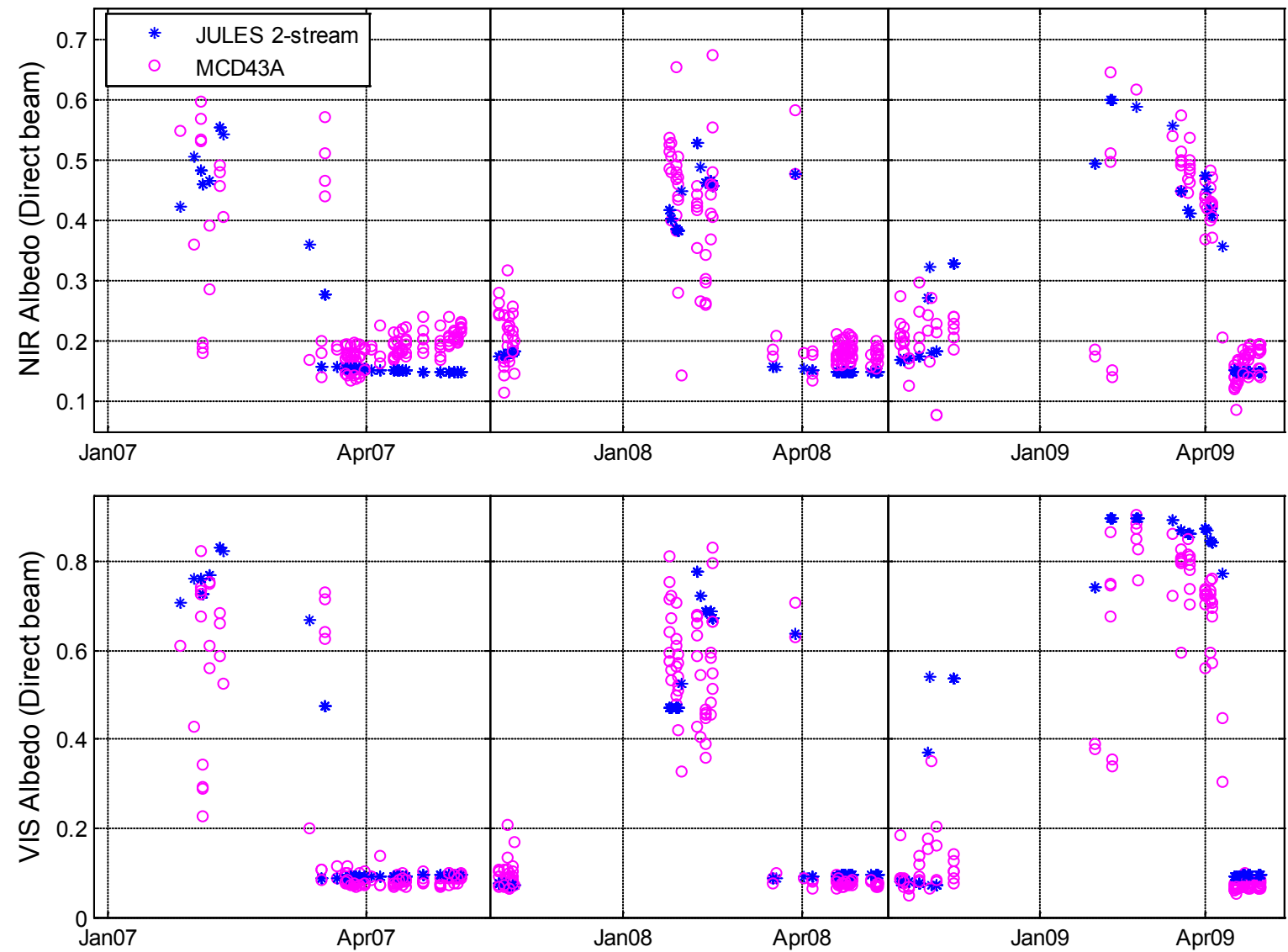

Figure S12. Predicted and observed daily black-sky albedo at the open sites (cropland) in Flisa. 
Rena, Open
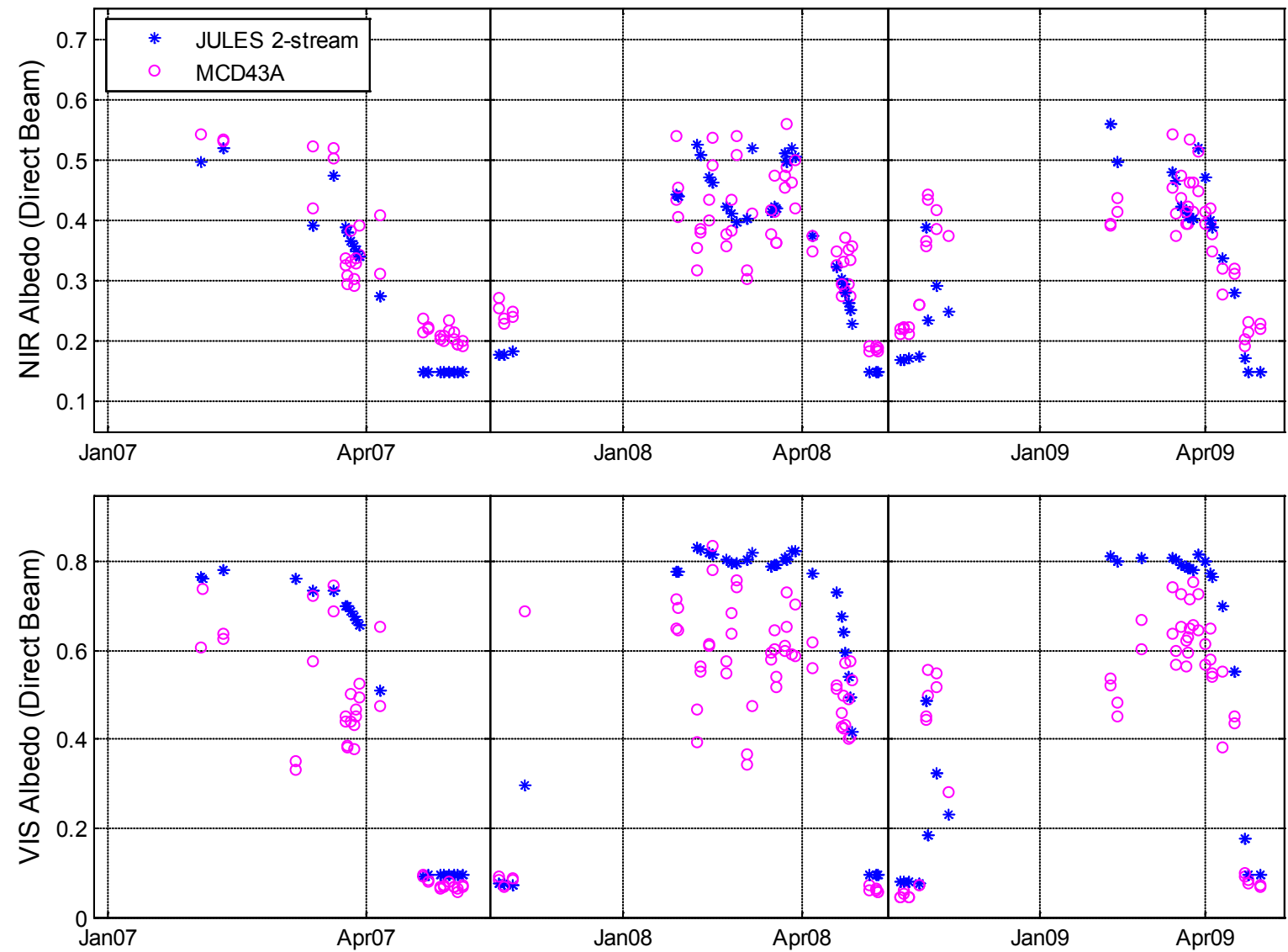

Figure S13. Predicted and observed daily black-sky albedo at the open sites (cropland) in Rena. 

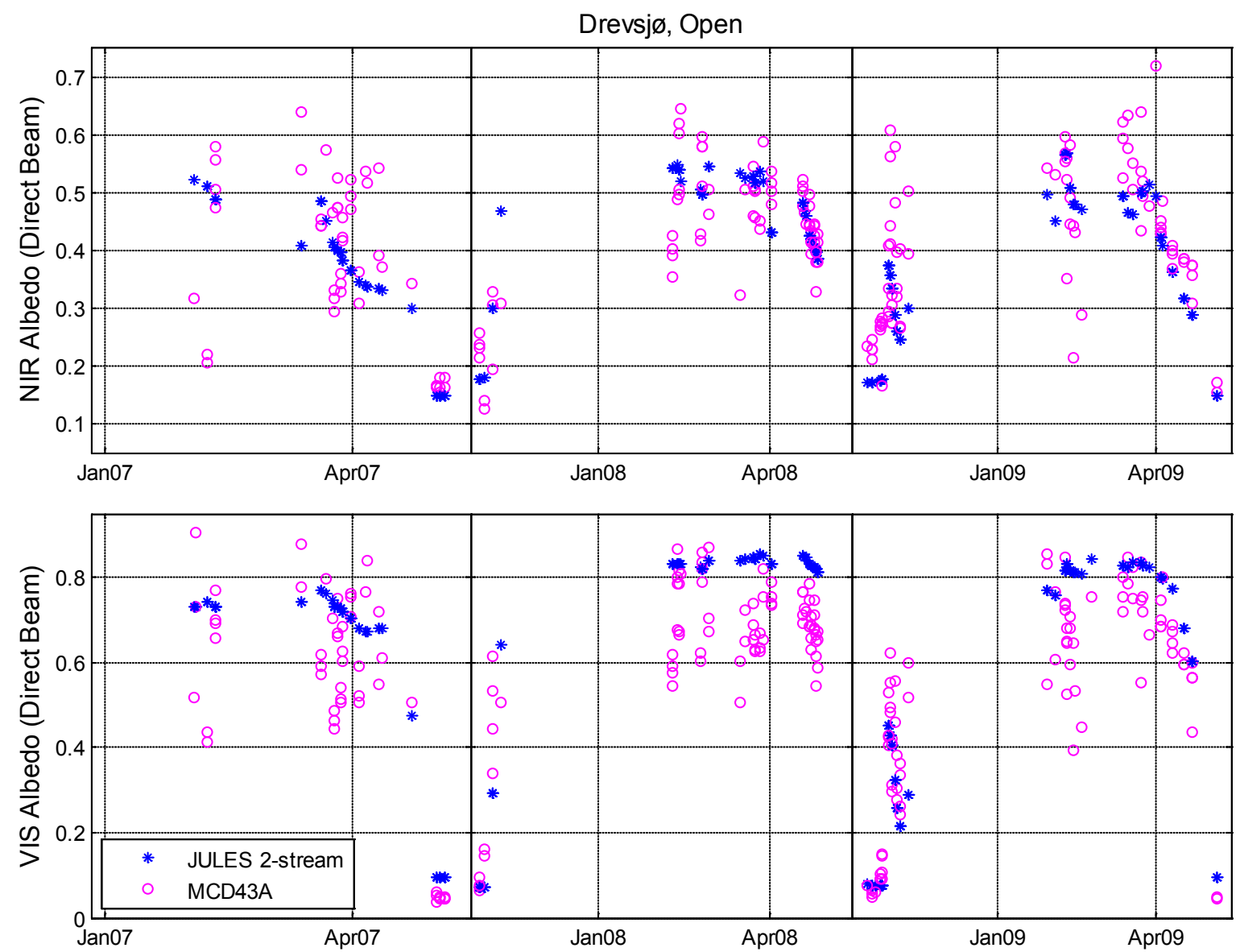

Figure S14. Predicted and observed daily black-sky albedo at the open sites (wetland/peatland) in Drevsjø. 
Flisa, Forest
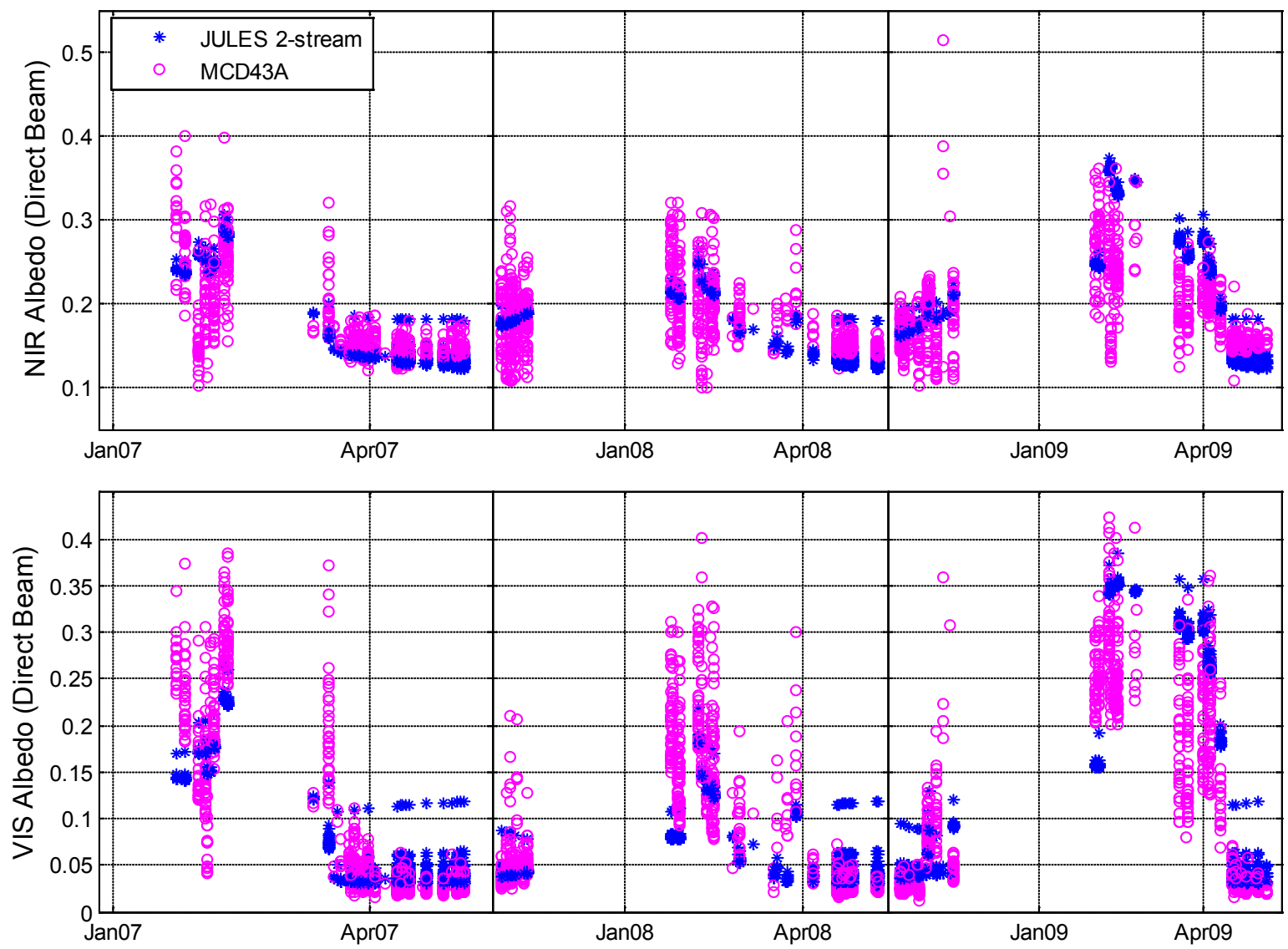

Figure S15. Predicted and observed daily black-sky albedo at the forested sites (evergreen needleleaf) in Flisa. 

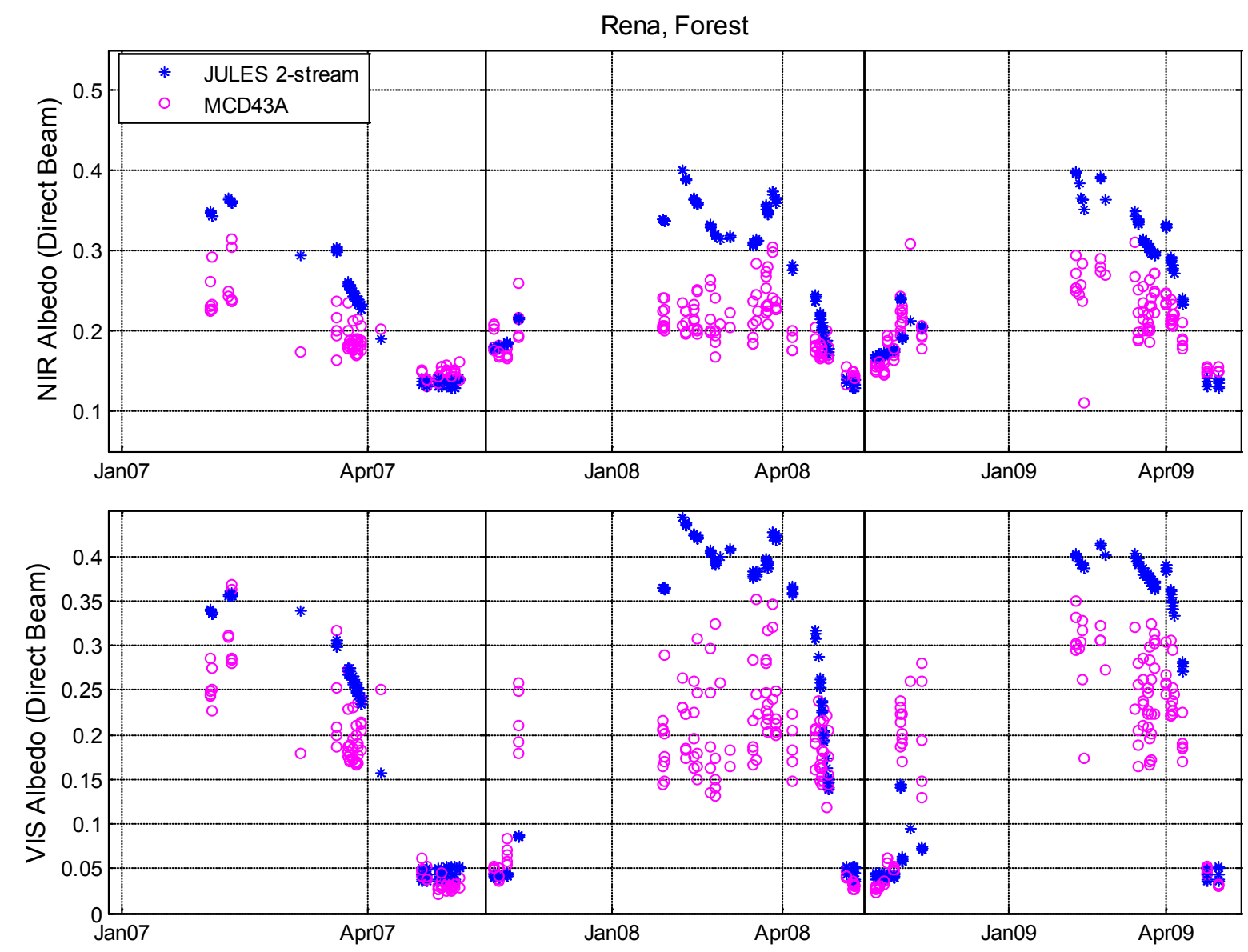

Figure S16. Predicted and observed daily black-sky albedo at the forested sites (evergreen needleleaf) in Rena. 

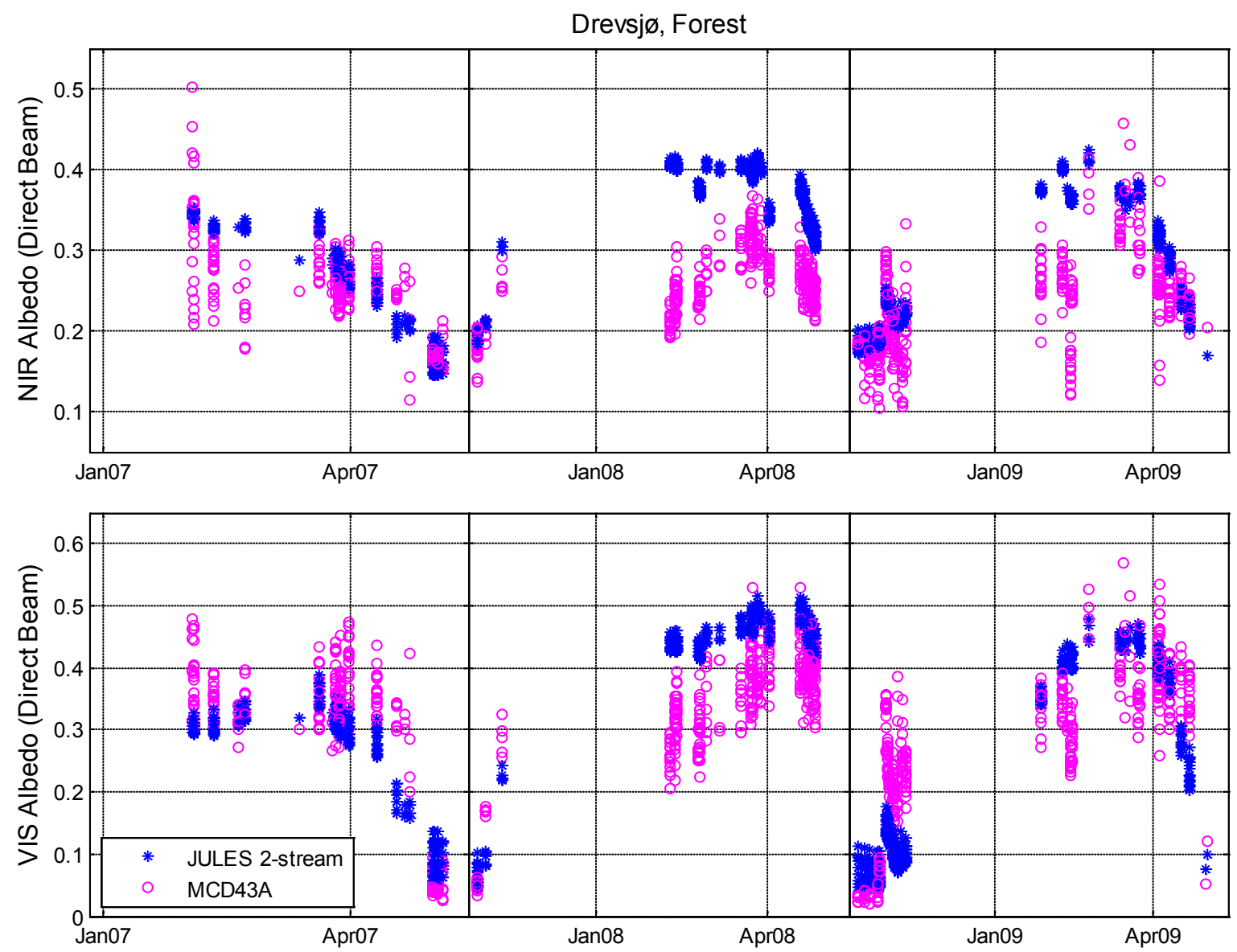

Figure S17. Predicted and observed daily black-sky albedo at the forested sites (evergreen needleleaf) in Drevsjø.

\section{S.5.3. CLM4}


Flisa, Open
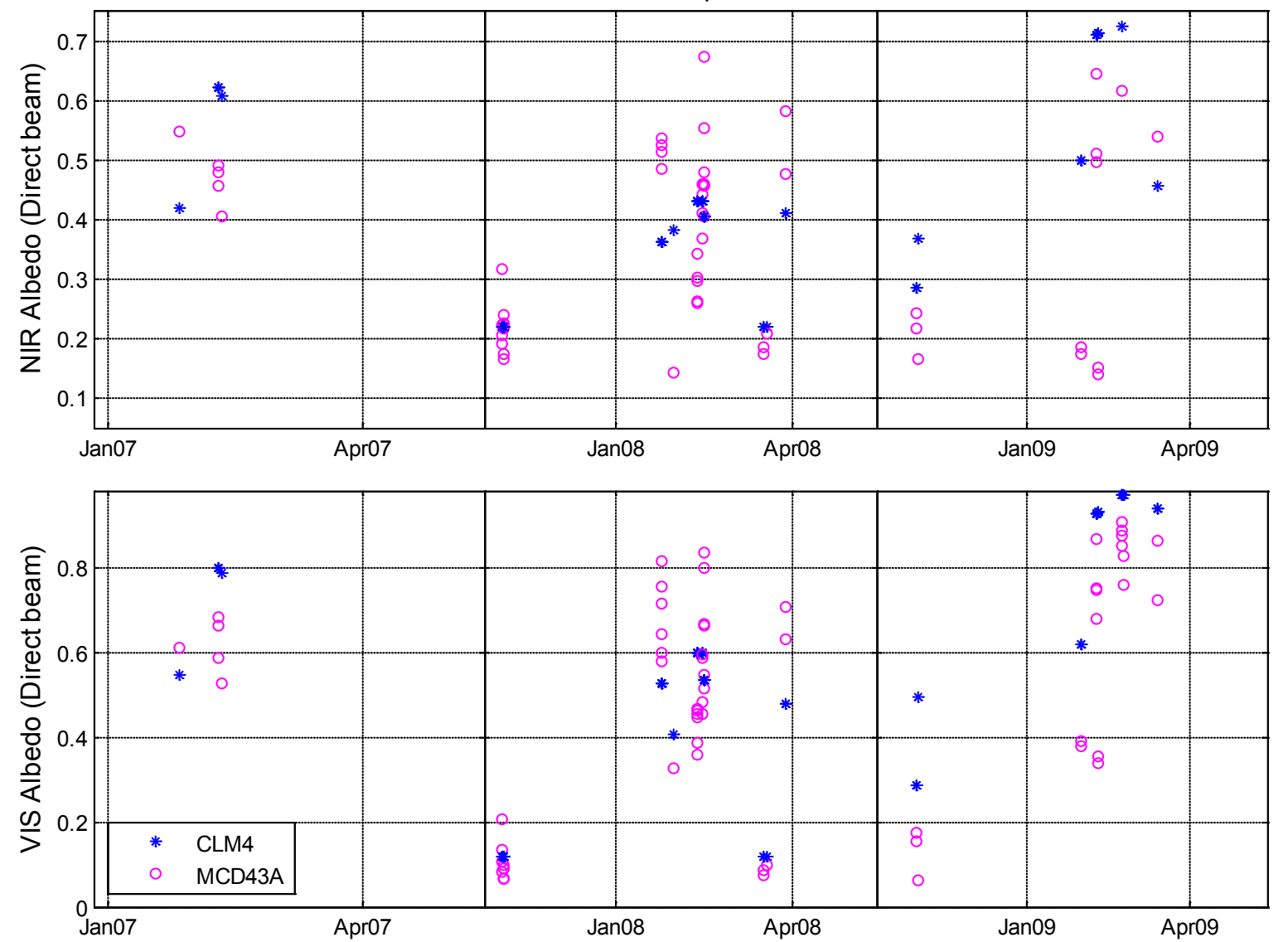

Figure S18. Predicted and observed daily black-sky albedo at the open area sites (cropland) in Flisa. 

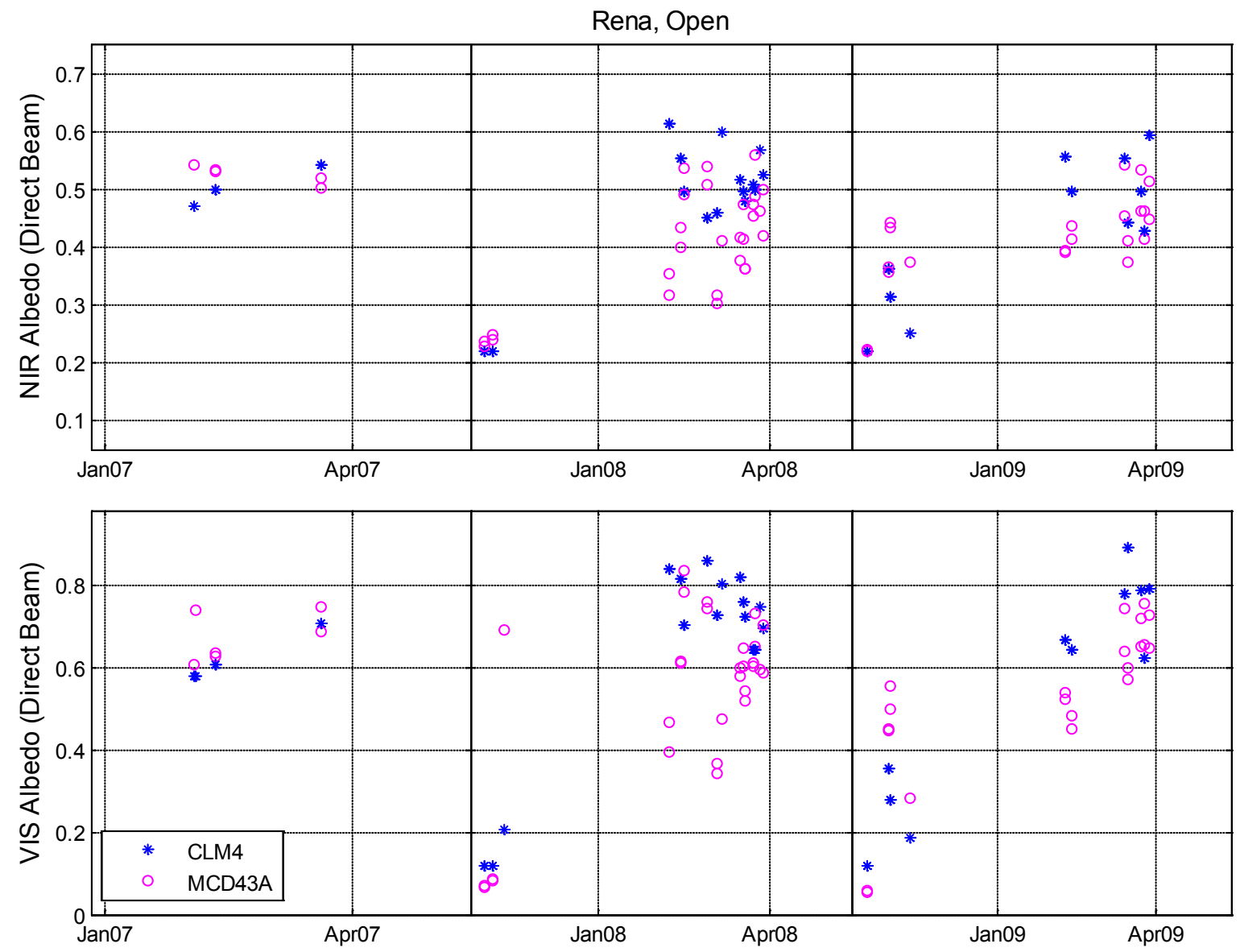

Figure S19. Predicted and observed daily black-sky albedo at the open area sites (cropland) in Rena. 

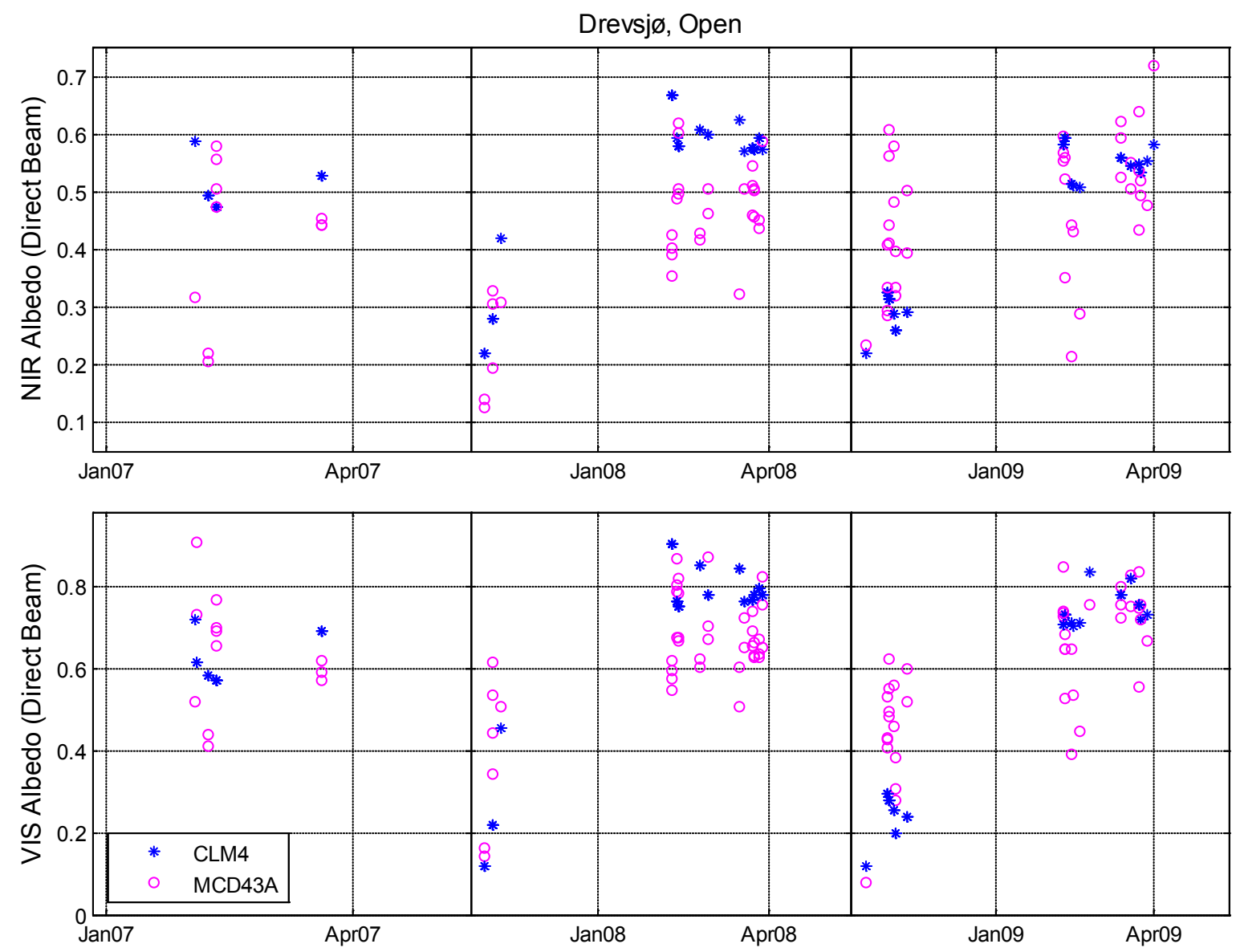

Figure S20. Predicted and observed daily black-sky albedo at the open area sites (wetland/peatland) in Drevsjø. 
Flisa, Forest
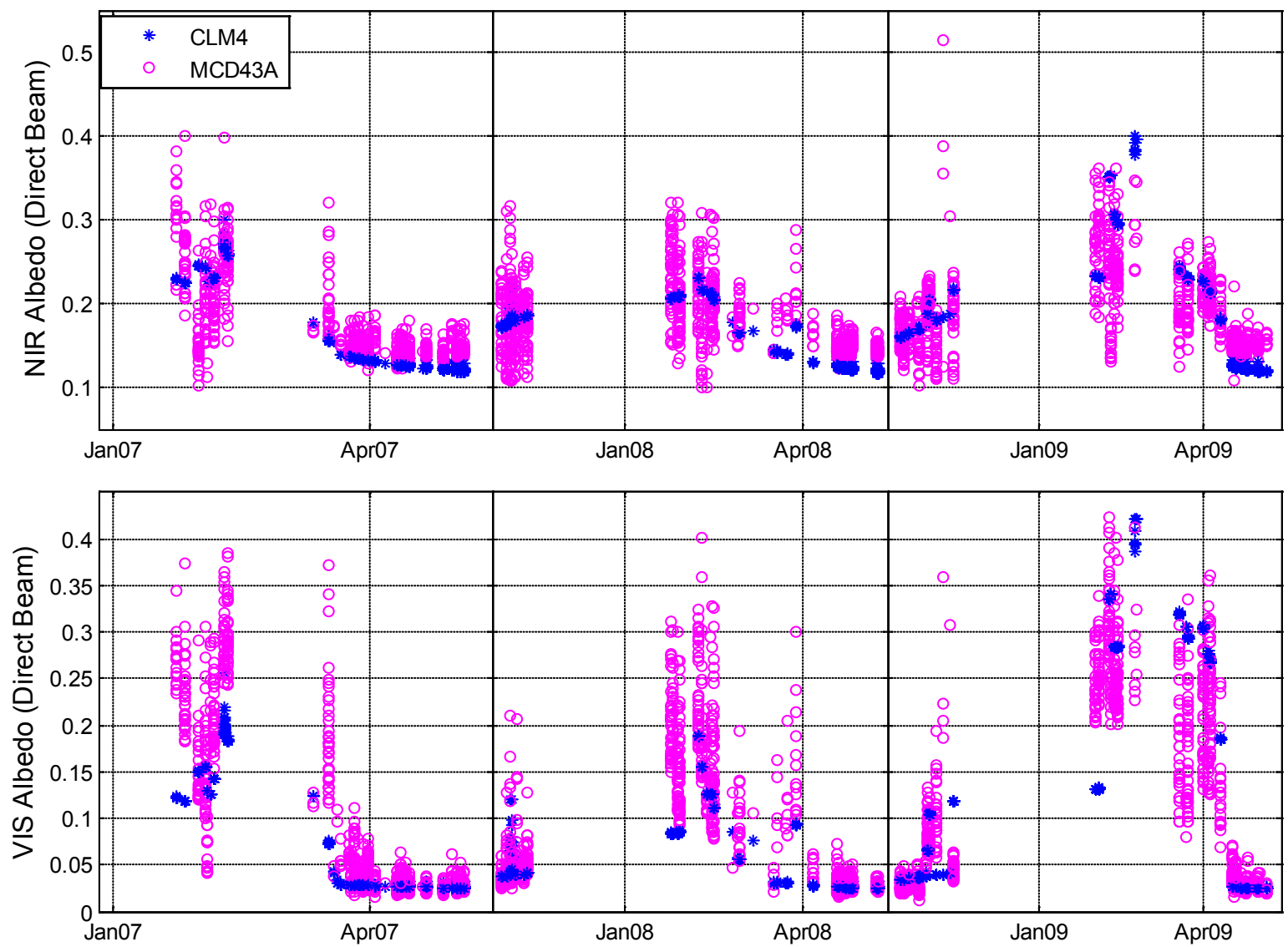

Figure S21. Predicted and observed daily black-sky albedo at the forested sites (evergreen needleleaf) in Flisa. 
Rena, Forest
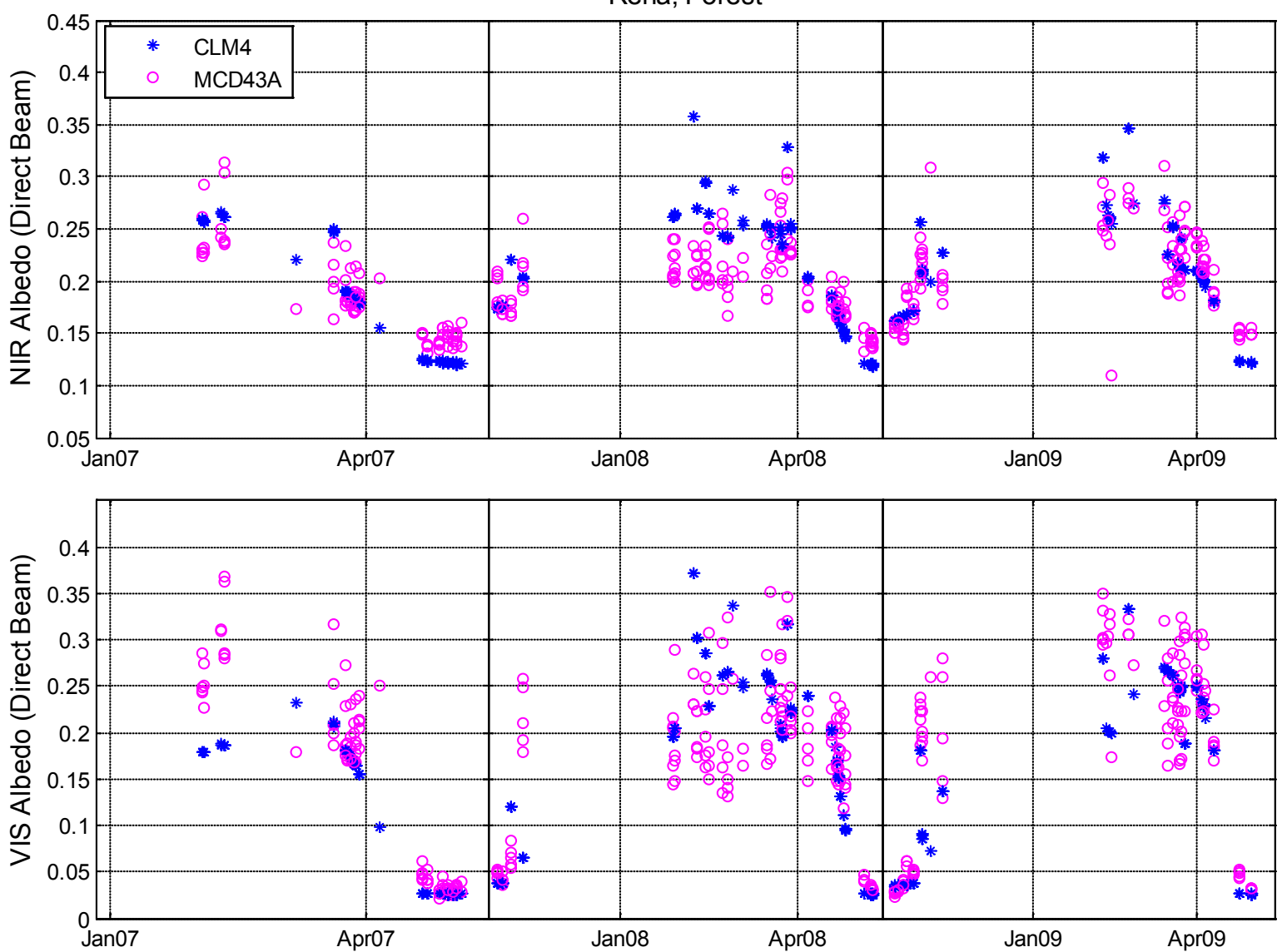

Figure S22. Predicted and observed daily black-sky albedo at the forested sites (evergreen needleleaf) in Rena. 

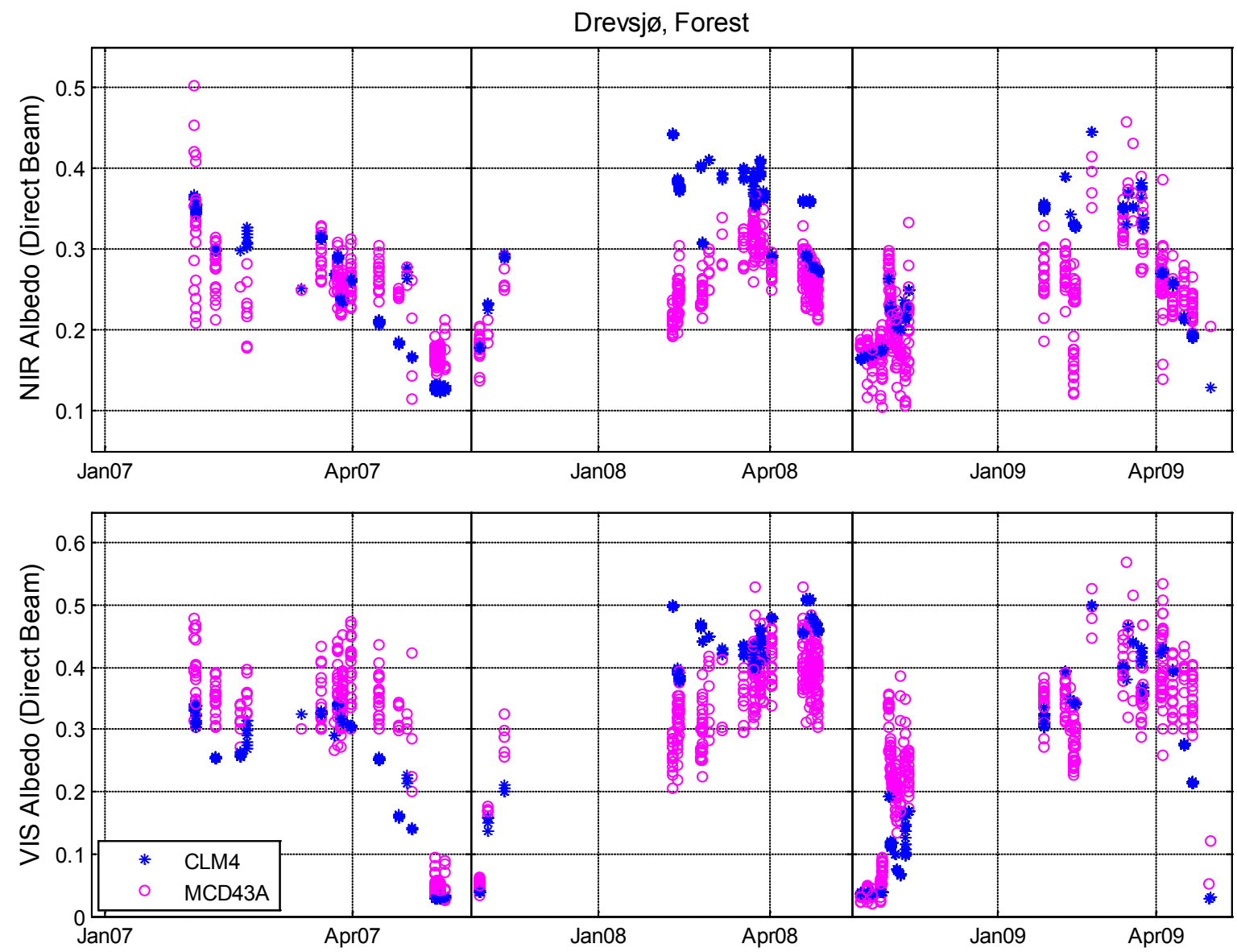

Figure S23. Predicted and observed daily black-sky albedo at the forested sites (evergreen needleleaf) in Drevsjø.

\section{S.5.4. JSBACH}


Flisa, Open
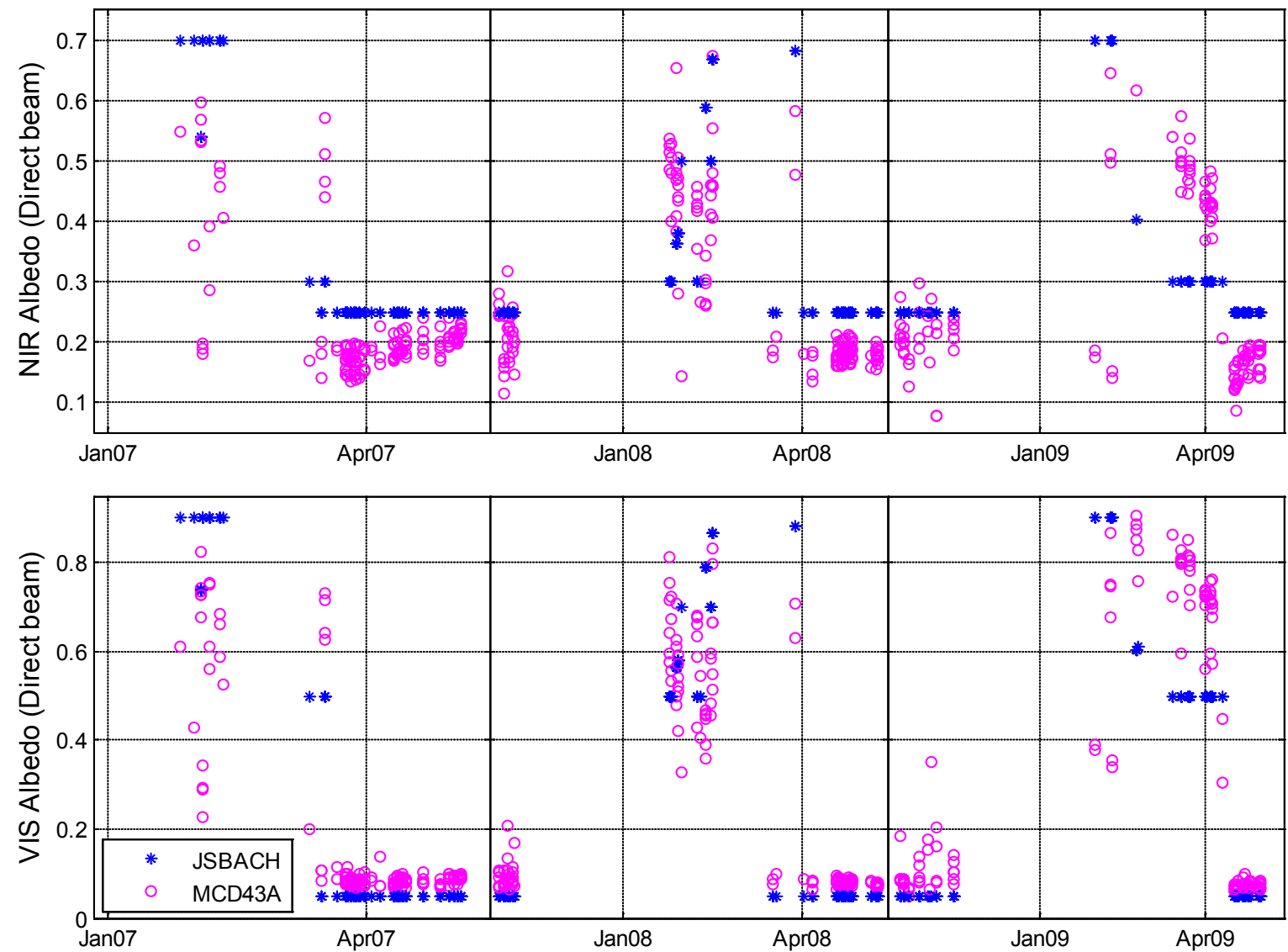

Figure S24. Predicted and observed daily black-sky albedo at the open area sites (cropland) in Flisa. 
Rena, Open
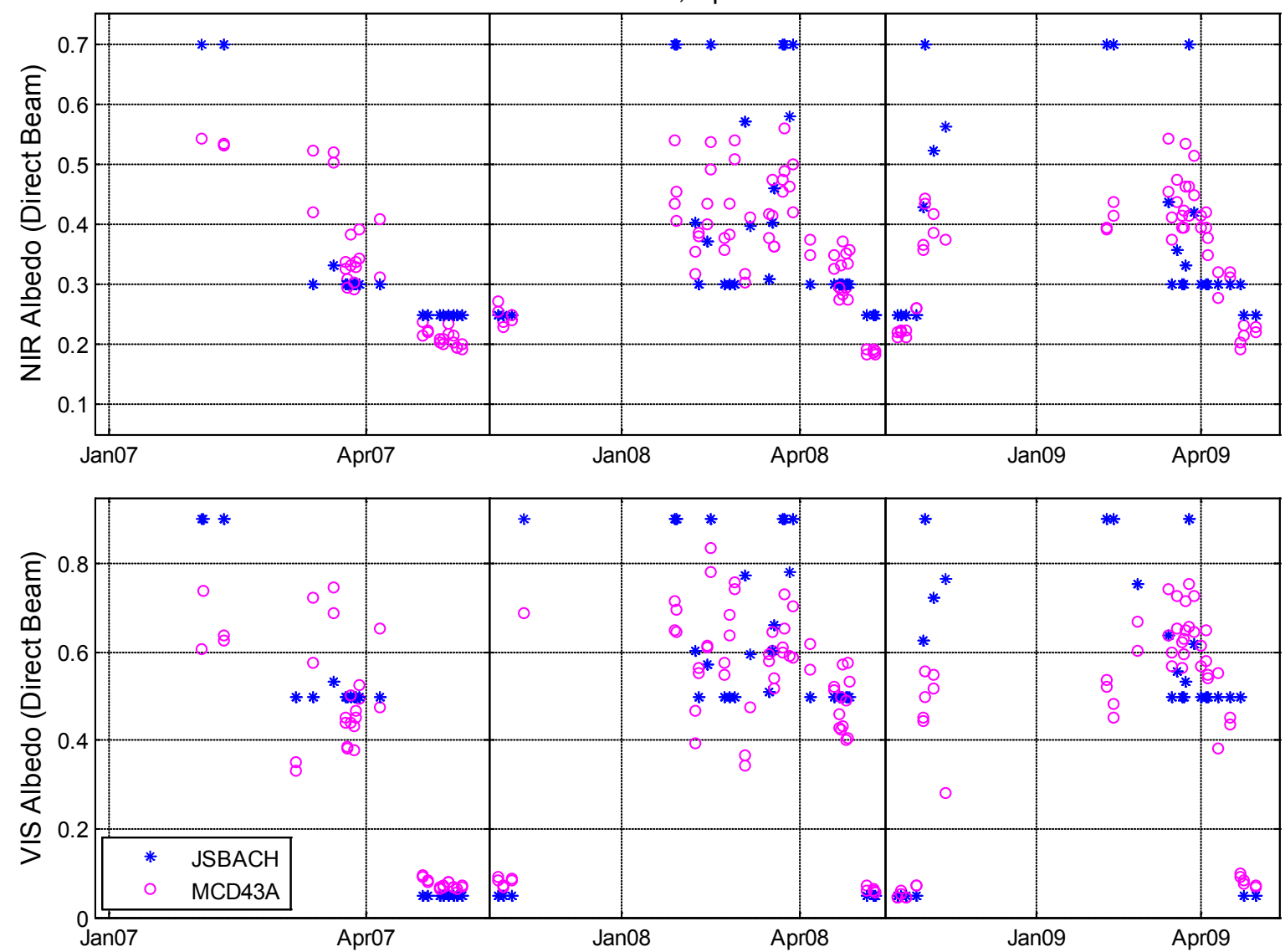

Figure S25. Predicted and observed daily black-sky albedo at the open area sites (cropland) in Rena. 

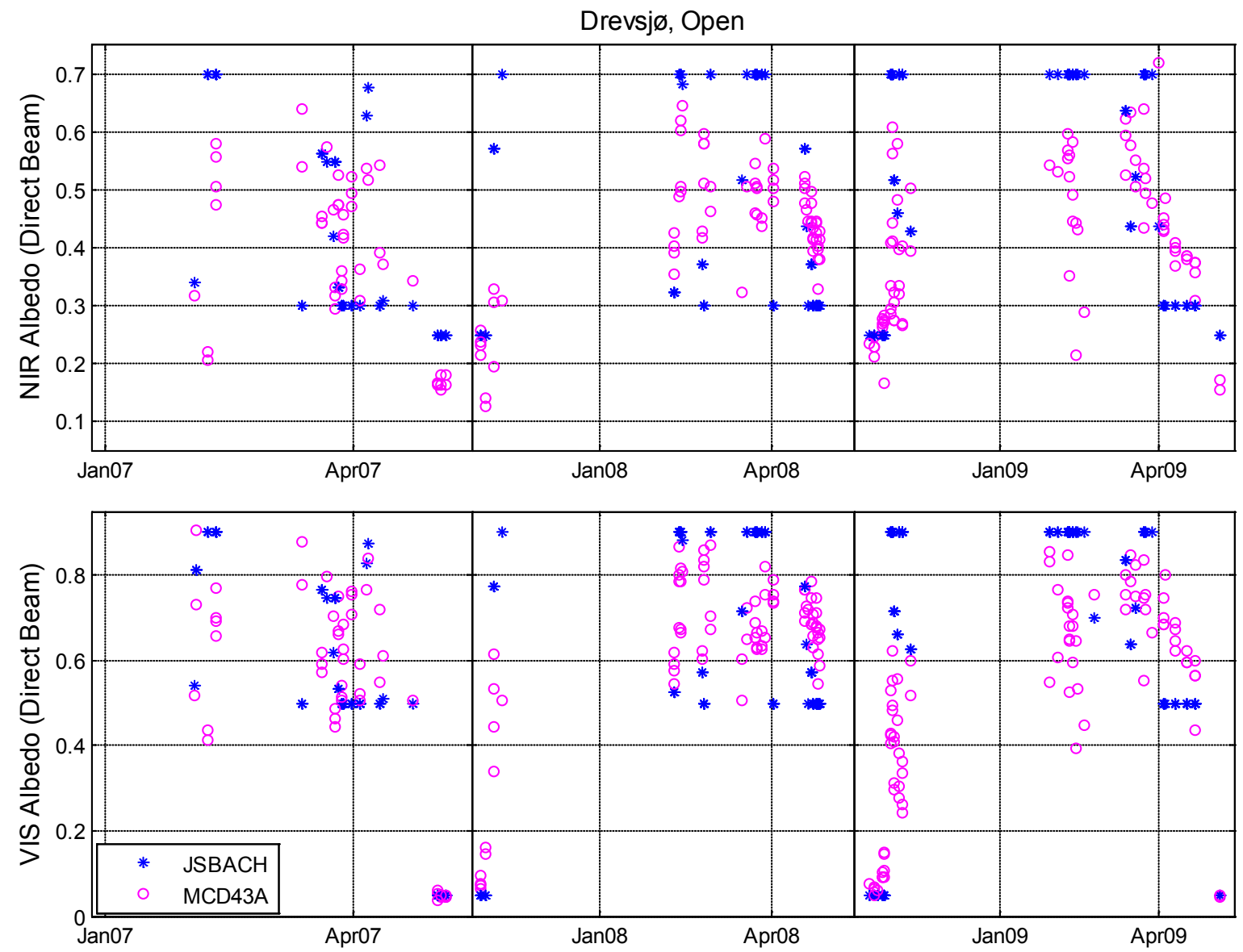

Figure S26. Predicted and observed daily black-sky albedo at the open area sites (wetland/peatland) in Drevsjø. 
Flisa, Forest
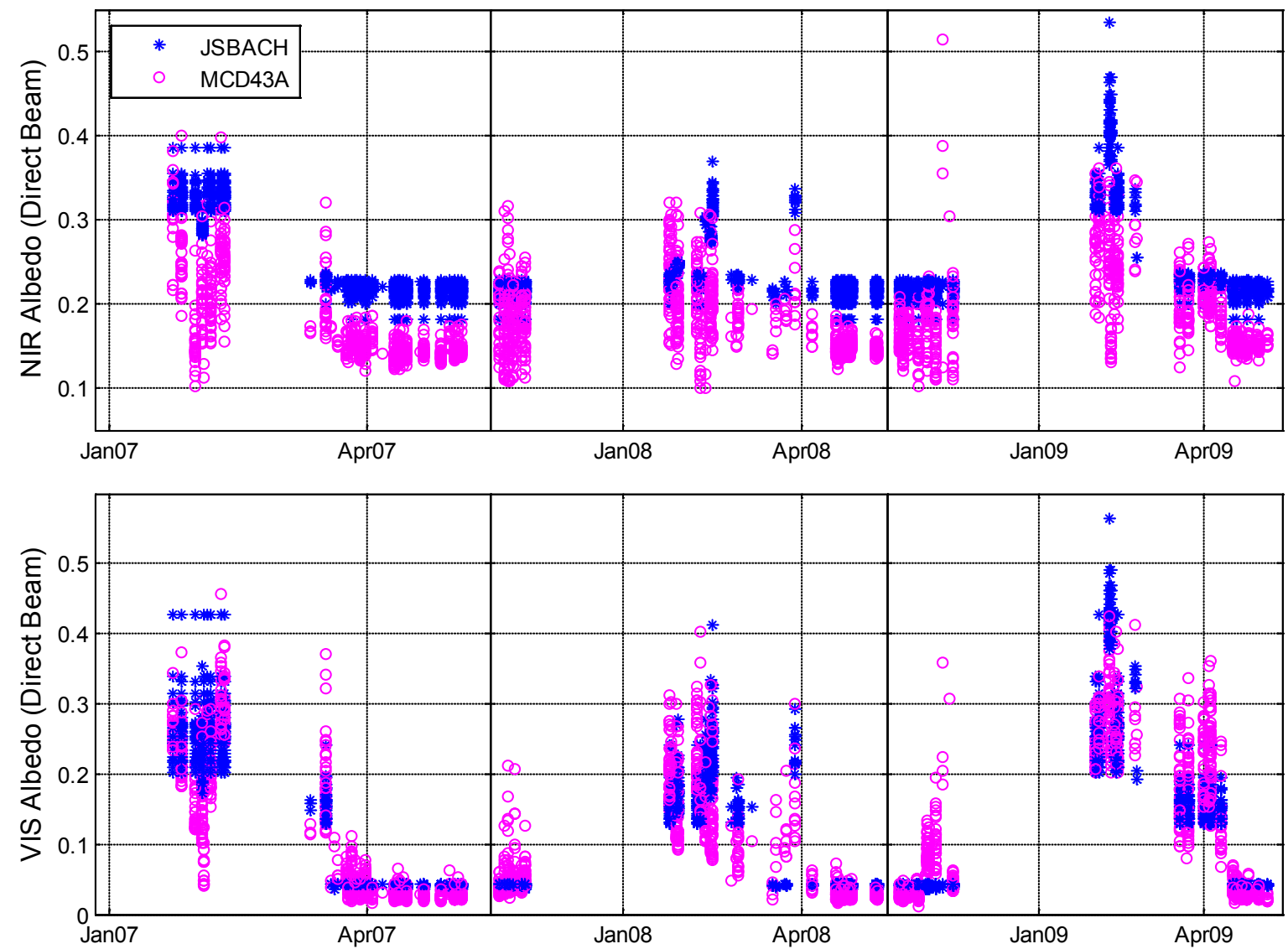

Figure S27. Predicted and observed daily black-sky albedo at the forested sites (evergreen needleleaf) in Flisa. 

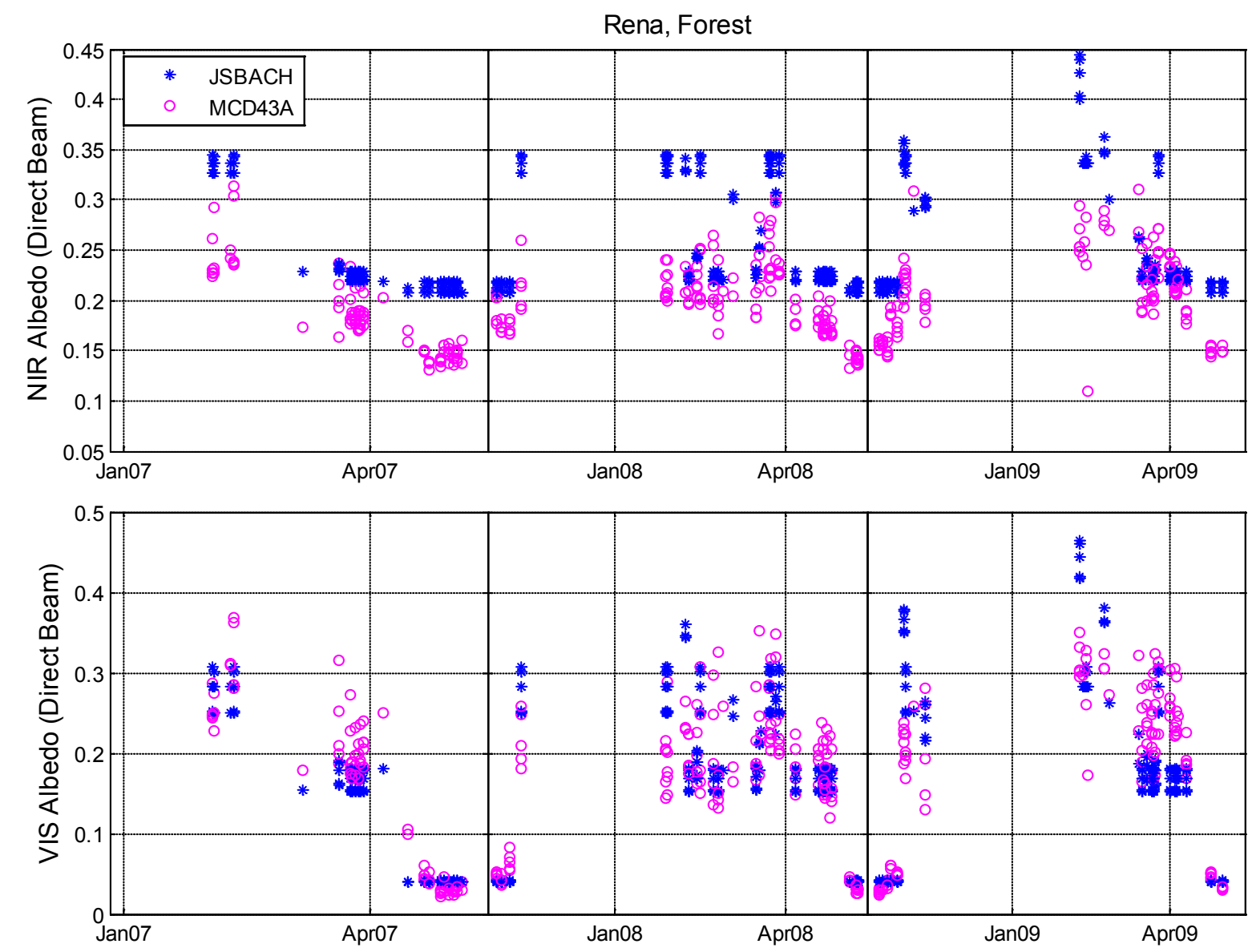

Figure S28. Predicted and observed daily black-sky albedo at the forested sites (evergreen needleleaf) in Rena. 

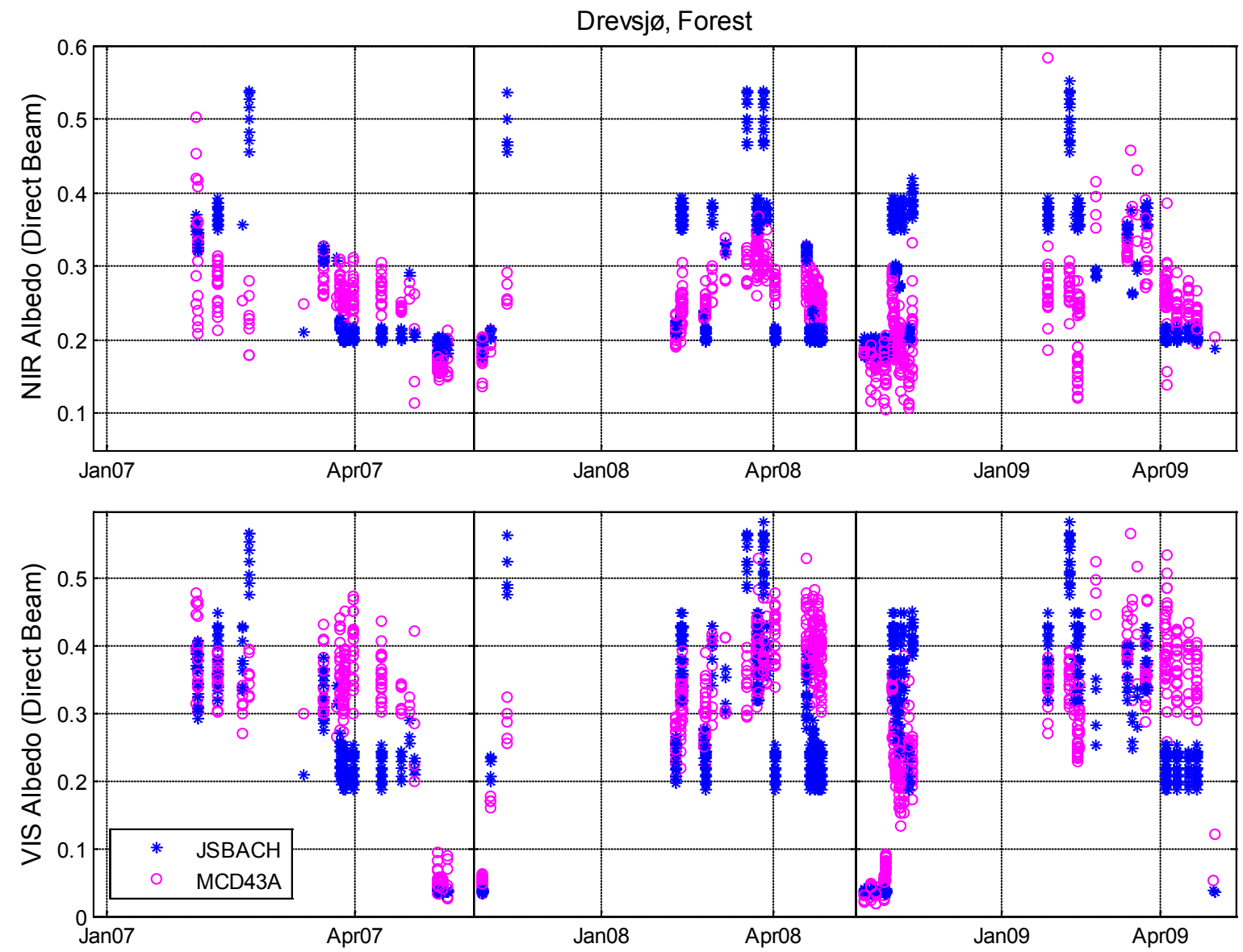

Figure S29. Predicted and observed daily black-sky albedo at the forested sites (evergreen needleleaf) in Drevsjø.

\section{S.5.5. CLASS}


Flisa, Open
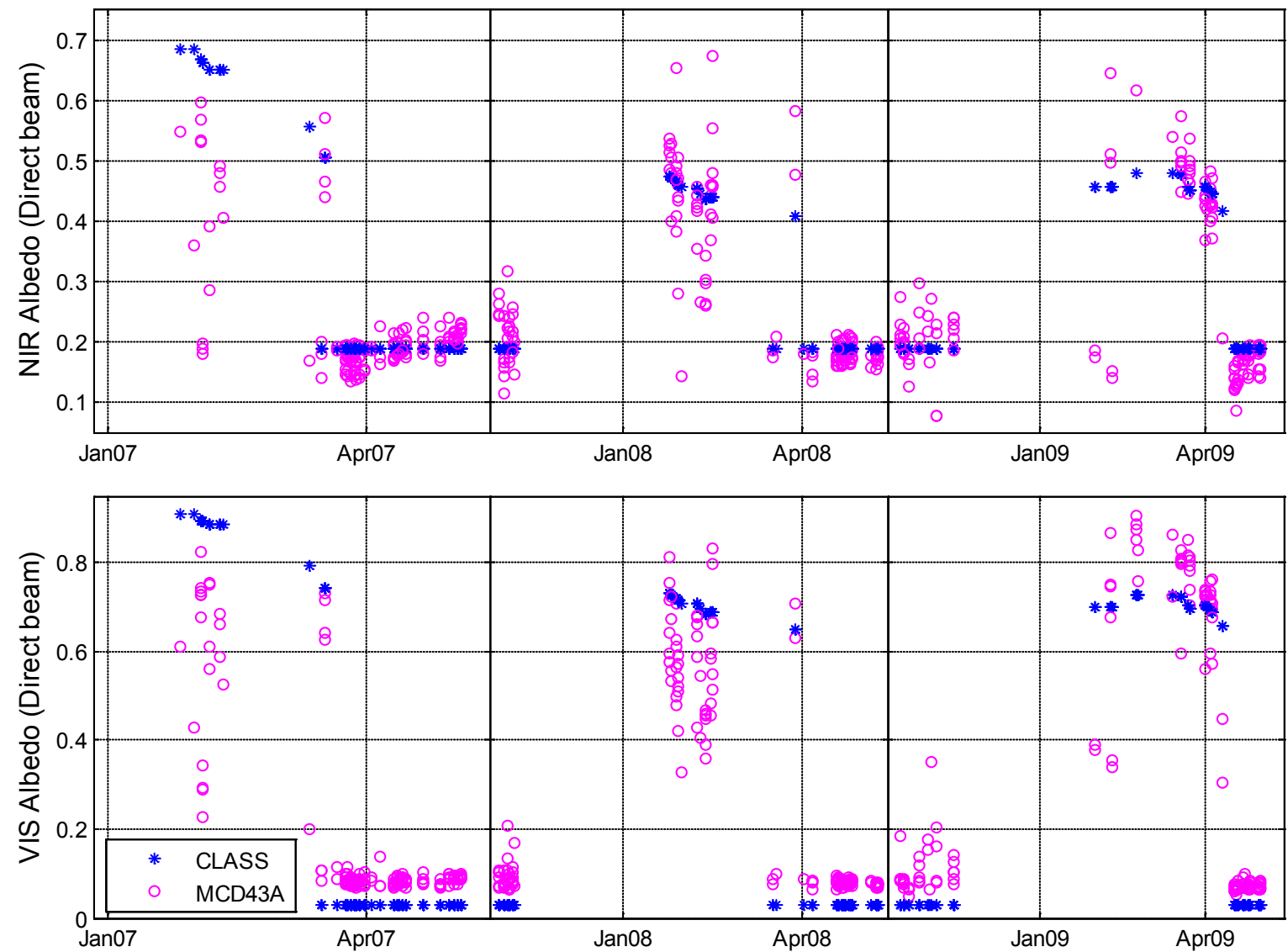

Figure S30. Predicted and observed daily black-sky albedo at the open area sites (cropland) in Flisa. 

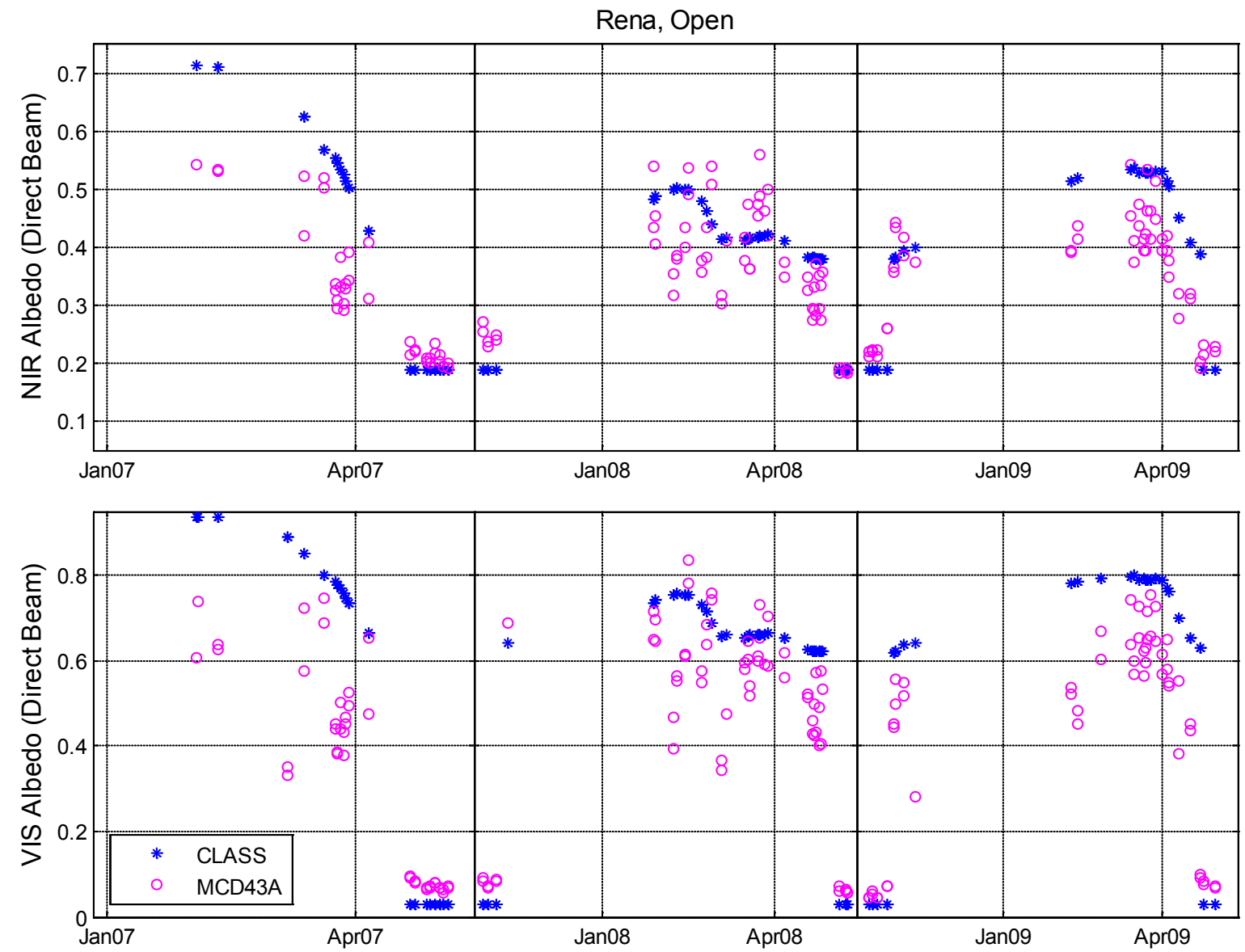

Figure S31. Predicted and observed daily black-sky albedo at the open area sites (cropland) in Rena. 

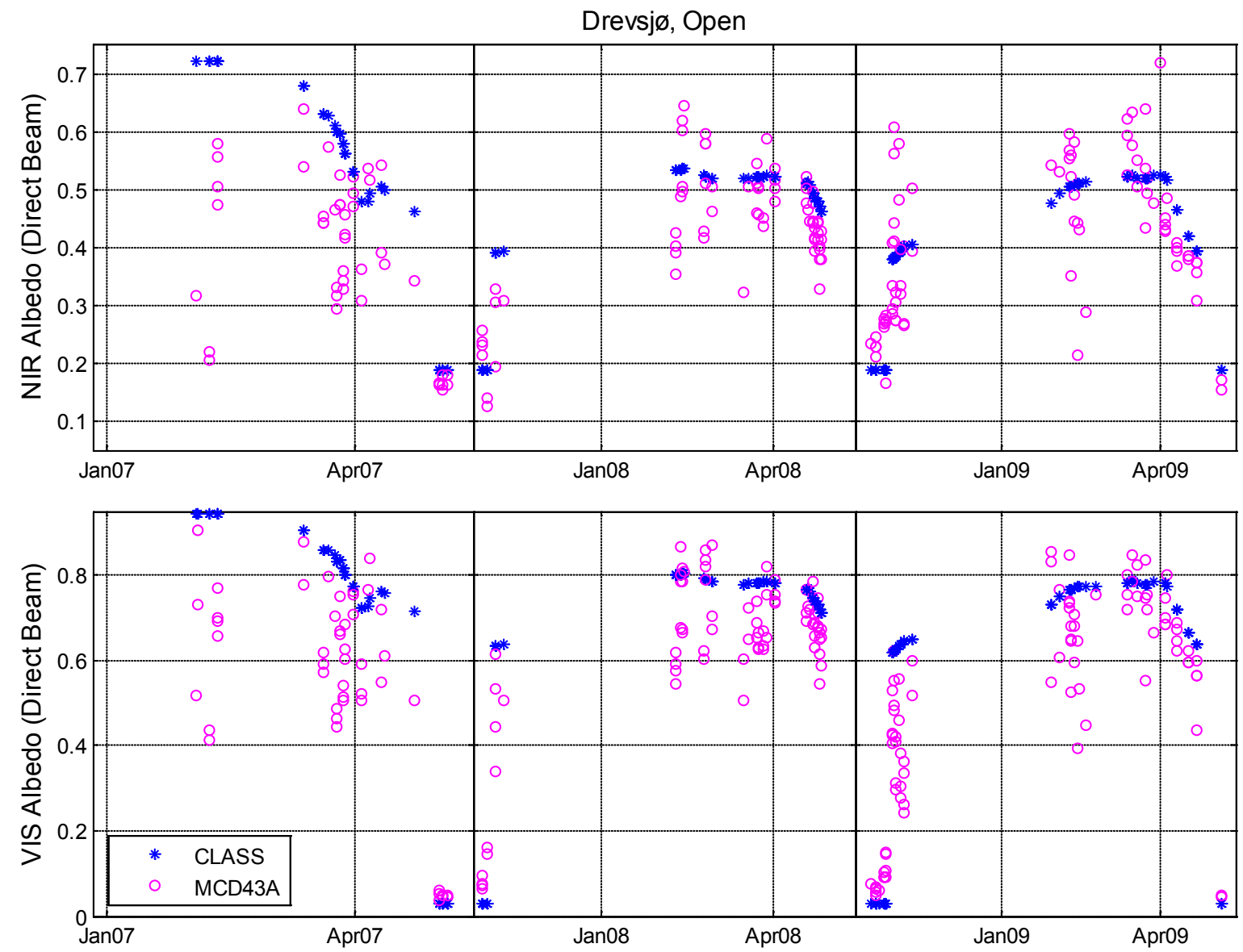

Figure S32. Predicted and observed daily black-sky albedo at the open area sites (wetland/peatland) in Drevsjø. 
Flisa, Forest
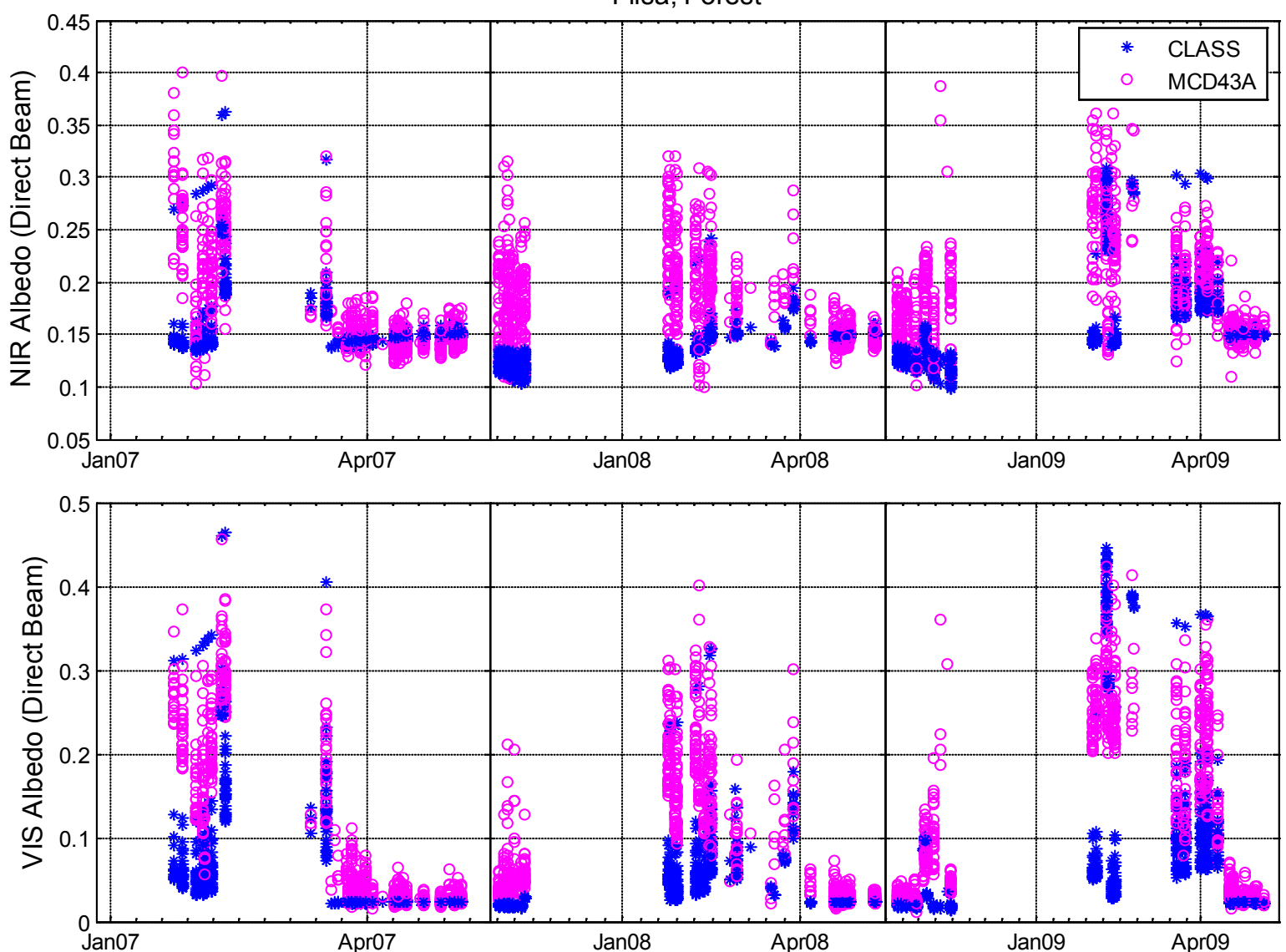

Figure S33. Predicted and observed daily black-sky albedo at the forested sites (evergreen needleleaf) in Flisa. 

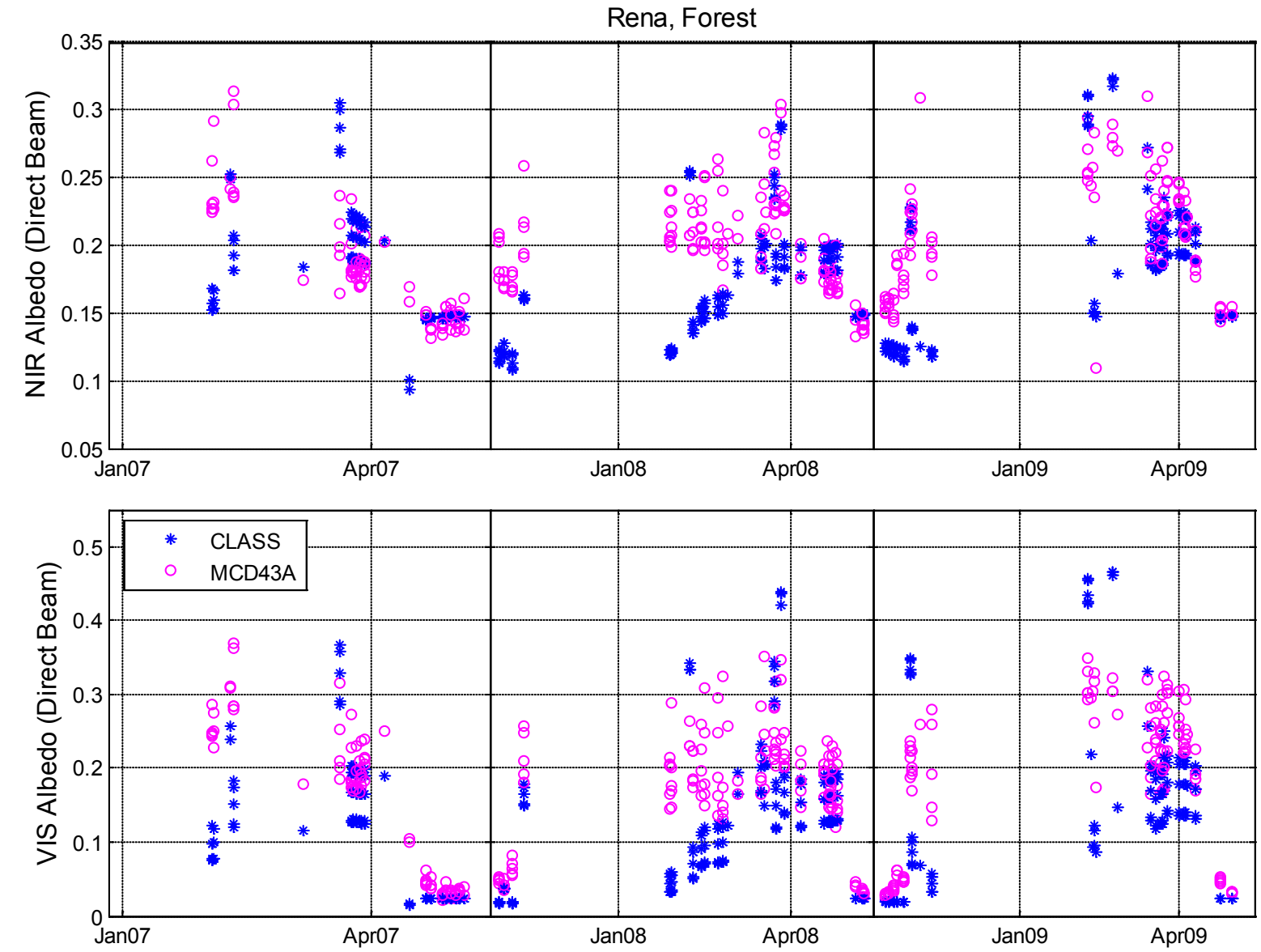

Figure S34. Predicted and observed daily black-sky albedo at the forested sites (evergreen needleleaf) in Rena. 

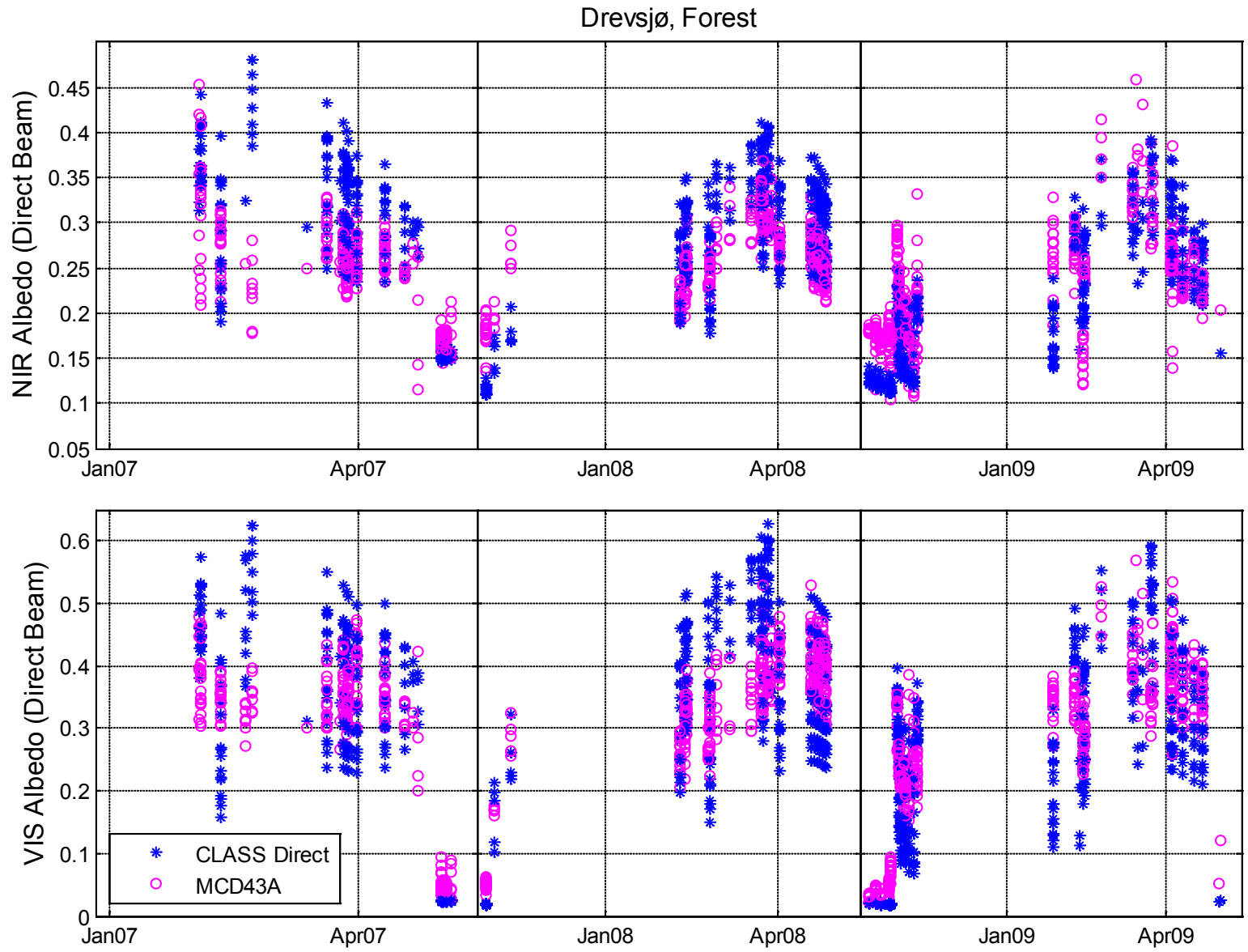

Figure S35. Predicted and observed daily black-sky albedo at the forested sites (evergreen needleleaf) in Drevsjø.

\section{S.5.6. GISS II}


Flisa, Open
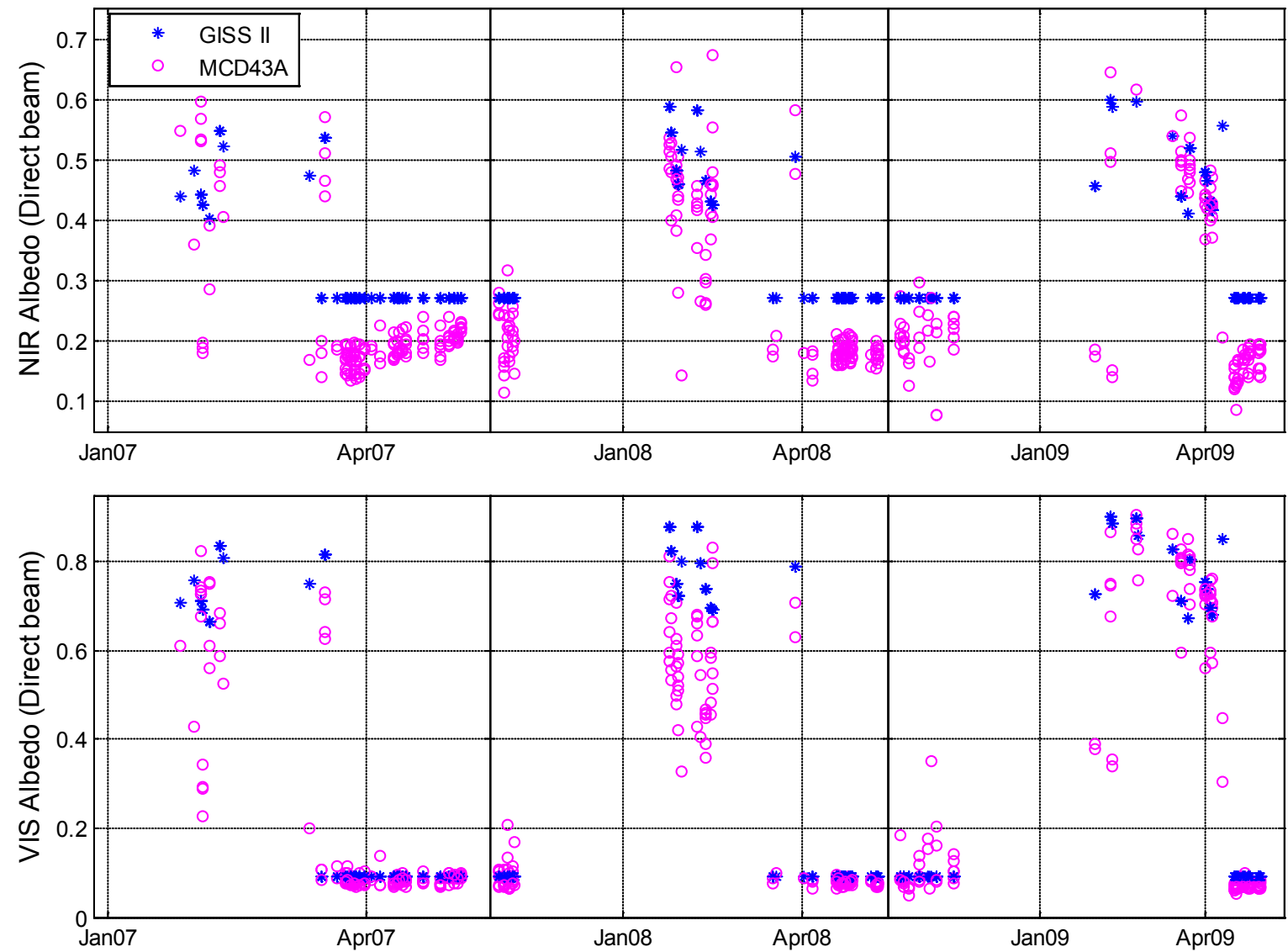

Figure S36. Predicted and observed daily black-sky albedo at the open area sites (cropland) in Flisa. 
Rena, Open
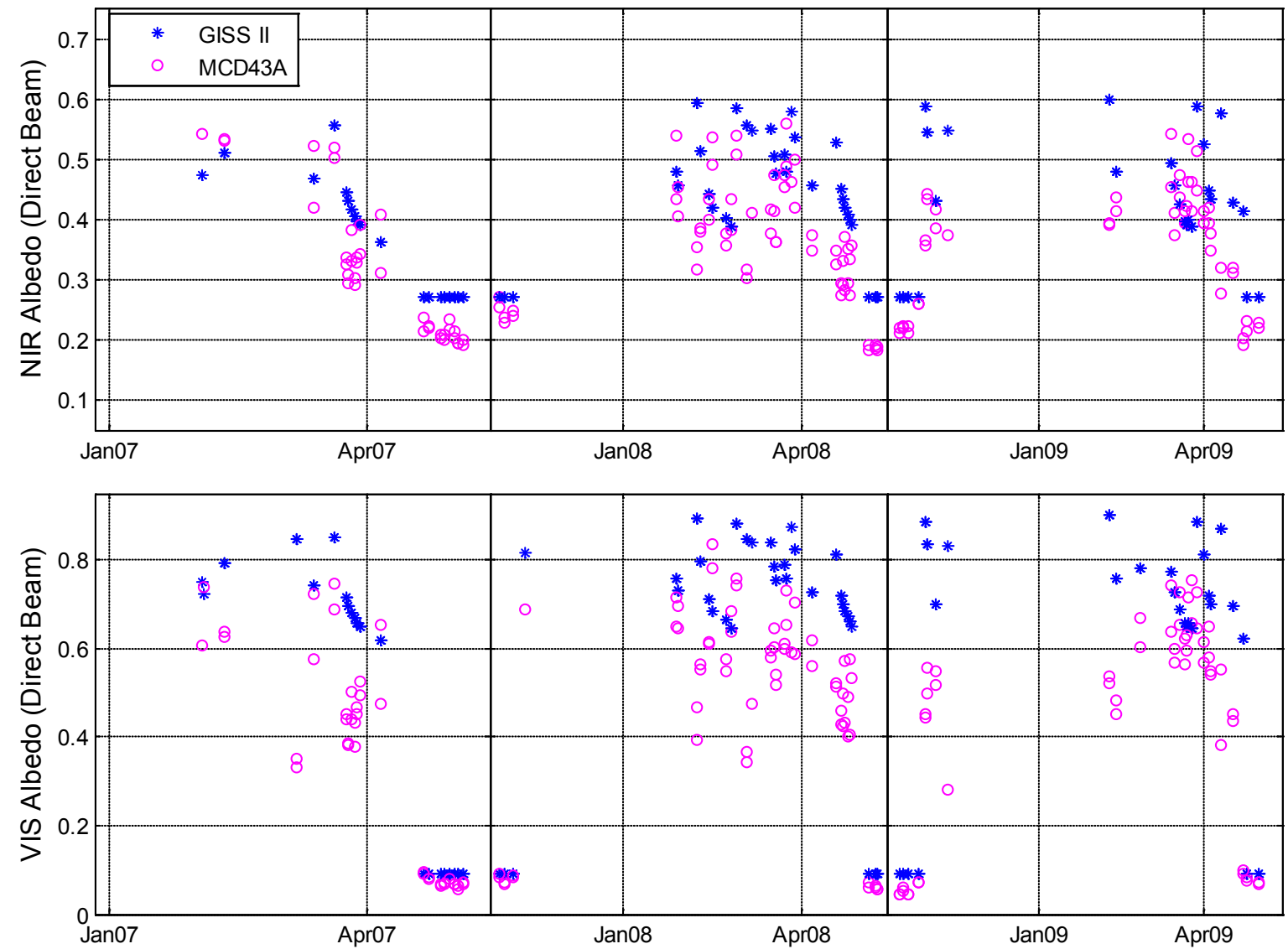

Figure S37. Predicted and observed daily black-sky albedo at the open area sites (cropland) in Rena. 

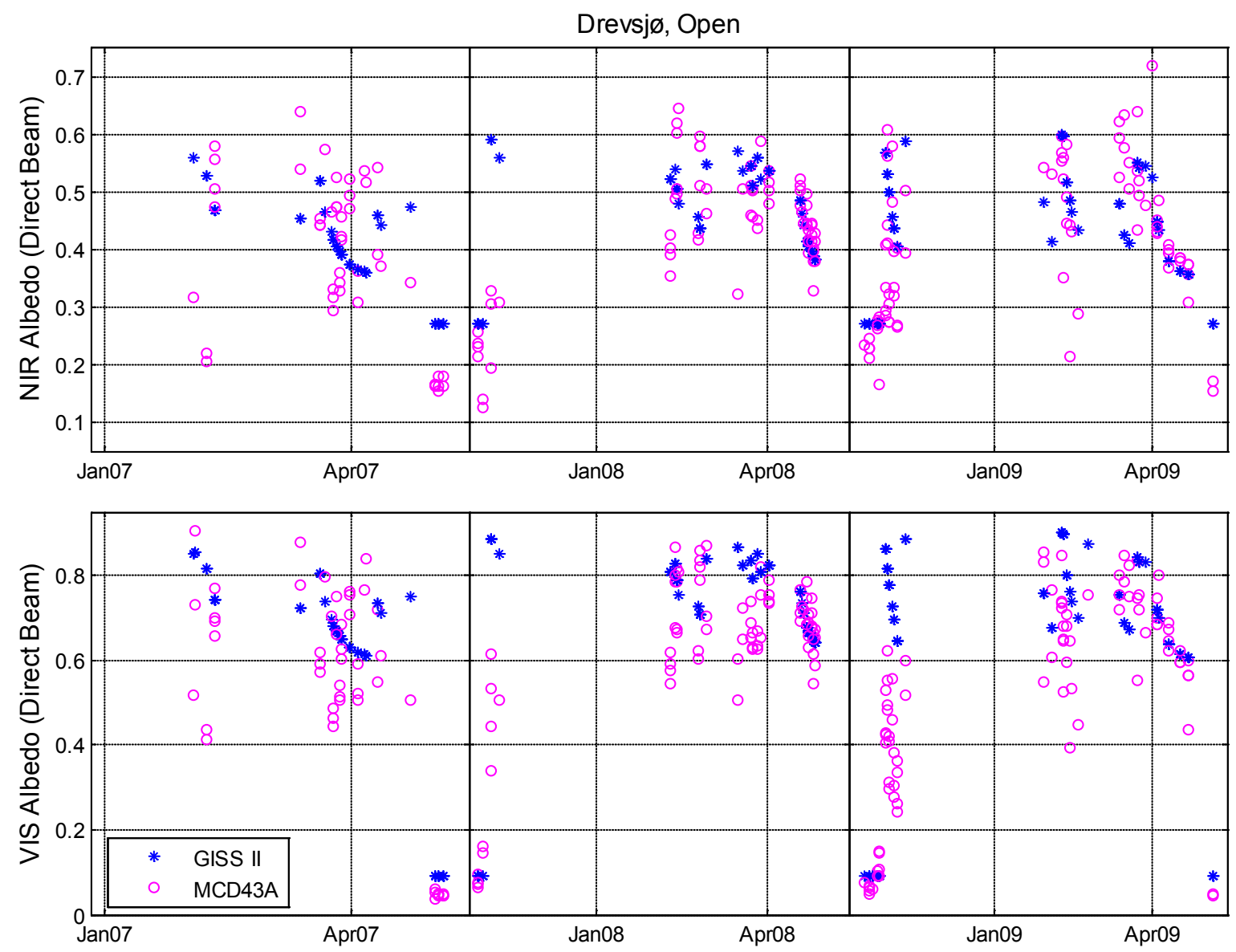

Figure S38. Predicted and observed daily black-sky albedo at the open area sites (wetland/peatland) in Flisa. 
Flisa, Forest
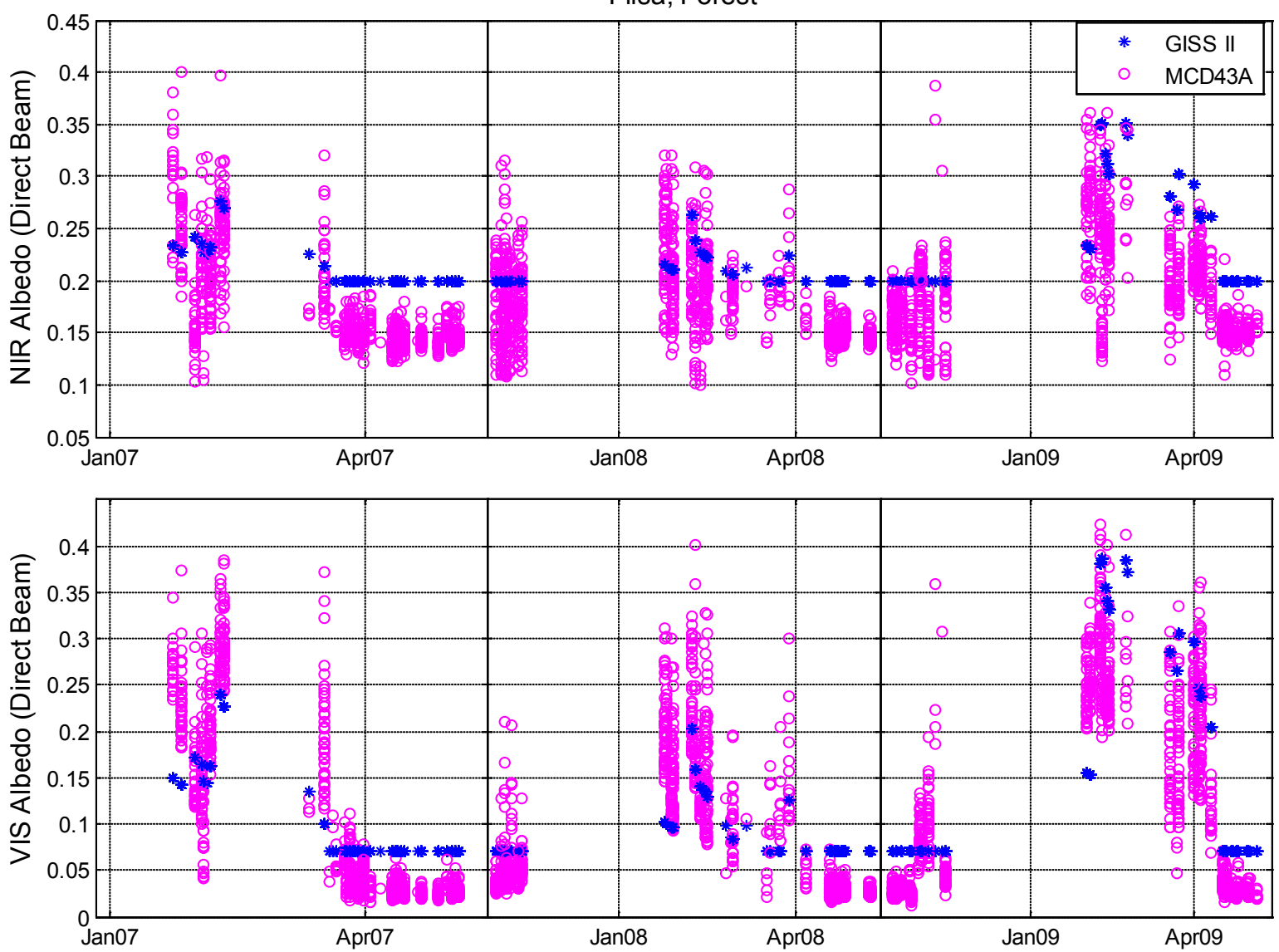

Figure S39. Predicted and observed daily black-sky albedo at the forested sites (evergreen needleleaf) in Flisa. 
Rena, Forest
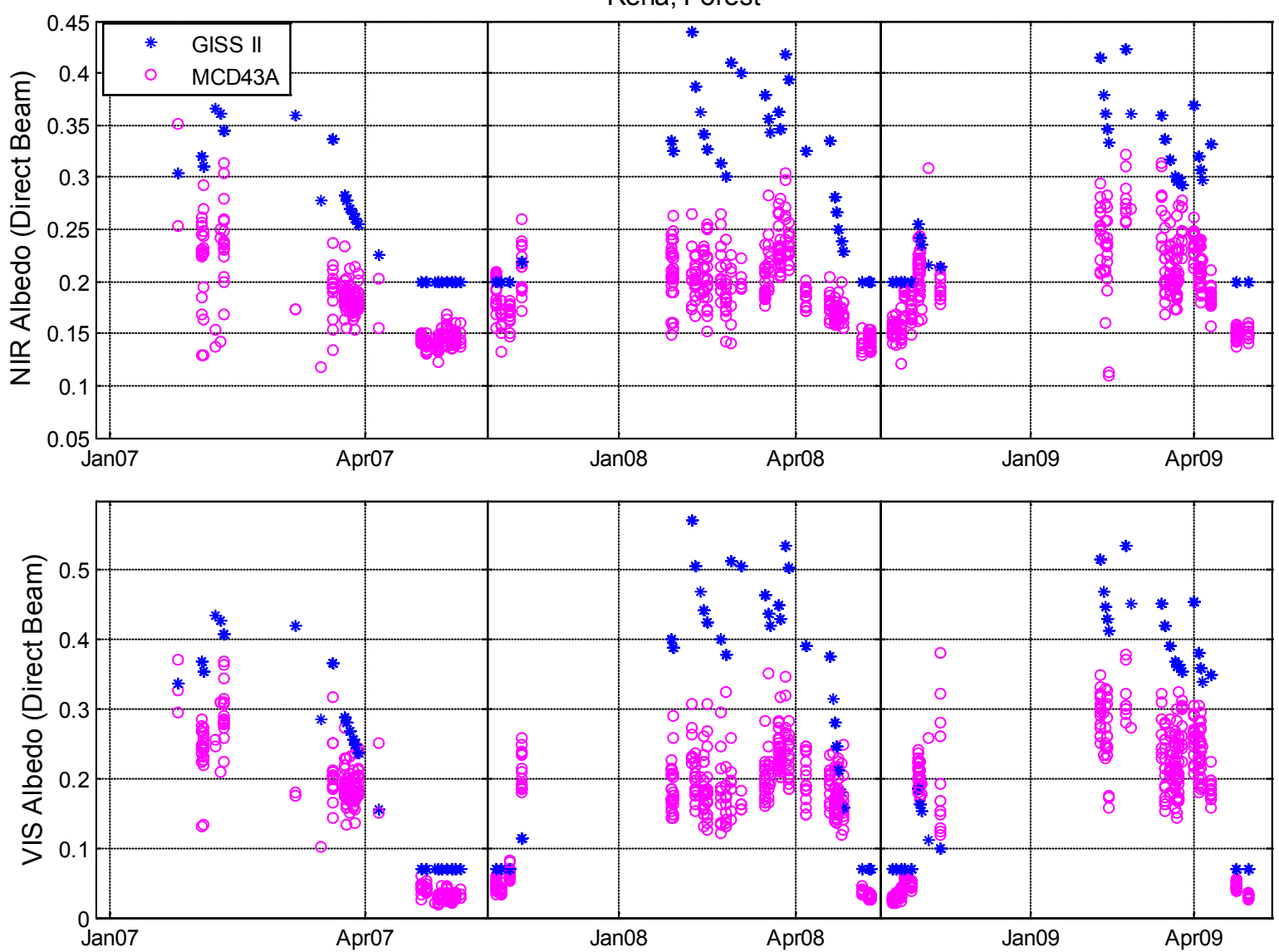

Figure S40. Predicted and observed daily black-sky albedo at the forested sites (evergreen needleleaf) in Rena. 

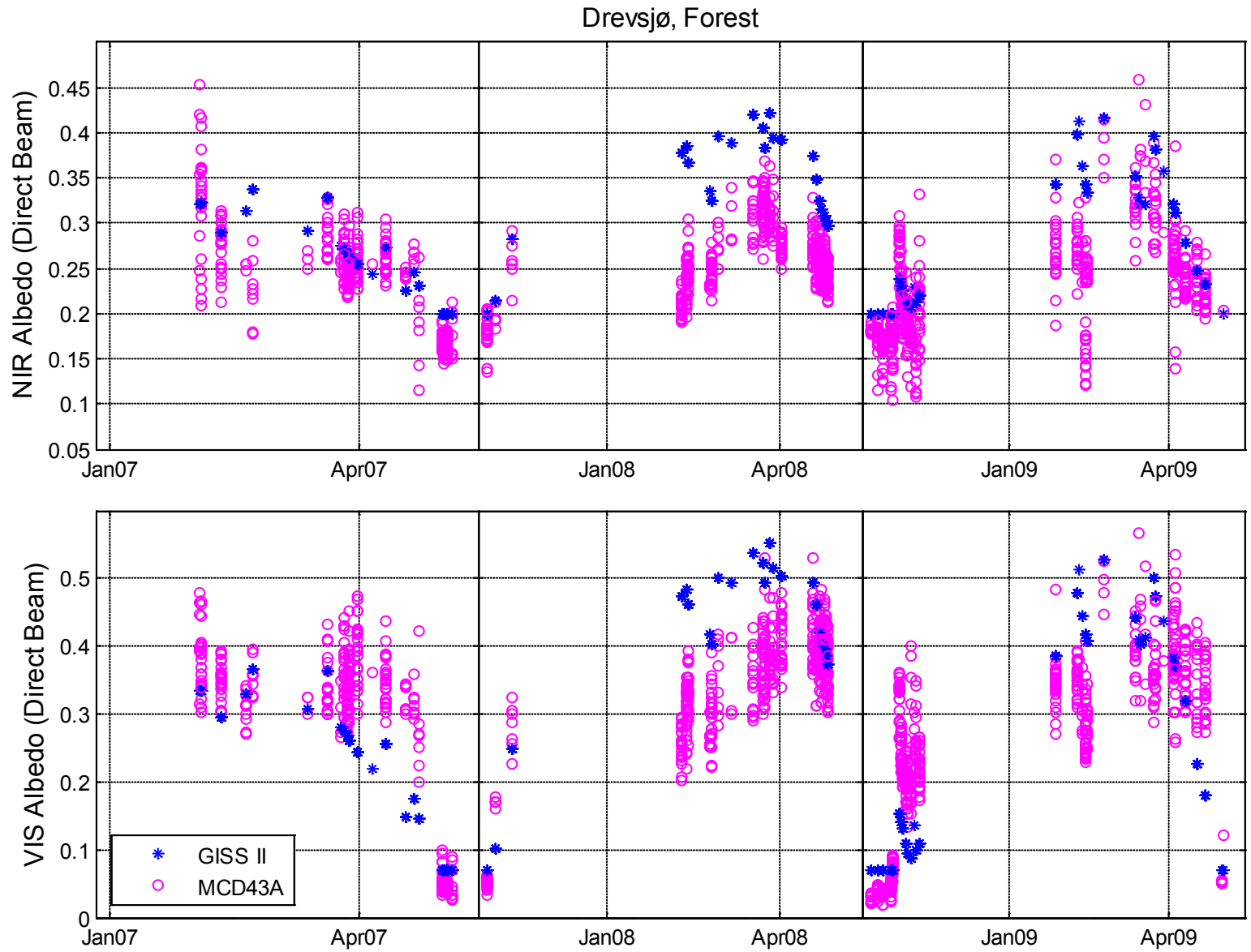

Figure S41. Predicted and observed daily black-sky albedo at the forested sites (evergreen needleleaf) in Drevsjø.

\section{S.5.7. Regression model}


Flisa, Open
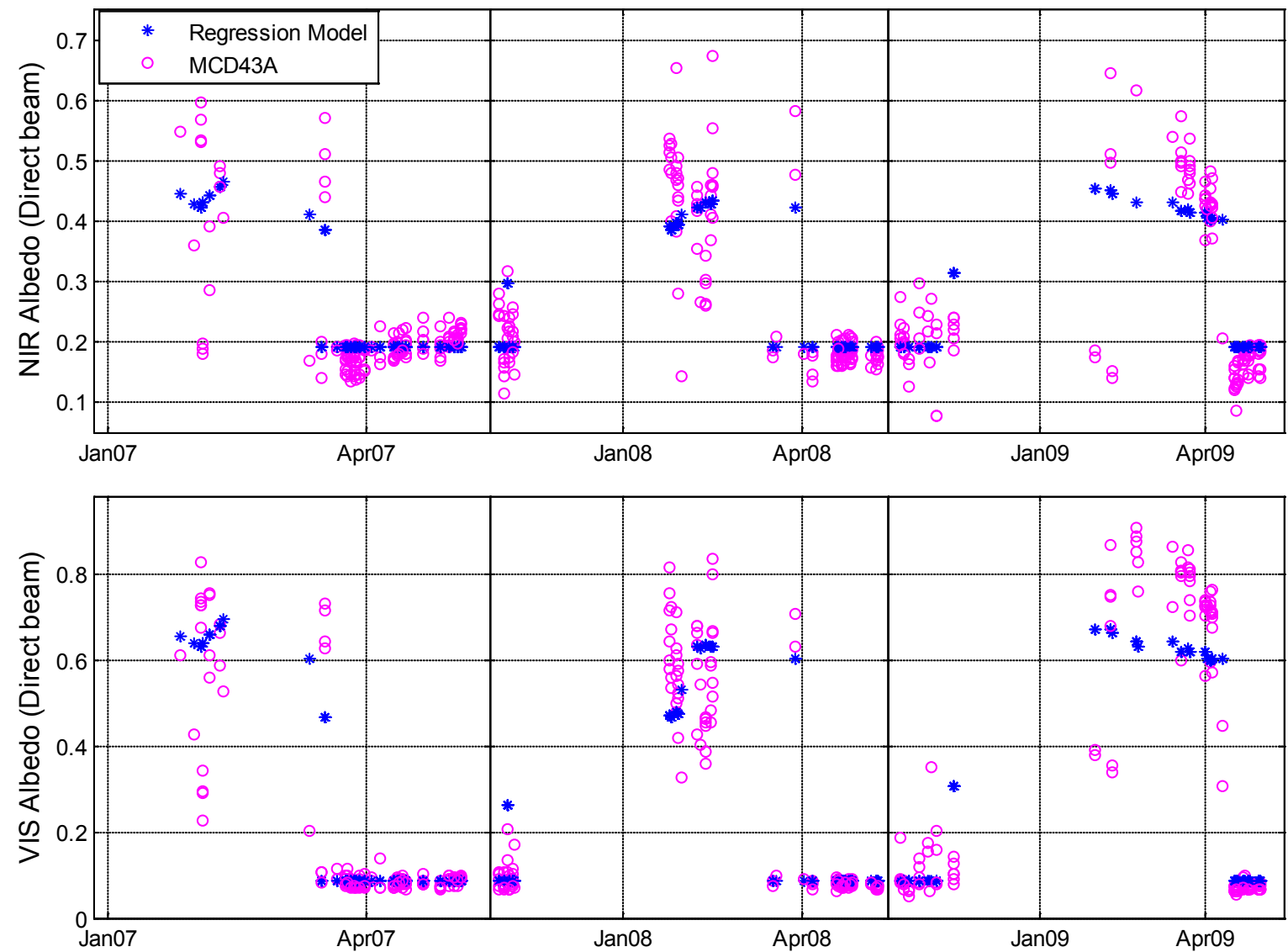

Figure S42. Predicted and observed daily black-sky albedo at the open area sites (cropland) in Flisa. 

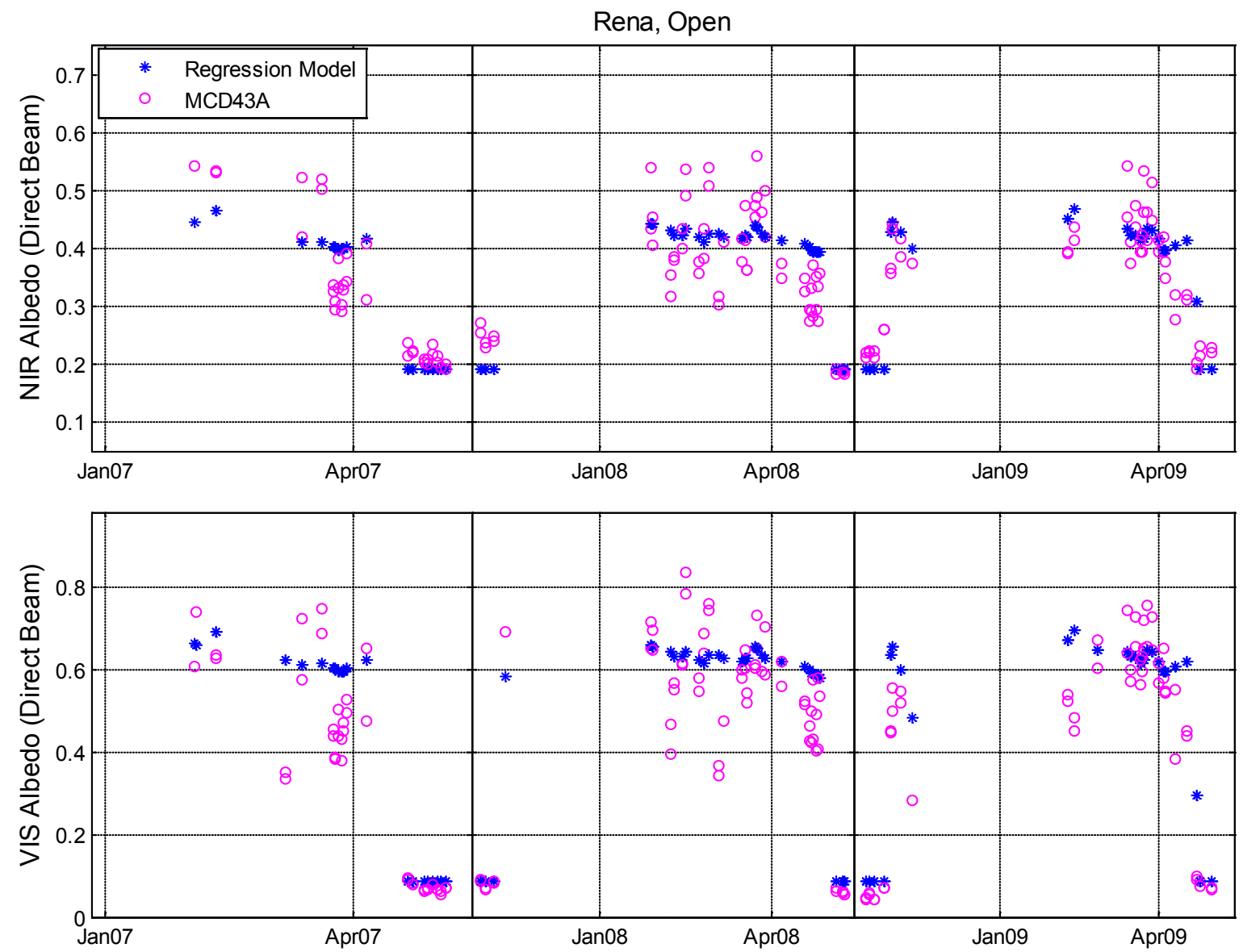

Figure S43. Predicted and observed daily black-sky albedo at the open area sites (cropland) in Rena. 

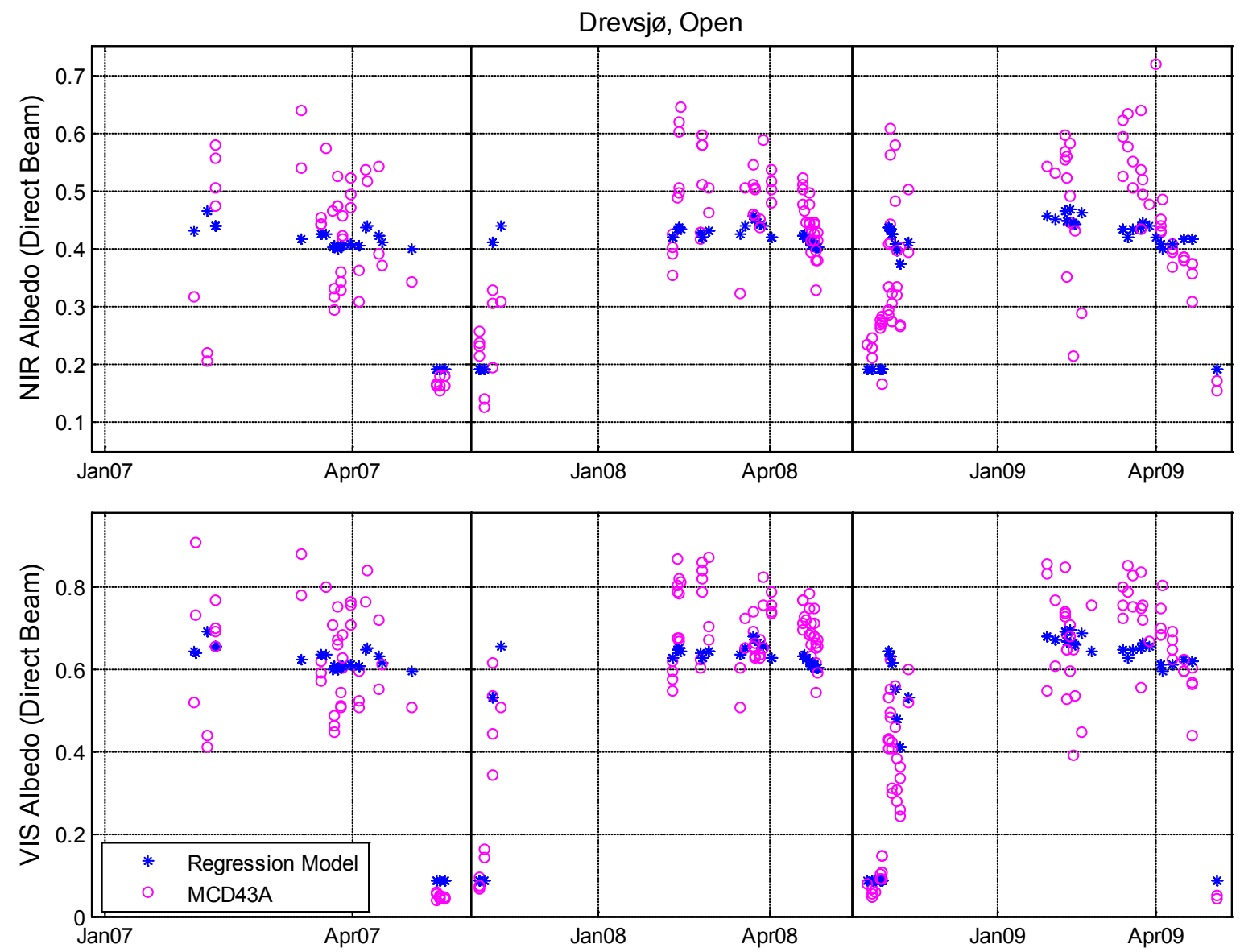

Figure S44. Predicted and observed daily black-sky albedo at the open area sites (wetland/peatland) in Drevsjø. 
Flisa, Forest
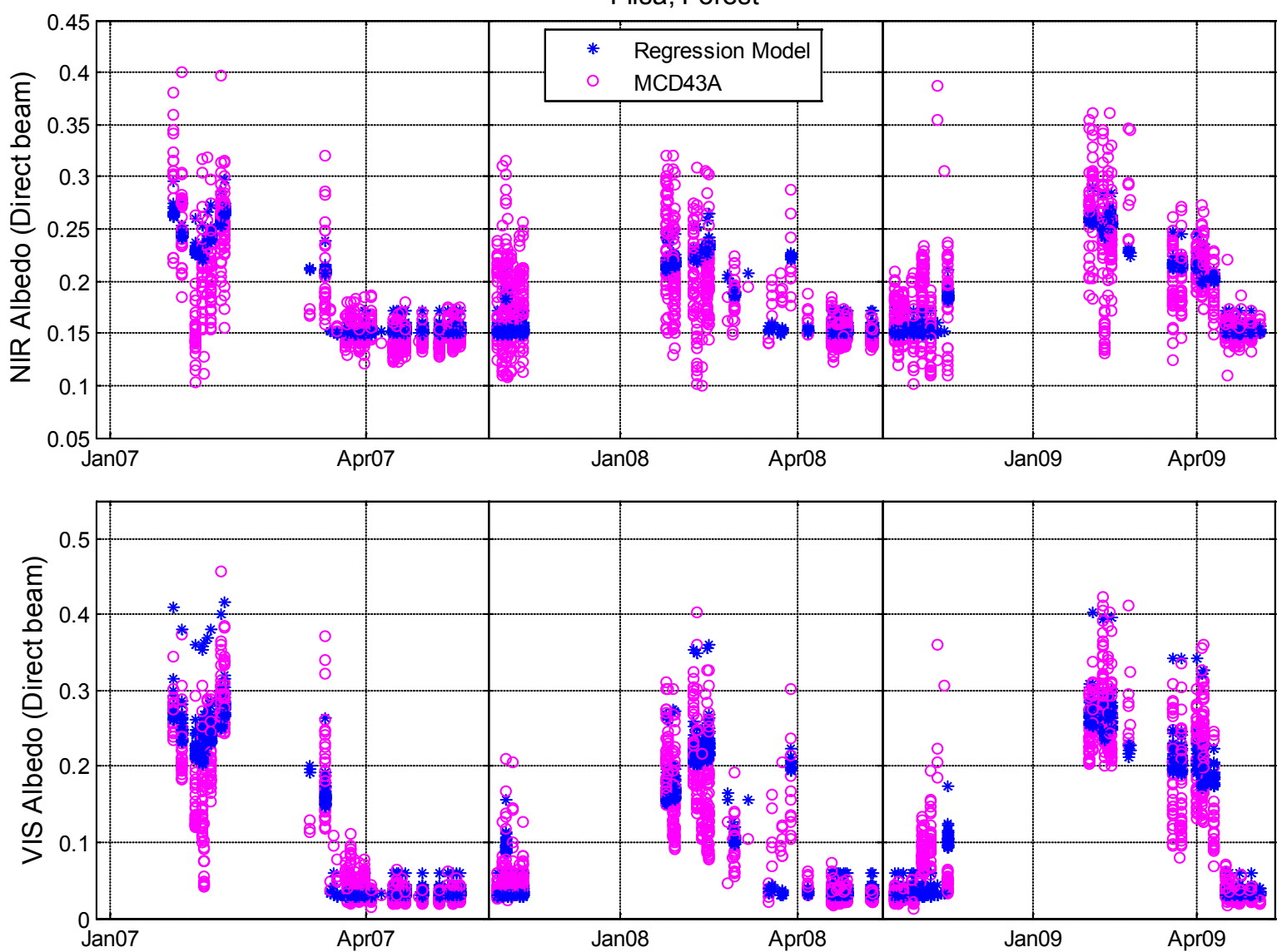

Figure S45. Predicted and observed daily black-sky albedo at the forested sites (evergreen needleleaf) in Flisa. 
Rena, Forest
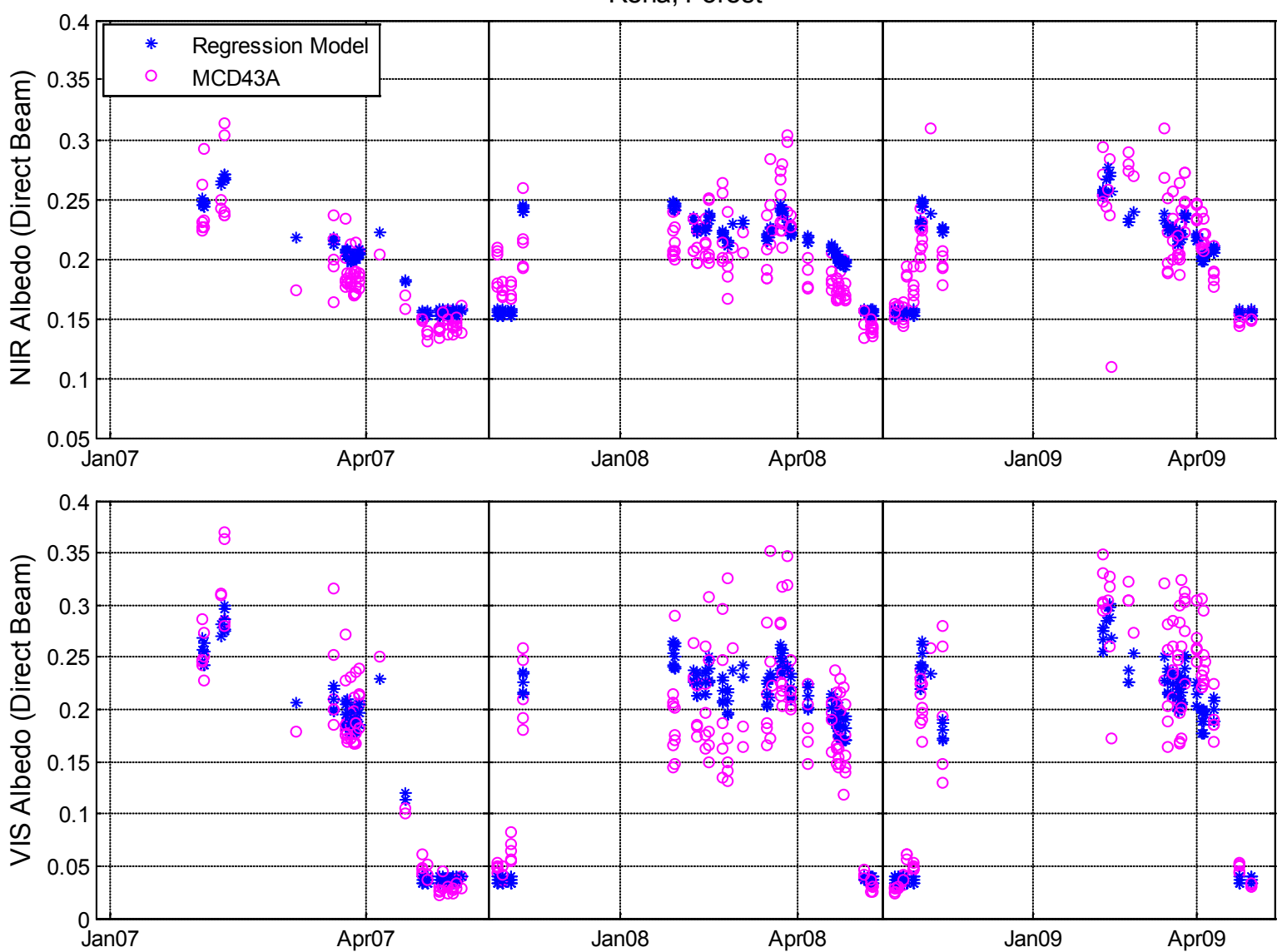

Figure S46. Predicted and observed daily black-sky albedo at the forested sites (evergreen needleleaf) in Rena. 

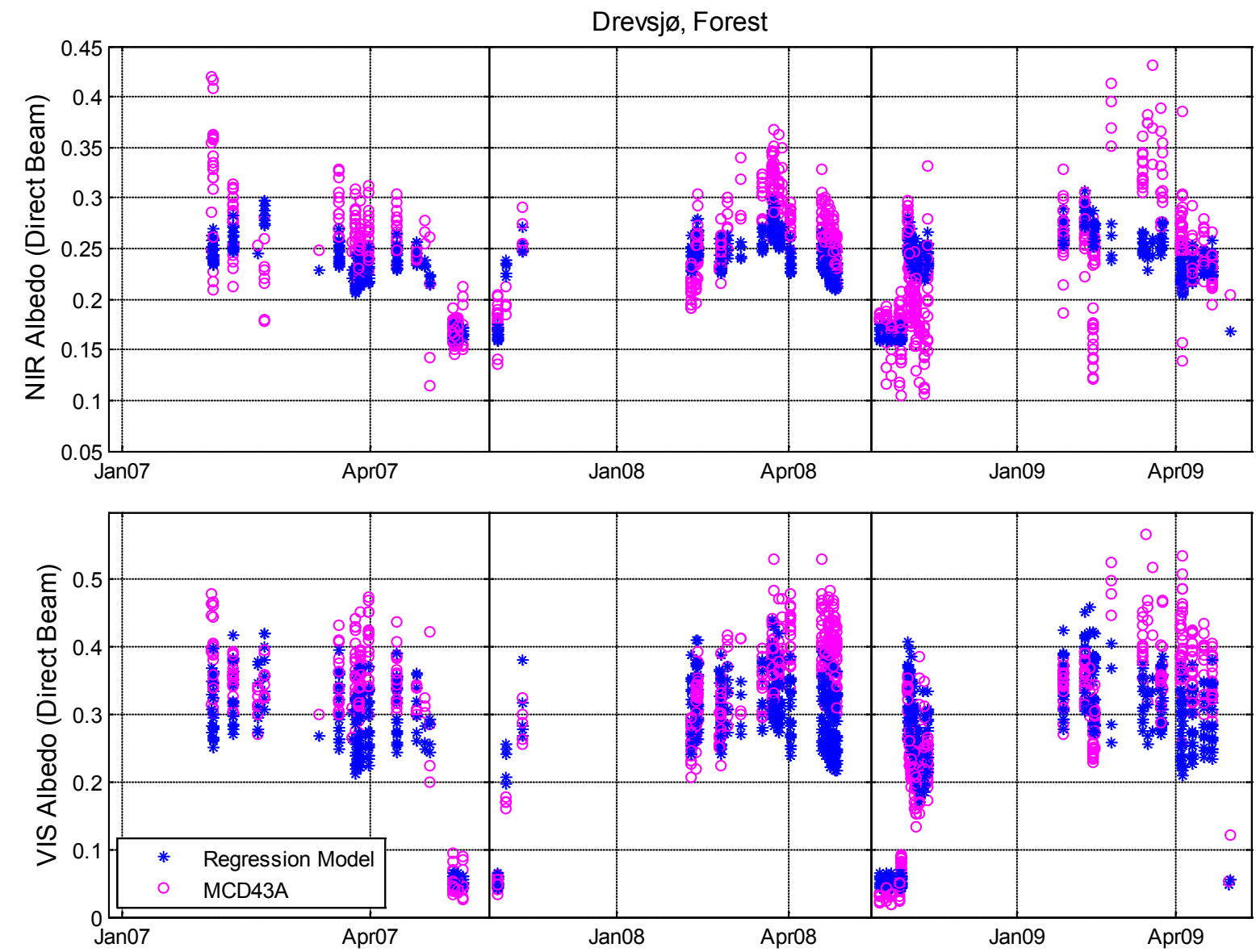

Figure S47. Predicted and observed daily black-sky albedo at the forested sites (evergreen needleleaf) in Drevsjø.

Table S3. Mean bias ${ }^{a}$, 2007-2009 Nov.-May mean and solar insolation-weighted mean $\Delta \alpha$ (Open - Forest). High solar zenith angles inhibit the number of sufficient MODIS observations in December, thus December is excluded from the calculations.

\begin{tabular}{|c|c|c|c|c|}
\hline \multirow[b]{2}{*}{ Model } & \multicolumn{2}{|r|}{ NIR } & \multicolumn{2}{|r|}{ VIS } \\
\hline & $\begin{array}{l}\text { Mean } \\
\text { (Nov.- } \\
\text { May) }\end{array}$ & $\begin{array}{l}\text { Insolation- } \\
\text { weighted Mean } \\
\text { (Nov.-May) }\end{array}$ & $\begin{array}{l}\text { Mean } \\
\text { (Nov.- } \\
\text { May) }\end{array}$ & $\begin{array}{l}\text { Insolation- } \\
\text { weighted Mean } \\
\text { (Nov.-May) }\end{array}$ \\
\hline & \multicolumn{4}{|c|}{$\Delta \alpha$, Flisa $\left(60.6^{\circ} \mathrm{N}, 12.0^{\circ} \mathrm{W}\right)$} \\
\hline Regression & 0.01 & 0.00 & 0.00 & 0.00 \\
\hline JULES 2-stream & 0.01 & -0.01 & 0.07 & 0.04 \\
\hline CLM4 & 0.03 & 0.01 & 0.05 & 0.01 \\
\hline JSBACH & 0.01 & 0.00 & 0.01 & -0.03 \\
\hline CLASS & 0.08 & 0.04 & 0.10 & 0.02 \\
\hline JULES All-band & -0.02 & -0.02 & -0.02 & -0.01 \\
\hline \multirow[t]{2}{*}{ GISS II } & 0.05 & 0.04 & 0.08 & 0.01 \\
\hline & \multicolumn{4}{|c|}{$\Delta \alpha, \operatorname{Rena}\left(61.2^{\circ} \mathrm{N}, 11.4^{\circ} \mathrm{W}\right)$} \\
\hline Regression & -0.01 & 0.00 & 0.03 & 0.04 \\
\hline JULES 2-stream & -0.08 & -0.06 & 0.01 & 0.03 \\
\hline
\end{tabular}




\begin{tabular}{|c|c|c|c|c|}
\hline CLM4 & 0.01 & 0.03 & 0.04 & 0.05 \\
\hline JSBACH & 0.00 & -0.02 & 0.07 & 0.03 \\
\hline CLASS & 0.07 & 0.04 & 0.16 & 0.11 \\
\hline JULES All-band & 0.03 & 0.00 & 0.05 & 0.04 \\
\hline \multirow[t]{2}{*}{ GISS II } & -0.02 & -0.01 & 0.03 & 0.02 \\
\hline & \multicolumn{4}{|c|}{$\Delta \alpha$, Drevsjø $\left(61.9^{\circ} \mathrm{N}, 12.1^{\circ} \mathrm{W}\right)$} \\
\hline Regression & -0.01 & 0.01 & 0.01 & 0.03 \\
\hline JULES 2-stream & -0.07 & -0.05 & 0.05 & 0.06 \\
\hline CLM4 & -0.01 & -0.02 & 0.02 & 0.03 \\
\hline JSBACH & 0.05 & 0.03 & 0.09 & 0.05 \\
\hline CLASS & 0.05 & 0.04 & 0.10 & 0.08 \\
\hline JULES All-band & 0.06 & 0.05 & 0.12 & 0.10 \\
\hline \multirow[t]{2}{*}{ GISS II } & -0.01 & 0.01 & 0.05 & 0.04 \\
\hline & \multicolumn{4}{|c|}{$\Delta \alpha$, Regional Mean (also shown in Figure 1 of main article) } \\
\hline Regression & 0.00 & 0.01 & 0.02 & 0.03 \\
\hline JULES 2-stream & -0.05 & -0.04 & 0.05 & 0.04 \\
\hline CLM4 & 0.01 & 0.01 & 0.04 & 0.03 \\
\hline JSBACH & 0.02 & 0.00 & 0.06 & 0.02 \\
\hline CLASS & 0.07 & 0.04 & 0.12 & 0.07 \\
\hline JULES All-band & 0.02 & 0.01 & 0.05 & 0.04 \\
\hline GISS II & 0.01 & 0.01 & 0.05 & 0.03 \\
\hline
\end{tabular}

\section{S.6. Contribution Analysis: Snow Metamorphosis and Vegetation Structure}

An additional set of simulations is executed to discern the relative importance of vegetation structure and temperature in ground masking and snow albedo parameterizations, respectively. The scheme used for a control is an older MOSES scheme described in Cox et al. [1999] and employed in Betts [2000]. MOSES can be classified as a "Type 3" scheme in which albedo is a weighted sum of the snow-free and snow albedo, with weights determined by snow cover [Qu and Hall, 2007]. Vegetation structure is not considered, and snow albedo is diagnosed using temperature. We henceforth label and refer to this scheme as "MOSES - Control".

Myhre and Myhre [2003] adapt this same scheme but do not diagnose snow albedo using temperature to account for snow metamorphosis effects, a scheme we henceforth refer to as "MOSES - No temp.".

The current JULES All-band scheme [M Best, 2009] is based on the older MOSES scheme yet has been updated to include ground-masking effects by vegetation through the introduction of a "radiative fraction" term $\left(f_{r}\right)$ that is based on LAI.

In order to isolate the sensitivity of structure and temperature parameterizations on total albedo, identical snow and vegetation-dependent albedo parameters are applied across all three model versions and may be found in Table S2. 
Forest
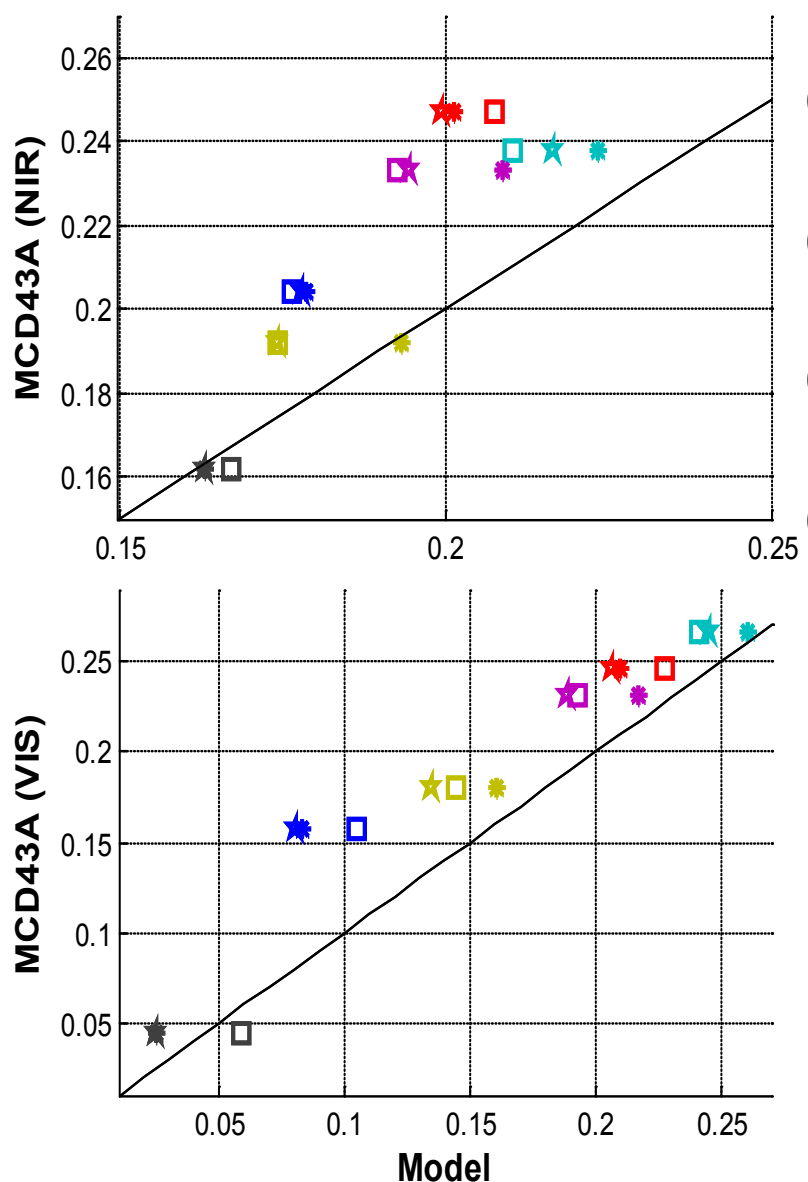

Open
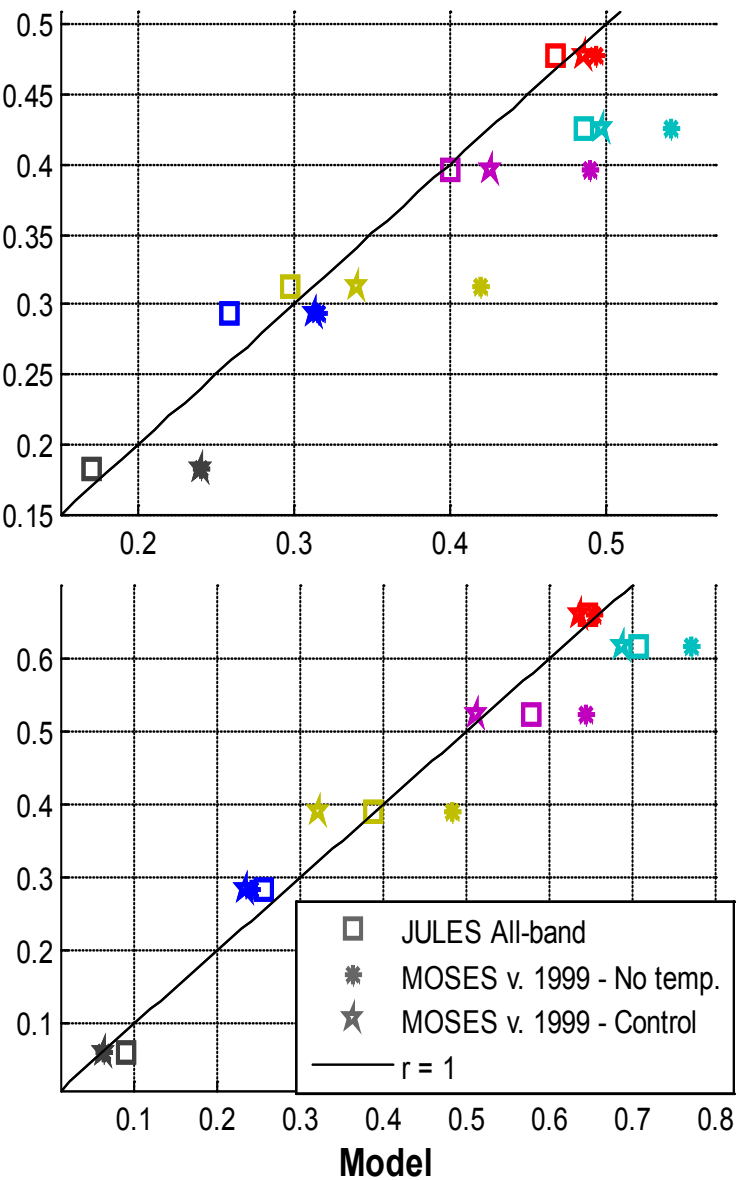

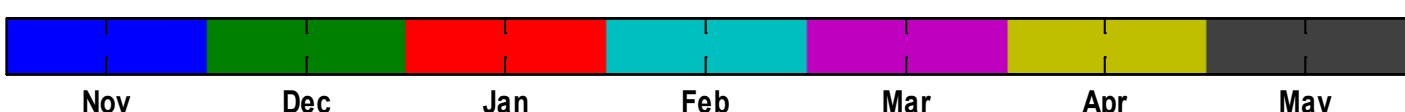

Figure S48.

Evident in the regional mean albedo predictions at open areas in Figure S48 (right column) is the improved accuracy when the temperature diagnostic snow albedo parameterization is included. All else being equal, the positive bias (both NIR and VIS) seen in the "No temp." MOSES scheme is greatly reduced in the "Control" scheme during months with persistent snow cover (Jan. - Mar.). Bias is further reduced - particularly in months without persistent snow cover (Nov., Apr., May.) - when the radiative fraction term is introduced, as in the JULES "All-band" scheme (and MOSES v. $\geq 2.2$ ). The introduction of this term results in a stronger contribution from soil (as opposed to vegetation) to the snow-free albedo term $\left(\alpha_{0}\right)$.

In forests and in particular the NIR band, negative bias is seen in the schemes with temperature diagnostic snow albedo parameterizations (JULES "All-band" and MOSES "Control") in all months except May. Here, the MOSES "No temp" scheme leads to more accurate predictions. The explanation here is that the parameter for cold deep-snow albedo of forested vegetation $\left(\alpha_{s}^{0}\right.$ ) is too low to begin with. The same is true for the VIS band although the bias is less severe.

\section{References}


Aguado, E. (1985), Radiation balances of melting snow covers at an open site in the central Sierra Nevada, California, Water Resources Research, 21, 1649-1654.

Aoki, T., A. Hachikubo, and M. Hori (2003), Effects of snow physical parameters on shortwave broadband albedos, Journal of Geophysical Research: Atmospheres, 108(D19), 4616.

Asner, G. P., C. A. Wessman, D. S. Schimel, and S. Archer (1998), Variability in leaf and litter optical properties: implications for BRDF model inversions using AVHRR, MODIS, and MISR, Remote Sensing of Environment, 63, 243-257.

Bartlett, P. A., M. D. MacKay, and D. L. Verseghy (2006), Modified snow algorithms in the Canadian land surface scheme: Model runs and sensitivity analysis at three boreal forest stands, AtmosphereOcean, 44(3), 207-222.

Best, M. (2009), JULES Technical DocumentationRep., Met Office, Joint Centre for HydroMeteorological Research, Wallingford, U.K.

Best, M. J., et al. (2011), The Joint UK Land Environment Simulator (JULES), model description - Part 1: Energy and water fluxes, Geosci. Model Dev., 4(3), 677-699.

Betts, A. K., and J. H. Ball (1997), Albedo over the boreal forest, Journal of Geophysical Research, 102(D24), 28901-28909.

Betts, R. A. (2000), Offset of the potential carbon sink from boreal forestation by decreases in surface albedo, Nature, 408, 187-190.

Bright, R. M., R. Astrup, and A. H. Strømman (2013), Empirical models of monthly and annual albedo in managed boreal forests of interior Norway, Climatic Change 120(1-2), 183-196.

Bright, R. M., C. Antón-Fernández, R. Astrup, and A. H. Strømman (2014), Empirical models of albedo transitions in managed boreal forests: Analysis of performance and transportability, Canadian Journal of Forest Research, DOI: 10.1139/cjfr-2014-0132

Broch, B. W., I. C. Willis, and M. J. Sharp (2000), Measurement and parameterization of albedo variations at Haut Glacier d'Arolla, Switzerland, Journal of Glaciology, 2, 374-394.

Brun, E. (1989), Investigation on wet-snow metamorphism in respect of liquid-water content, Annals of Glaciology, 13, 22-26.

Cox, P. M., R. A. Betts, C. B. Bunton, R. L. H. Essery, P. R. Rowntree, and J. Smith (1999), The impact of new land surface physics on the GCM simulation of climate and climate sensitivity, Climate Dynamics, 15(3), 183-203.

Dickinson, R. E. (1983), Land surface processes and climate-surface albedos and energy balance, Advances in Geophysics, 25, 305-353.

Dickinson, R. E., A. Henderson-Sellers, and P. J. Kennedy (1993), Biosphere-Atmosphere Transfer Scheme (BATS) version 1e as coupled to the NCAR Community Climate Model. NCAR Technical Note 387.Rep., 251 pp, National Center for Atmospheric Research (NCAR), Boulder, Colorado, USA.

Dirmhirn, I., and F. D. Eaton (1975), Some characteristics of the albedo of snow, Journal of Applied Meteorology, 14, 375-379.

Dorman, J. L., and P. Sellers (1989), A global climatology of albedo, roughness length, and stomatal resistance for atmospheric general circulation models as represented by the simple biosphere model (SiB), Journal of Applied Meteorology, 28, 833-855.

Essery, R., M. Best, and P. Cox (2001), MOSES 2.2 Technical documentation. Hadley Centre Technical Note 30Rep., 1-31 pp, U.K. Met Office Hadley Centre, Exeter, U. K.

Essery, R., S. Morin, Y. Lejeune, and C. B Ménard (2013), A comparison of 1701 snow models using observations from an alpine site, Advances in Water Resources, 55(0), 131-148.

Gao, F., C. B. Schaaf, A. Strahler, H.,, A. Roesch, W. Lucht, and R. E. Dickinson (2005), MODIS bidirectional reflectance distribution function and albedo Climate Modeling Grid products and the variablility of albedo for major global vegetation types, Journal of Geophysical Research, 110(D01104), 1-13.

Goudriaan, J. (1988), The bare bones of leaf angle distribution in radiation models for canopy photosynthesis and energy exchange, Agricultural and Forest Meteorology, 43, 155-169.

Granhus, A., G. Hylen, and J.-E. Ø. Nilsen (2012), Statistics of forest conditions and resources in NorwayRep., Norwegian Forest and Landscape Institute, Ås. 
Hansen, J., G. Russell, D. Rind, P. Stone, A. Lacis, S. Lebedeef, R. Ruedy, and L. Travis (1983), Efficient three-dimensional global models for climate studies: Models I and II., Monthly Weather Review, 111, 609-662.

Hedstrom, N. R., and J. W. Pomeroy (1998), Measurements and modelling of snow interception in the boreal forest, Hydrological Processes, 12(10-11), 1611-1625.

Kuusinen, N., P. Kolari, J. Levula, A. Porcar-Castell, P. Stenberg, and F. Berninger (2012), Seasonal variation in boreal pine forest albedo and effects of canopy snow on forest reflectance, Agricultural and Forest Meteorology, 164(0), 53-60.

Lawrence, P. J., and T. N. Chase (2007), Representing a new MODIS consistent land surface in the Community Land Model (CLM 3.0), Journal of Geophysical Research: Biogeosciences, 112(G1), G01023.

Meløysund, V., B. Leira, K. V. Høiseth, and K. R. Lisø (2007), Predicting snow density using meteorological data, Meteorological Applications, 14(4), 413-423.

Miller, D. (1962), Snow in trees -- where did it go?, Proceedings of the 30th annual meeting of the Western Snow Conference, 30, 21-29.

Mölders, N., H. Luijting, and K. Sassen (2008), Use of atmospheric radiation measurement program data from Barrow, Alaska, for evaluation and development of snow-albedo parameterizations, Meteorol Atmos Phys, 99(3-4), 199-219.

Myhre, G., and A. Myhre (2003), Uncertainties in Radiative Forcing due to Surface Albedo Changes Cause by Land-Use Changes, Journal of Climate, 16, 1511-1524.

Nakai, Y., T. Sakamoto, T. Terajima, H. Kitahara, and T. Saito (1994), Snow interception by forest canopies: weighing a conifer tree, meteorological observation and analysis by the Penman-Monteith formula, IAHS Publications, 223, 227-236.

Niu, G.-Y., and Z.-L. Yang (2007), An observation-based formulation of snow cover fraction and its evaluation over large North American river basins, Journal of Geophysical Research: Atmospheres, 112(D21), D21101.

Norwegian Meteorological Institute (2013a), eKlima - Monthly Historical Meteorology, edited, Norwegian Meteorological Institute. Accessed Jan 31, 2013 at:

http://sharki.oslo.dnmi.no/portal/page? pageid=73,39035,73 39049\& dad=portal\& schema=PORT $\underline{A L}$

Norwegian Meteorological Institute (2013b), eKlima - Daily Historical Meteorology, edited, Norwegian Meteorological Institute. Accessed Sept. 15, 2013 at:

http://sharki.oslo.dnmi.no/portal/page? pageid=73,39035,73 39049\& dad=portal\& schema=PORT $\underline{\mathrm{AL}}$

Oleson, K., et al. (2004), Technical description of the Community Land Model (CLM). NCAR Technical Note 461Rep., 174 pp, National Center for Atmospheric Research (NCAR), Boulder, Colorado, USA. Oleson, K., et al. (2010), Technical description of version 4.0 of the Community Land Model (CLM)Rep., 266 pp, National Center for Atmospheric Research, Climate and Global Dynamics Division, Boulder, CO, USA.

Otto, J., T. Raddatz, and M. Claussen (2011), Strength of forest-albedo feedback in mid-Holocene climate simulations, Clim. Past, 7(3), 1027-1039.

Pedersen, C., and J.-G. Winther (2005), Intercomparison and validation of snow albedo parameterization schemes in climate models, Climate Dynamics, 25(4), 351-362.

Peel, M. C., B. L. Finlayson, and T. A. McMahon (2007), Updated world map of the Köppen-Geiger climate classification, Hydrology and Earth System Sciences, 11, 1633-1644.

Pirazzini, R. (2009), Challenges in snow and ice albedo parameterizations, Geophysica 45(1-2), 41-62. Qu, X., and A. Hall (2007), What Controls the Strength of Snow-Albedo Feedback?, Journal of Climate, 20(15), 3971-3981. 
Reick, C. H., V. Gayler, T. Raddatz, and R. Schnur (2012), JSBACH - The new land component of ECHAMRep., 1-167 pp, Max Planck Insitute for Meteorology, Hamburg, Germany.

Robinson, D. A., and G. Kukla (1984), Albedo of a disappearing snow cover, Journal of Applied Meteorology, 23, 1626-1634.

Roesch, A., M. Wild, H. Gilgen, and A. Ohmura (2001), A new snow cover fraction parametrization for the ECHAM4 GCM, Climate Dynamics, 17(12), 933-946.

Rutter, N., et al. (2009), Evaluation of forest snow processes models (SnowMIP2), Journal of Geophysical Research: Atmospheres, 114(D6), D06111.

Schmidt, G. A., et al. (2006), Present-Day Atmospheric Simulations Using GISS ModelE: Comparison to In Situ, Satellite, and Reanalysis Data, Journal of Climate, 19(2), 153-192.

Schmidt, R. A., and D. R. Gluns (1991), Snowfall interception on branches of three conifer species, Canadian Journal of Forest Research, 21, 1262-1269.

Sellers, P. J. (1985), Canopy reflectance, photosynthesis, and transpiration, International Journal of Remote Sensing, 6(8), 1335-1372.

Shuai, Y. (2010), Tracking daily land surface albedo and reflectance anisotropy with MODerateResolution Imaging Spectroradiometer (MODIS), Geography and Environment, Boston University, Boston.

Solberg, S., E. Næsset, K. H. Hanssen, and E. Christiansen (2006), Mapping defoliation during a severe insect attack on Scots pine using airborne laser scanning, Remote Sensing of Environment, 102(3-4), 364-376.

Solberg, S., A. Brunner, K. H. Hanssen, H. Lange, E. Næsset, M. Rautiainen, and P. Stenberg (2009), Mapping LAI in a Norway spruce forest using airborne laser scanning, Remote Sensing of Environment, 113(11), 2317-2327.

Verseghy, D. L. (2009), CLASS - The Canadian land surface scheme (version 3.4) - Technical documentation (version 1.1)Rep., 1-183 pp, Environment Canada, Quebec, Canada.

Verseghy, D. L., N. A. McFarlane, and M. Lazare (1993), CLASS - A Canadian land surface scheme for GCMs. II. Vegetation model and coupled runs, International Journal of Climatology, 13, 347-370. Wang, Z., and X. Zeng (2009), Evaluation of Snow Albedo in Land Models for Weather and Climate Studies, Journal of Applied Meteorology and Climatology, 49(3), 363-380.

Wang, Z., and C. Schaaf (2013), MCD43 1-day and 16-day daily Albedo/BRDF dataset, edited, University of Massachusetts, Boston and Boston University, March 23, 2013, Boston.

Wang, Z., C. B. Schaaf, M. J. Chopping, A. H. Strahler, J. Wang, M. O. Román, A. V. Rocha, C. E. Woodcock, and Y. Shuai (2012), Evaluation of Moderate-resolution Imaging Spectroradiometer (MODIS) snow albedo product (MCD43A) over tundra, Remote Sensing of Environment, 117(0), 264280.

Wiscombe, W. J., and S. G. Warren (1980), A model for the spectral albedo of snow. I. Pure Snow, Journal of Atmospheric Science, 37, 2712-2733.

Wright, P., et al. (2014), Comparing MODIS daily snow albedo to spectral albedo field measurements in Central Greenland, Remote Sensing of Environment, 140(0), 118-129.

Yamazaki, T., K. Fukabori, and J. Kondo (1996), Albedo of a forest with crown snow, Journal of the Japanese Society of Snow and Ice, 58, 11-18.

Yang, Z.-L., R. E. Dickinson, A. Robock, and K. Y. Vinnikov (1997), Validation of the Snow Submodel of the Biosphere-Atmosphere Transfer Scheme with Russian Snow Cover and Meteorological Observational Data, Journal of Climate, 10(2), 353-373.

Zeng, X., M. Shaikh, Y. Dai, R. E. Dickinson, and R. Myneni (2002), Coupling of the Common Land Model to the NCAR Community Climate Model, Journal of Climate, 15(14), 1832-1854. 